QL
696
P7H516
1895
BIRDS

Dr. Carl 2R. Lenuticte

Der (5raupapagei

in der freiheit und in der Befangenichaft

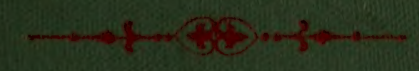

\author{
Gera. \\ G. M, Kührgen Vurfay,
}








\section{Oruttlologildie

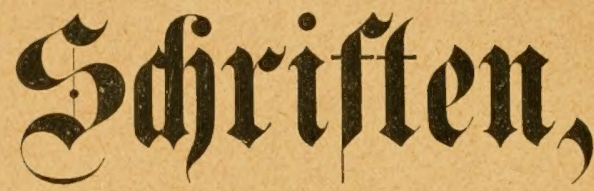

herausgegeben

vom Doritande des

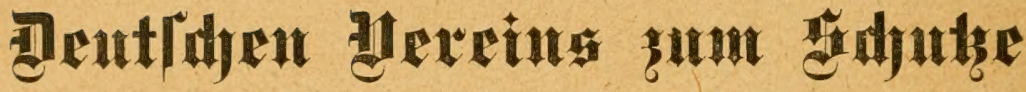

tav flageliuclt.

No. I.

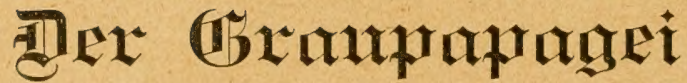

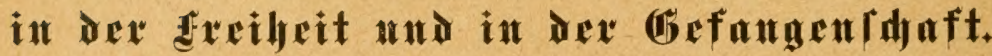

(Siejd)illoert von

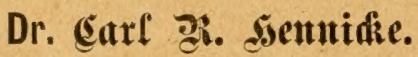

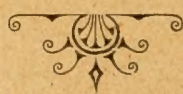

(biar.

Derlag von (E. At. fä̈bler. 


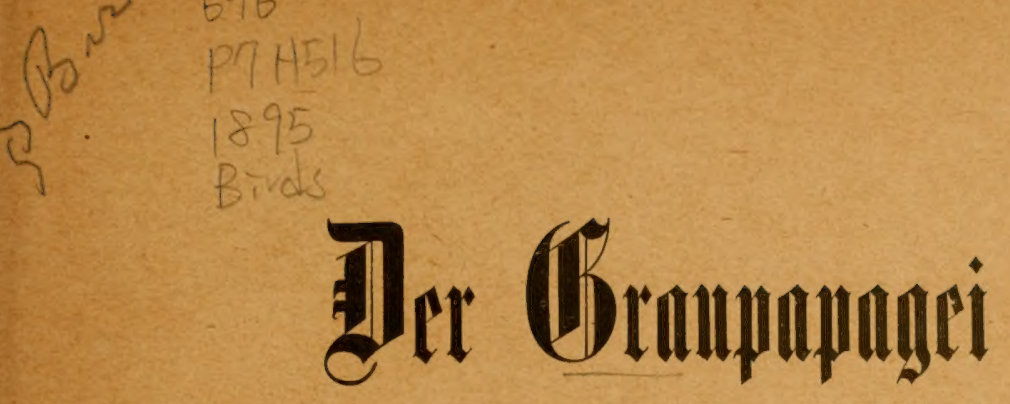

\title{
in der freiheit und in Der (befangenichaft.
}

\author{
(S) jejildert von
}

\section{Dr. Cant d dentuidke.}

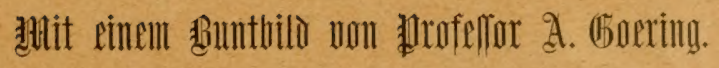

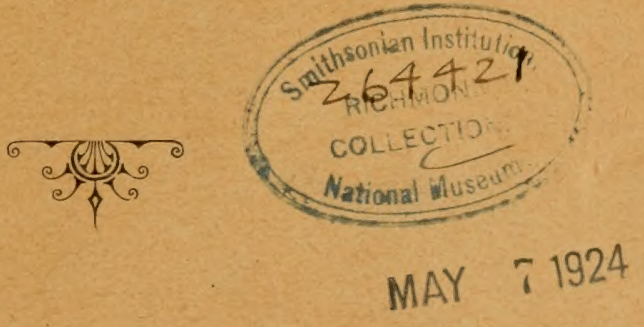

(15) $\mathbf{x}$.

Derlag vou (E. At. fäjler. 1895. 



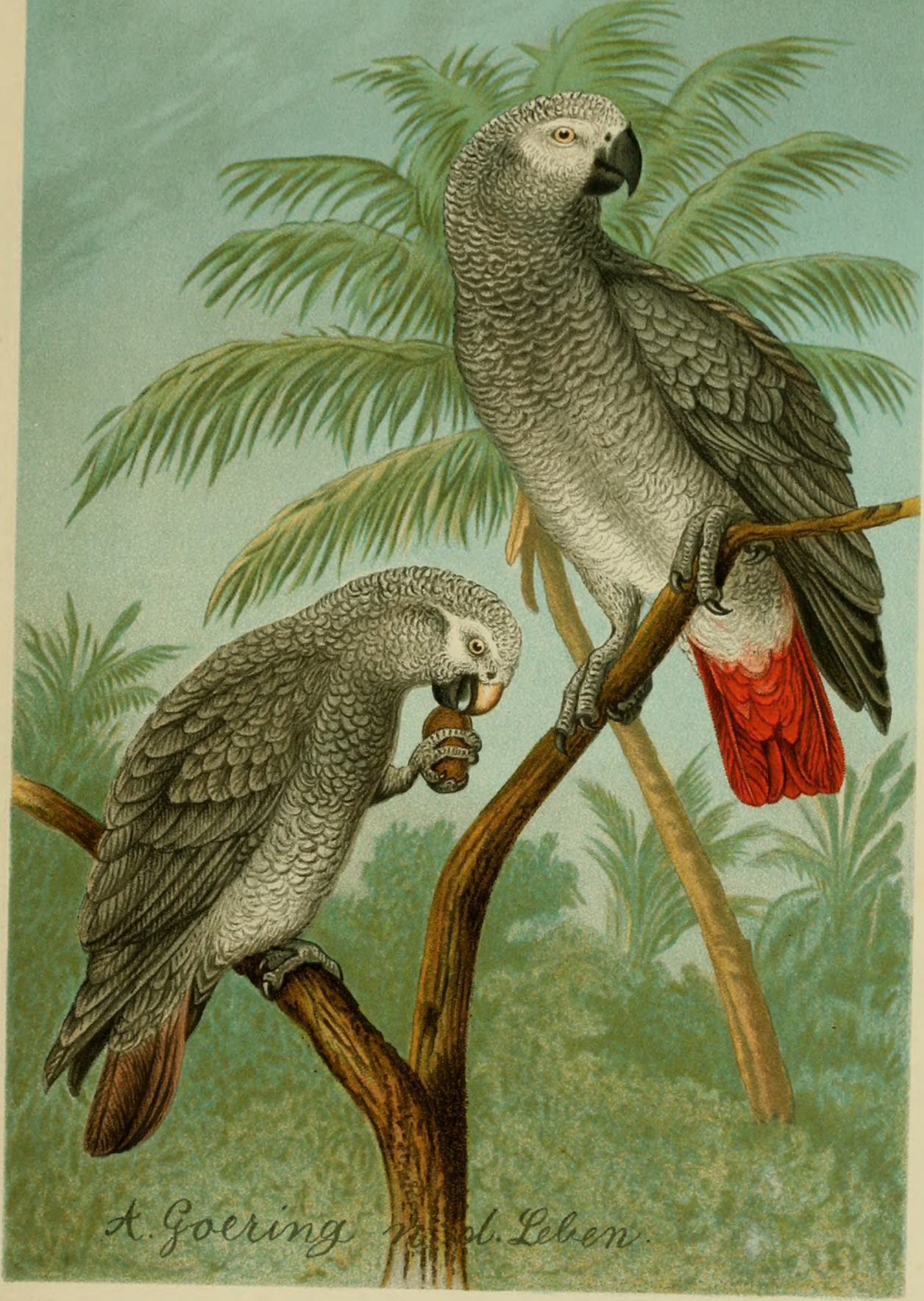

Chromolith. Ortomar Rottler \& Comp. Gera, Reuss

Psittacus timneh Fras.
Psittacus erithacus L. 



\section{AुIoxumt.}

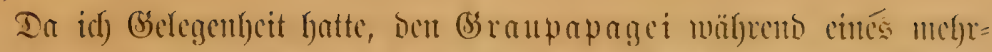

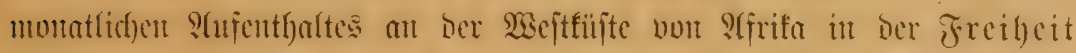

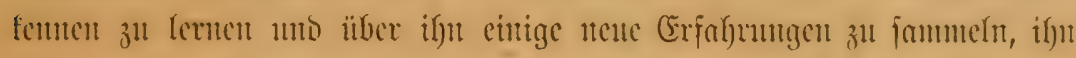

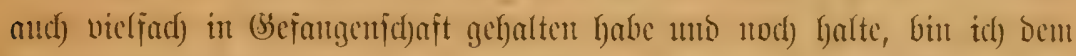

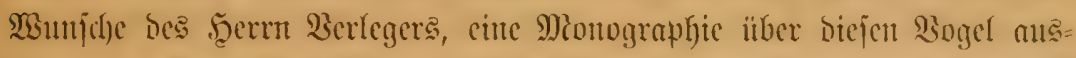
zuarbeiten, gern uad)gefoument. Dic babei bemub̧te Litteratur habe id)

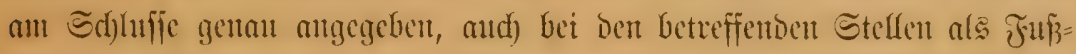
stoten antgefiifyrt.

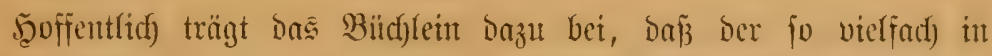

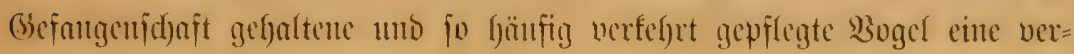
unuftgemäßzere Pflege findet.

Dem dos ift ja audf) cin Teil bes \$ogelfojubes.

Bera, im sunt 1895 .

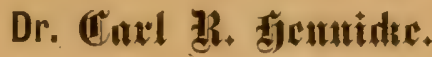





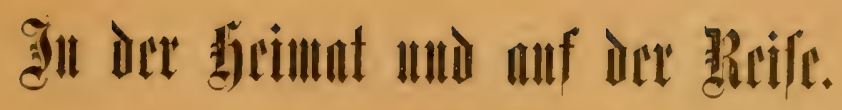





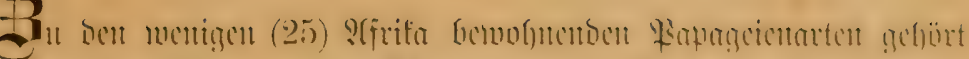

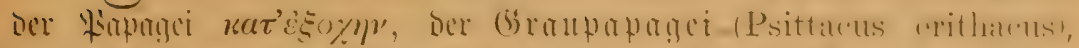

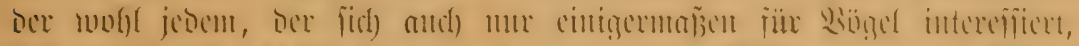

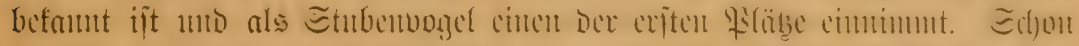

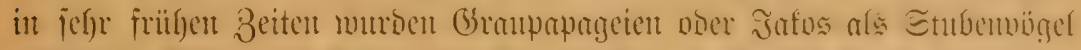

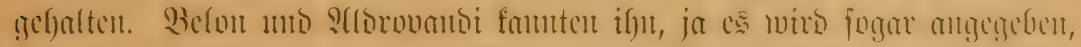

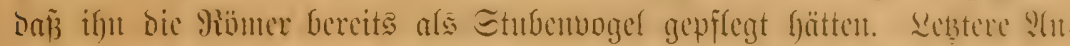

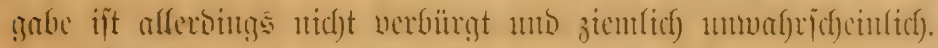

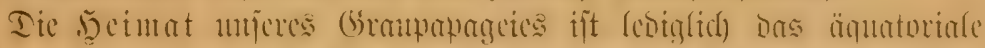

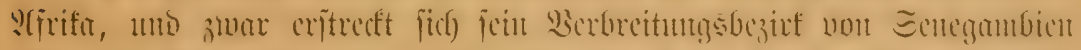

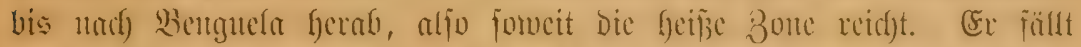

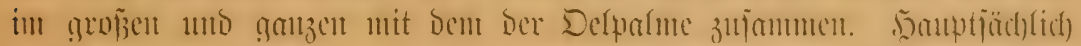

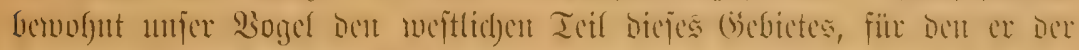

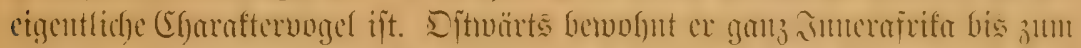

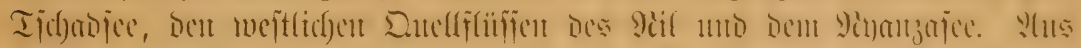

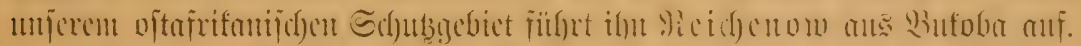

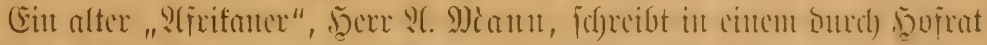

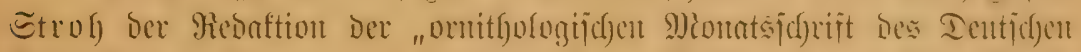

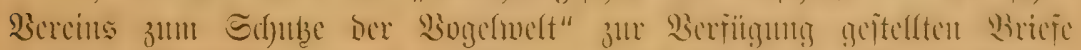

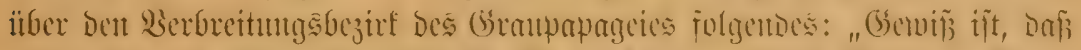

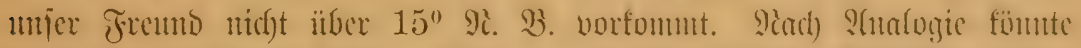

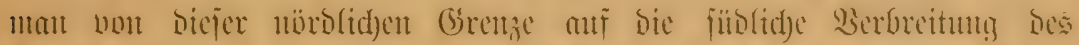

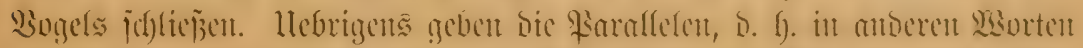

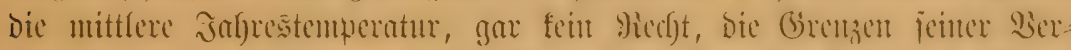

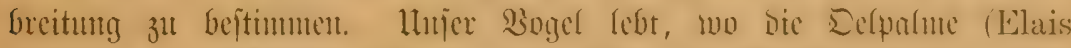

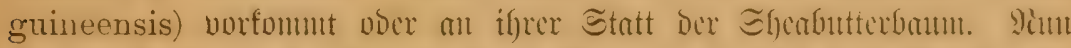

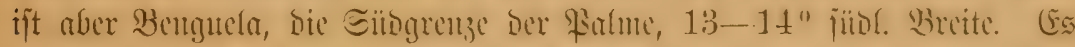

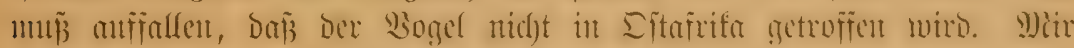

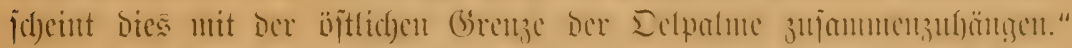

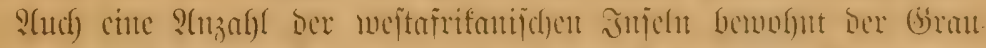

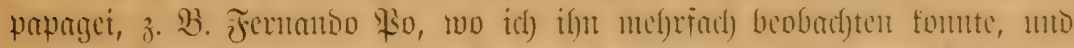

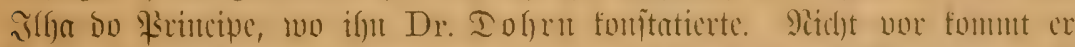

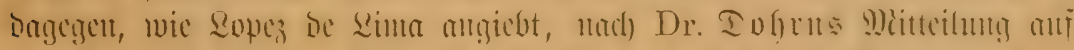

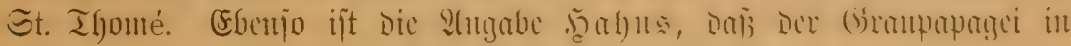




\section{- $8-$}

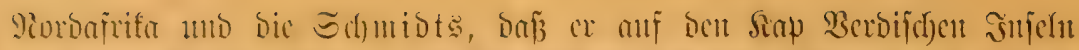

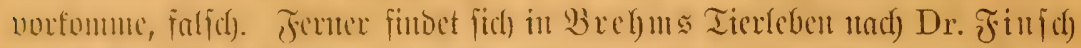

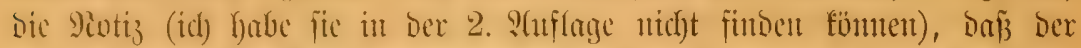

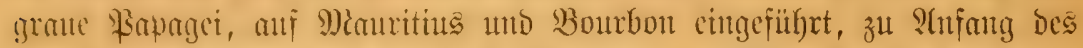

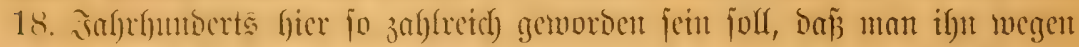

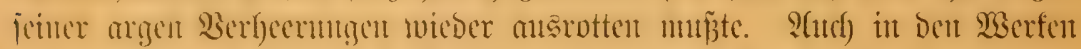

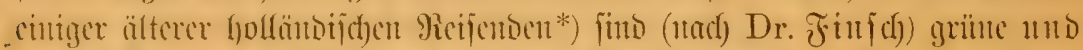

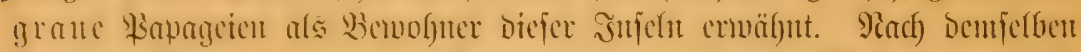

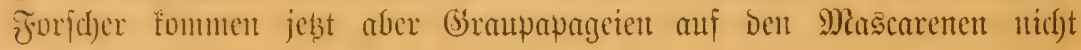
mejhr vor.

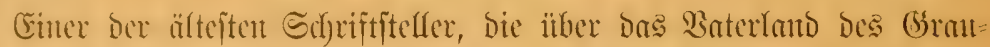

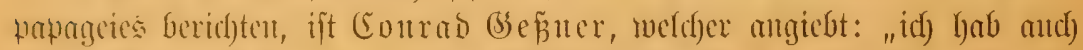

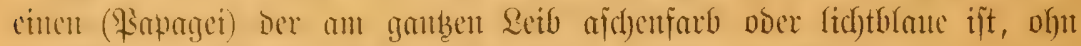

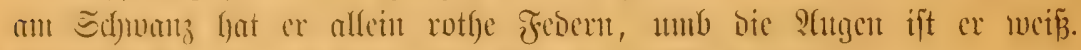

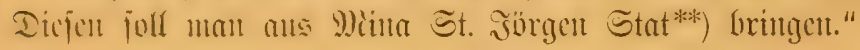

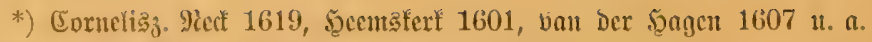

**) St. (Seorge Del Mitia. 


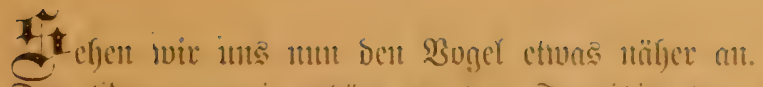

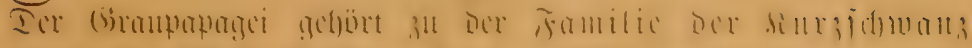

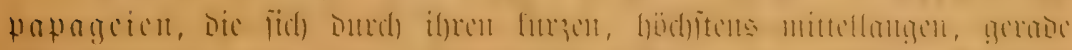

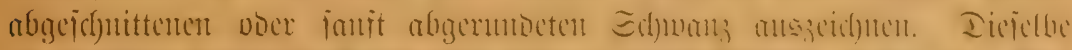

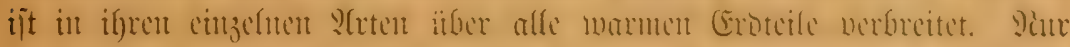

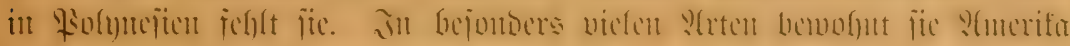

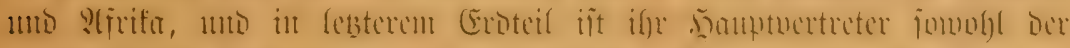

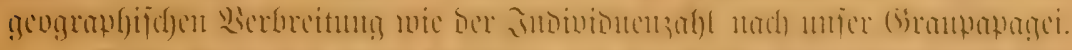

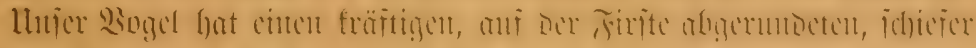

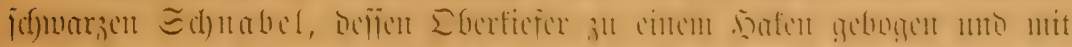

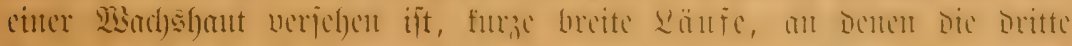

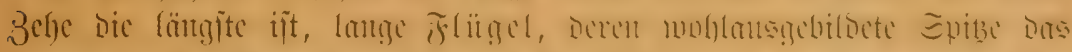

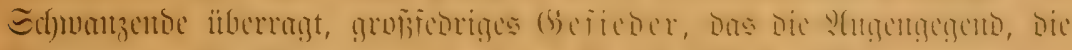

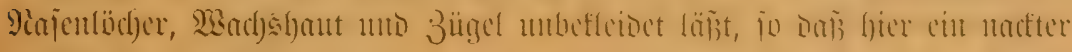
weip̃er Fllcct enttitefyt.

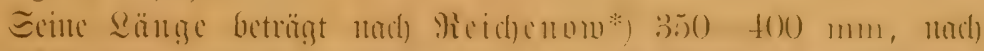

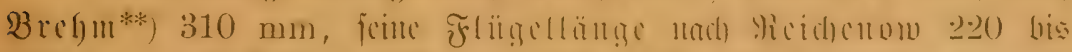

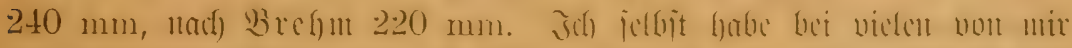

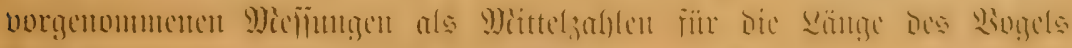
340, für bie ber Fllïget 233 gefuntoct.

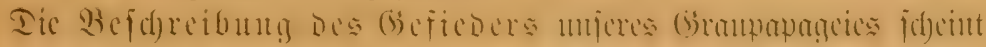

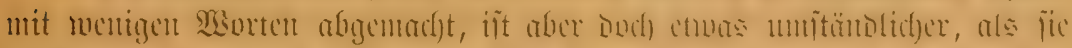

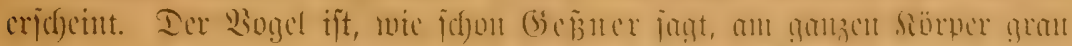

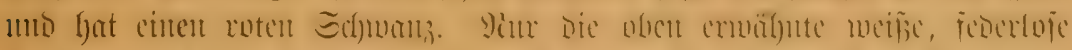

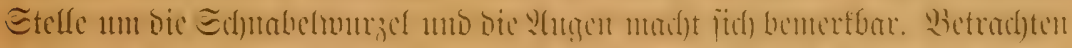

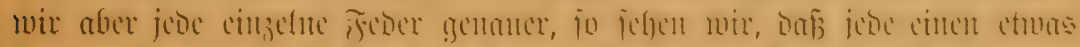

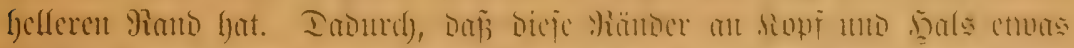

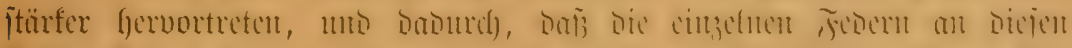

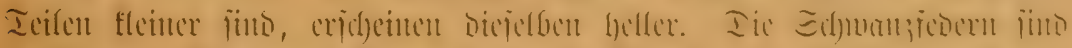

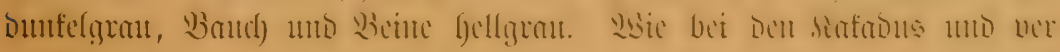

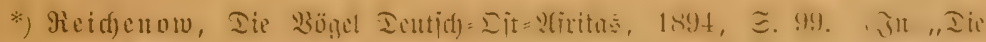

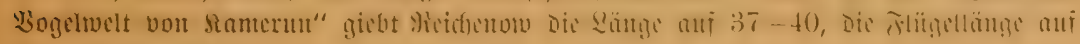
$22-24 \mathrm{~cm}$ (in.)

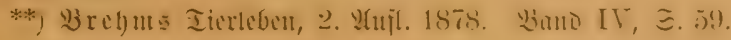




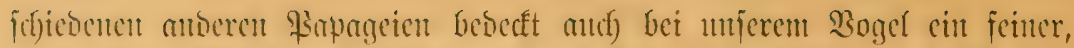

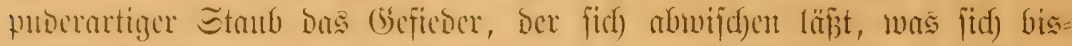

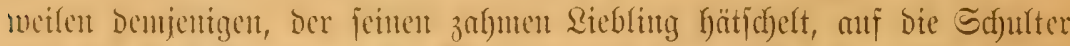

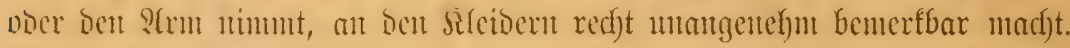

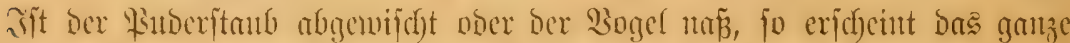

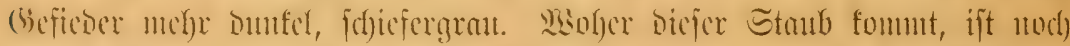

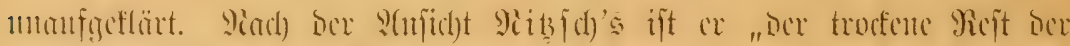

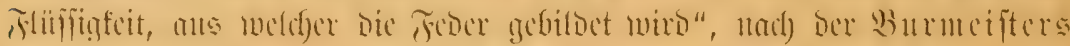

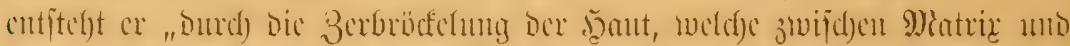

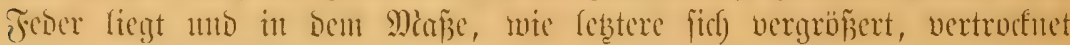
Into abgejtopien iviro."

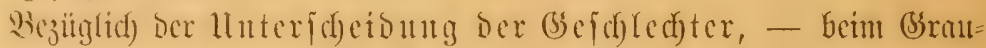

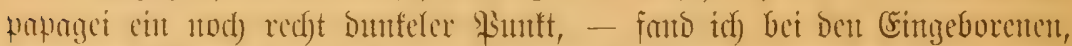

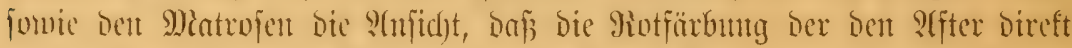

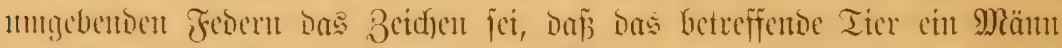

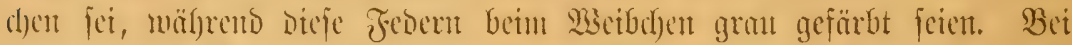

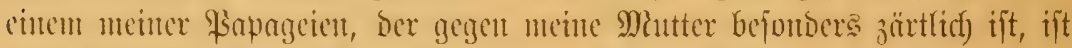

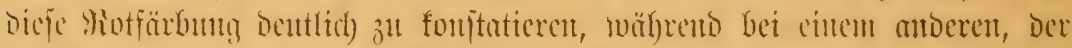

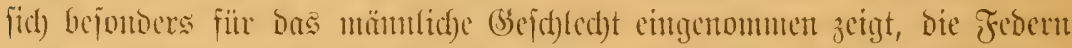

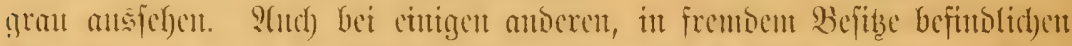

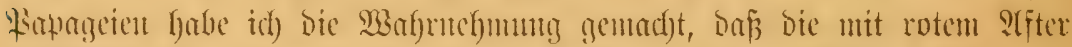
verjebencu gegen Danten, bie mit groulen bagegen gegen Mä̈nter febr jaf)m

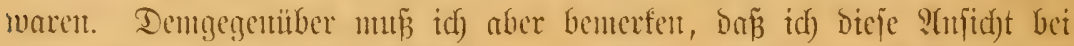

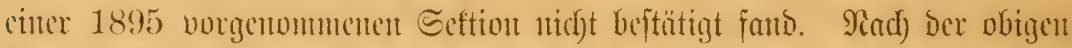

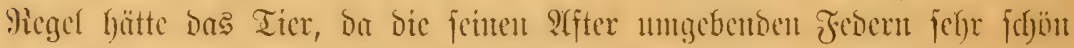

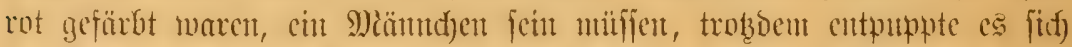
bet ber Eeftion als 2 seifuchen. Diejes Mefultat war mir 1 un jo ïber=

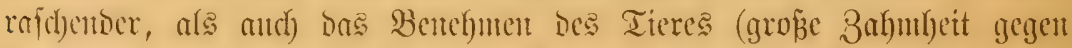

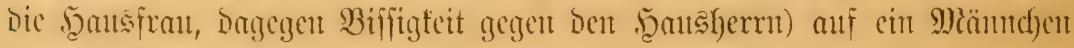

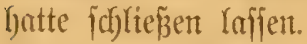

Revaillant fagt, dañ bie bänoler bie Dutfferen Eremplare für

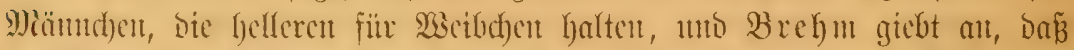

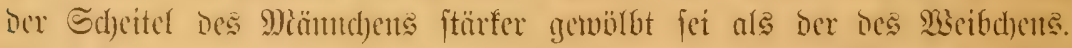

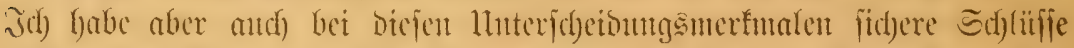

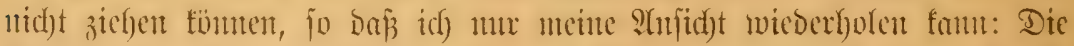

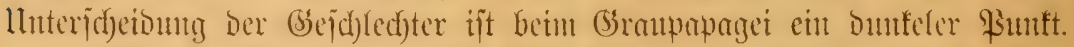

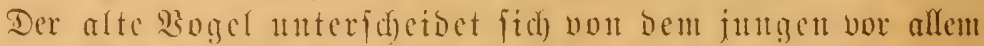

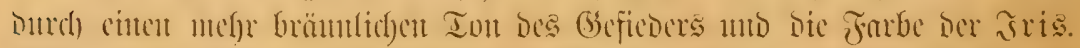

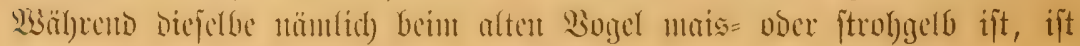




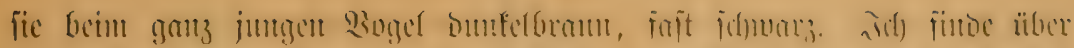

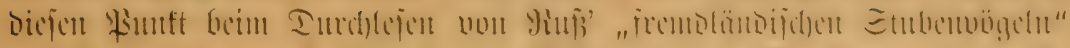

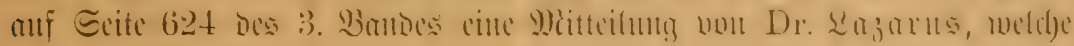
folgenton Bortlaut hat:

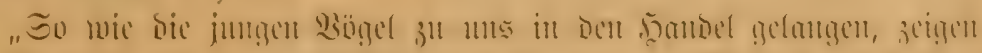

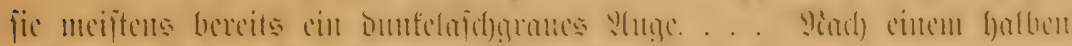

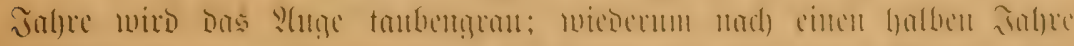

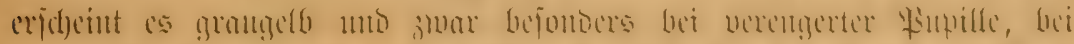

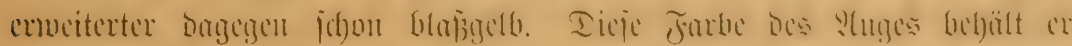

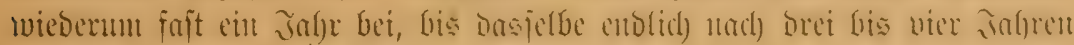
v'tute ftänbig mtaisgelbe Färbung amtummt."

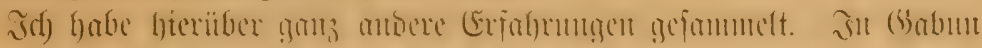

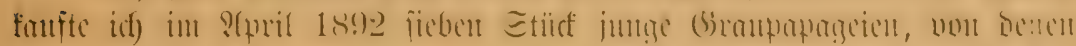

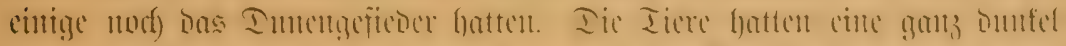

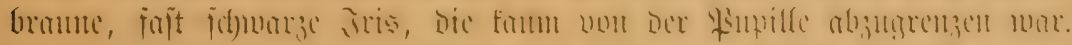

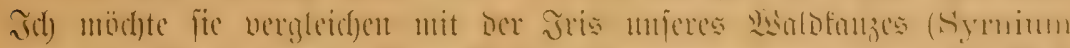

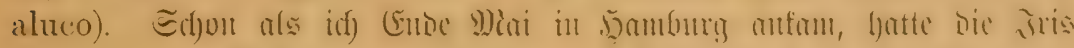

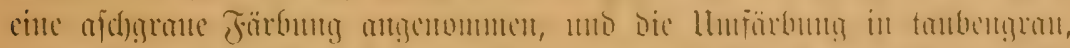

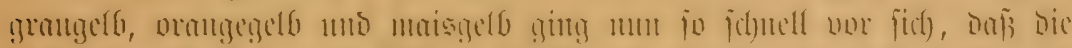

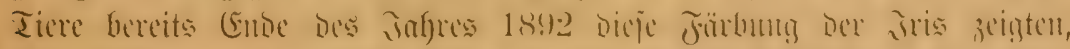

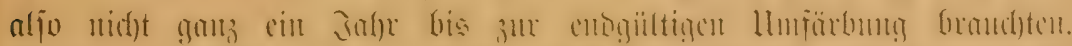

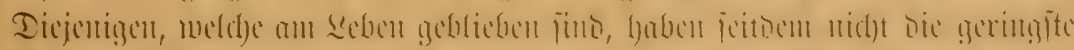

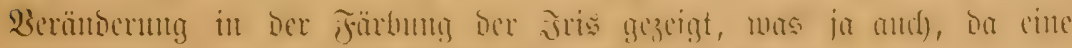

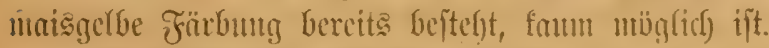

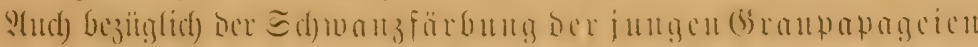

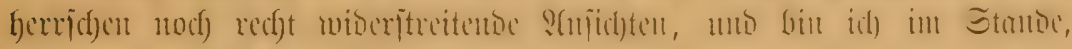
einiges zur श̂fflärung beizutragen.

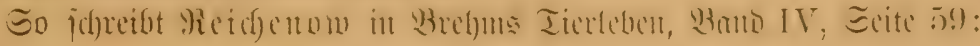

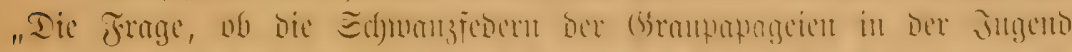

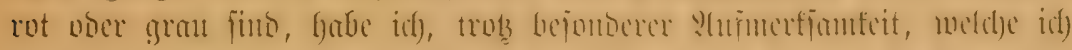

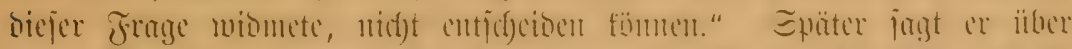

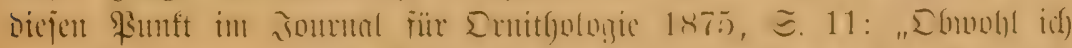

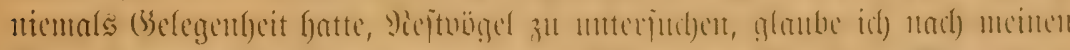

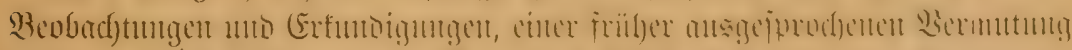

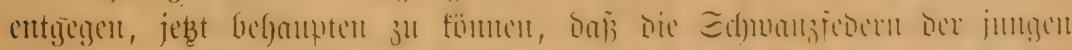

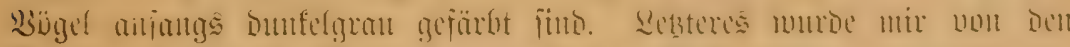

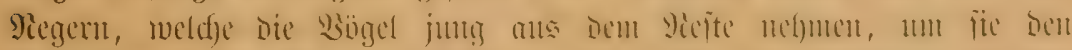

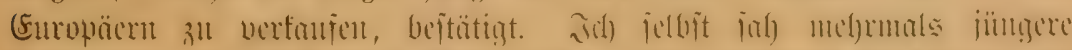

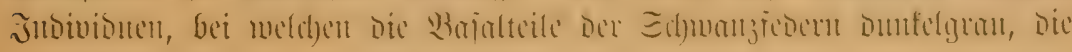




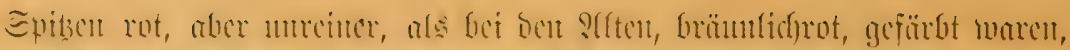

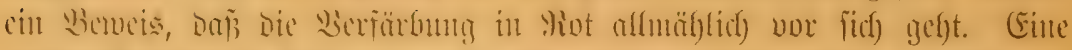

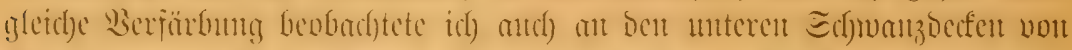

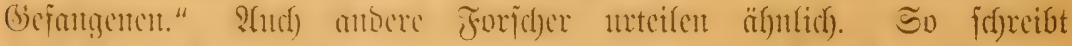

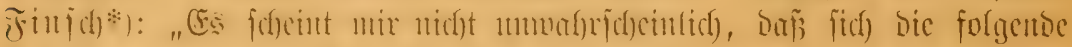

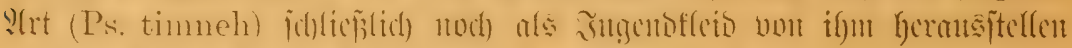

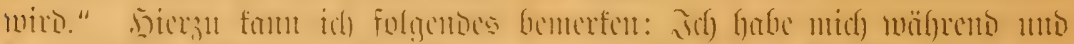

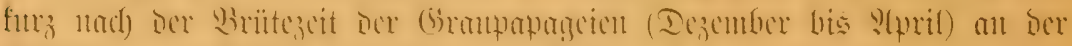

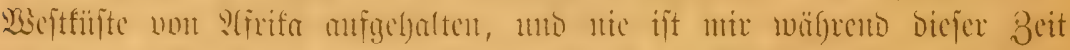

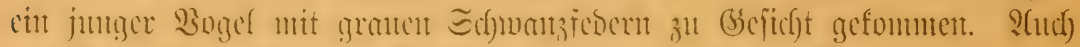

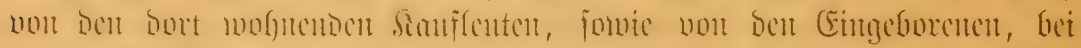

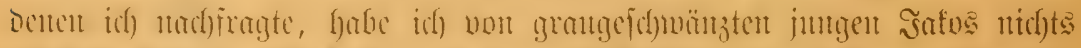

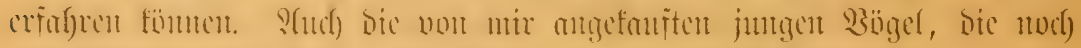

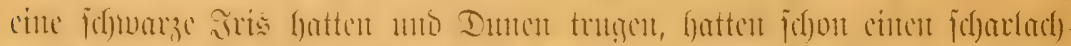

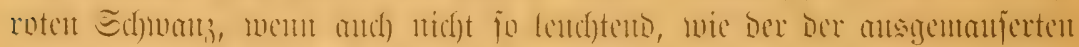

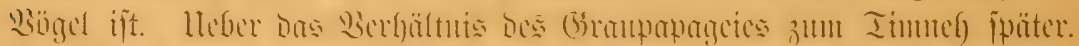

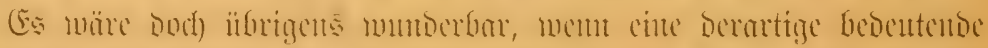

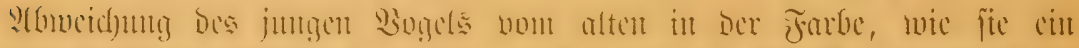

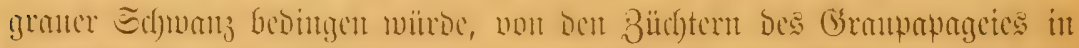

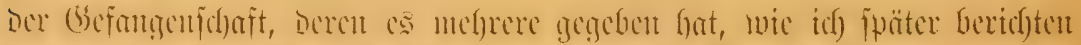

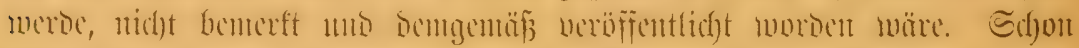

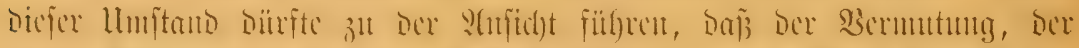

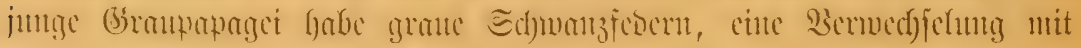
Dem Timmet) zu (Simulde liegt.

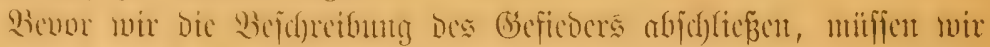

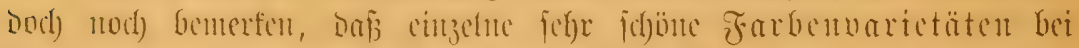

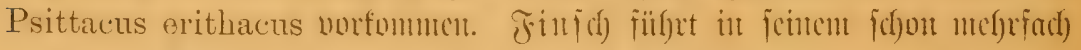
cruälynten Werfe folgende bier ßarietäten bejontoers an:

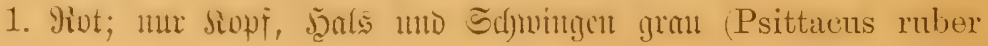
Scop., Ps. erithacus var. $\delta \mathrm{Gml}$.).

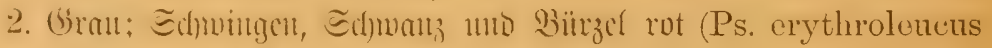
Aldrov. Ps. varius Müll. Ps. erythrolencus L.).

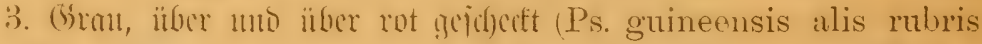
Briss., Ps. guiueensis rubrovarius Briss. Ps. erithacus var. p et " Gml.).

4. Banj grou (? Maracana brasiliensibus Marcgr., Psittacus brasiliensis cinereus Briss., Ps. cinereus Gml.).

*) Dic \$apagcien, Rciocn 1868. 2amo II, S. 311. 


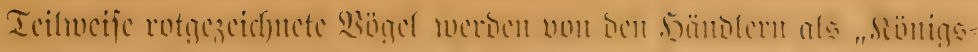

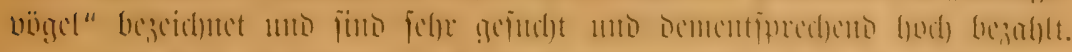

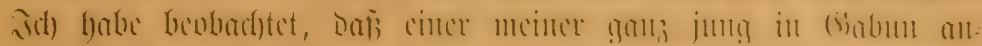

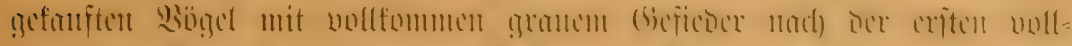

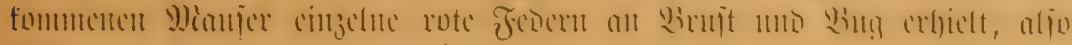

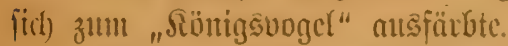

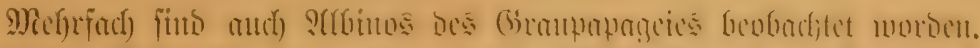

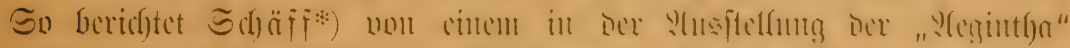

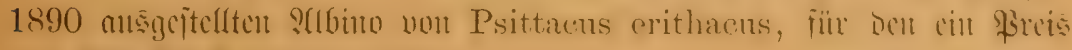
wou 800 9larf verlangt unurbe.

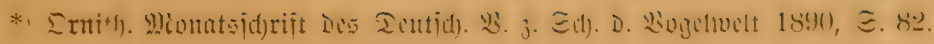




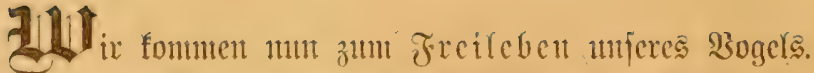

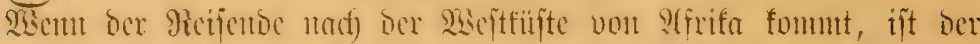

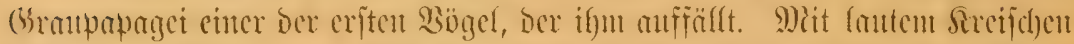

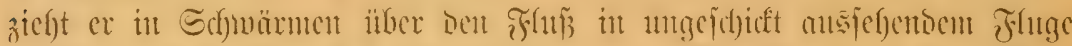

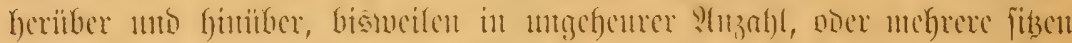

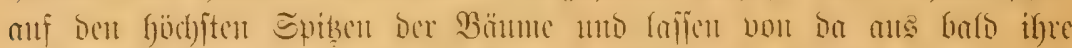

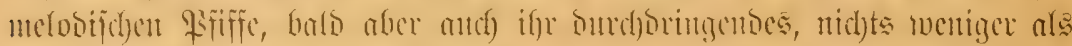

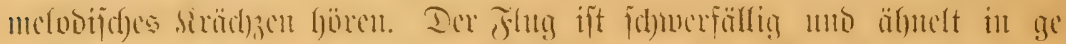

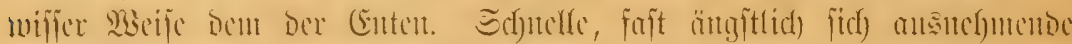

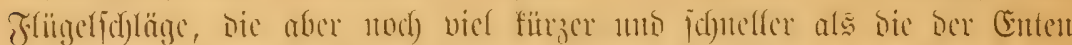

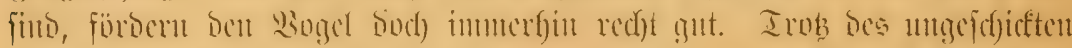

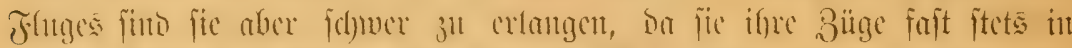

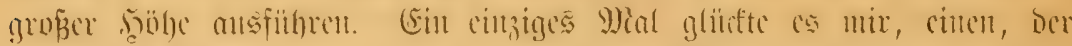

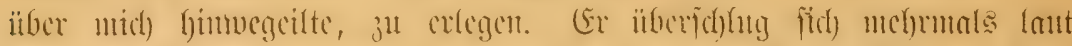

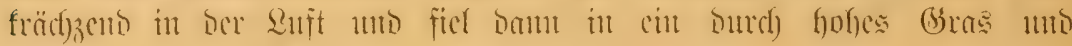

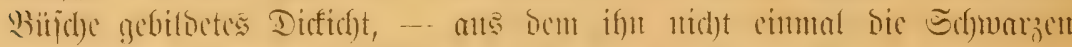

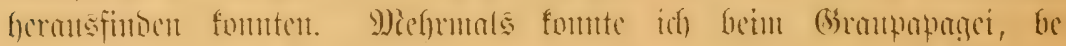

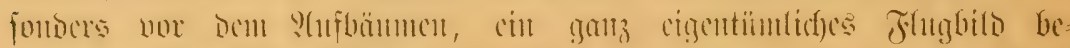

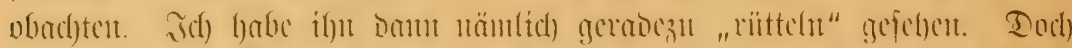

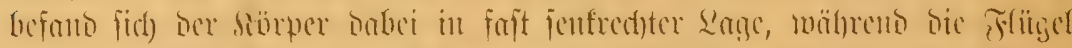

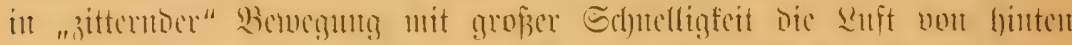

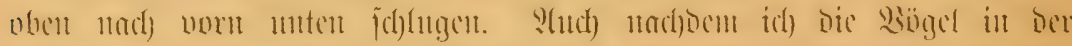

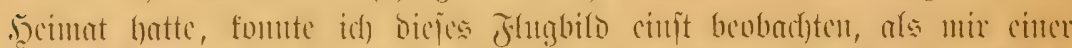

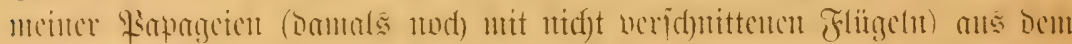

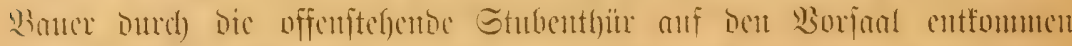

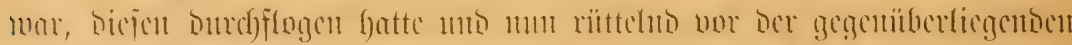

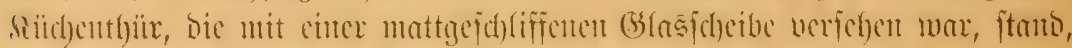
offertbar unffar üfree Das "Wobjin nun weiter".

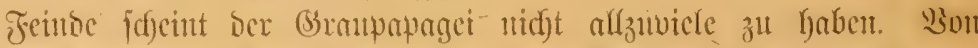

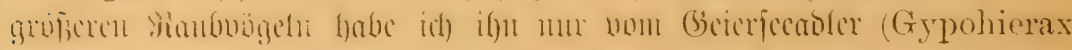

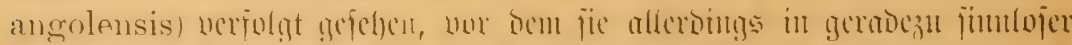

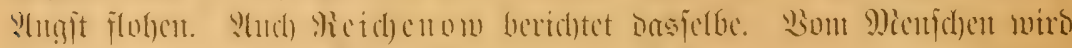

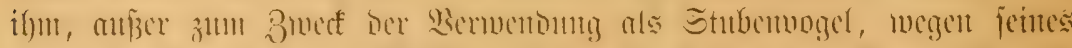

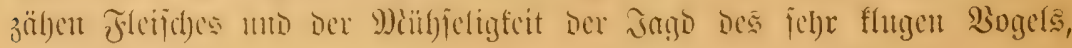




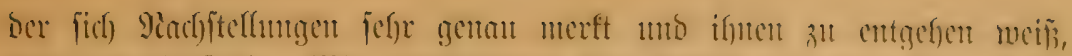

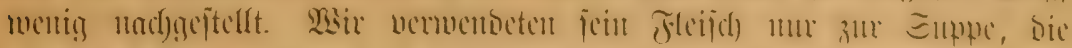

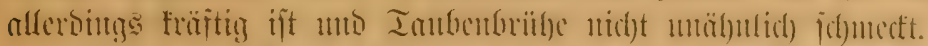

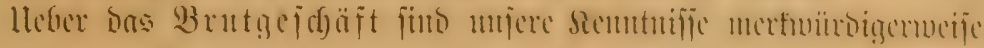

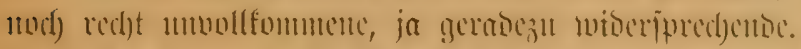

Iic bepten Shadrichten

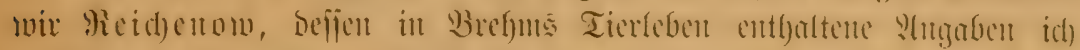
atad)folgents wiebergetbe. Fr fdjecibt:

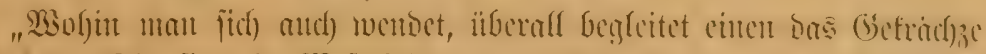

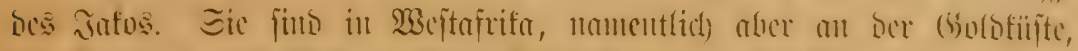

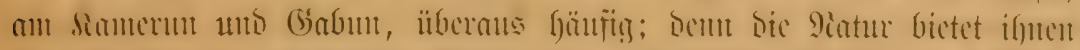

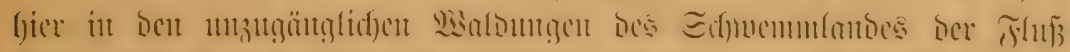

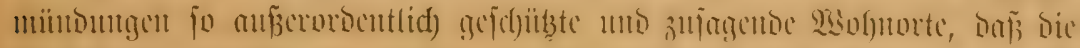

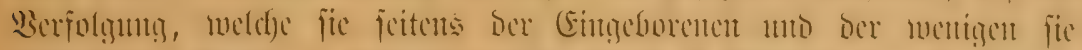

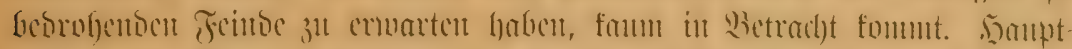

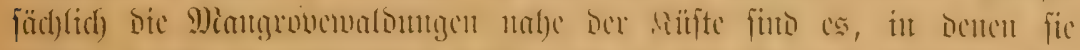

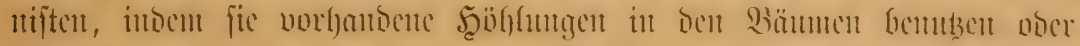

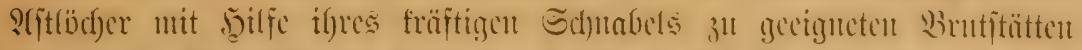

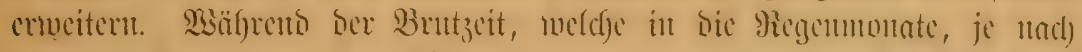

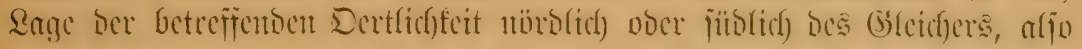

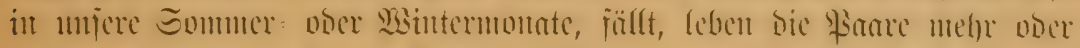

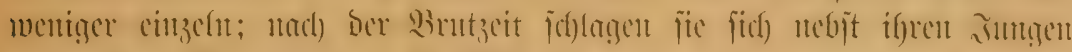

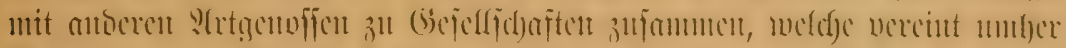

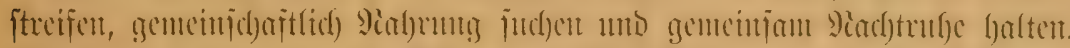

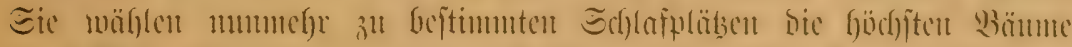

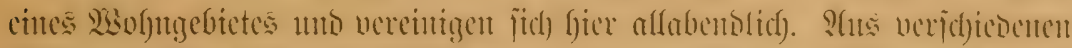

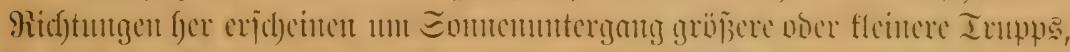

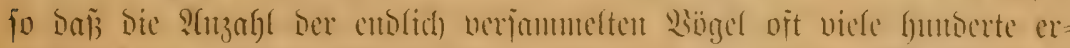

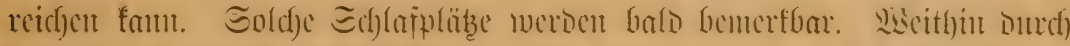

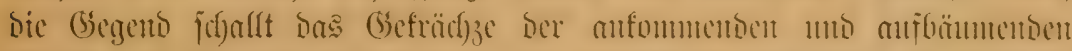

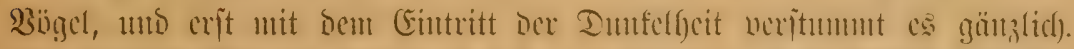

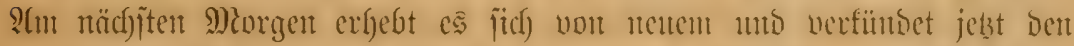

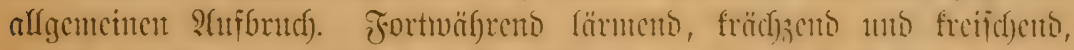

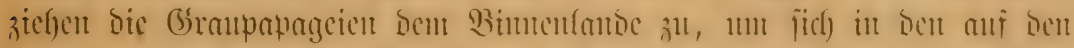

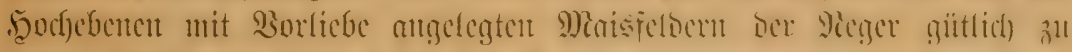

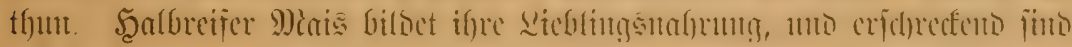

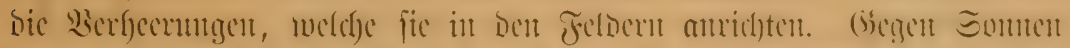
untergang treten fie bon ?lüft, pläben żt verfanmeln. 


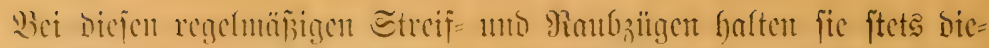

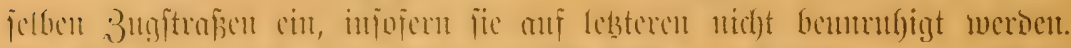

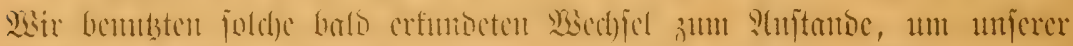

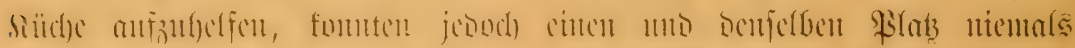

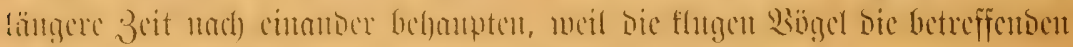
Steflen fich merftent mo in weitent Bogen umflogent.

Der. Flug ber Grampapageten ift erbärmlich) zu nenten. Mit

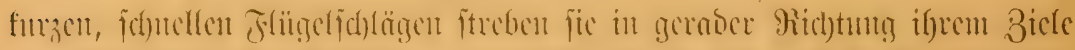

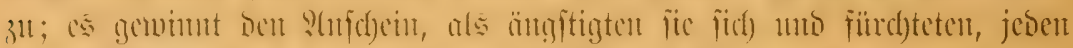

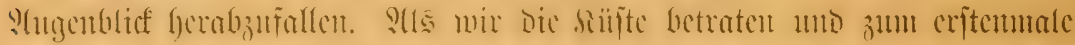

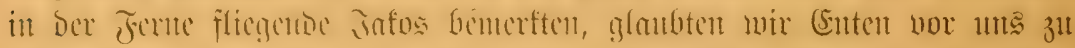

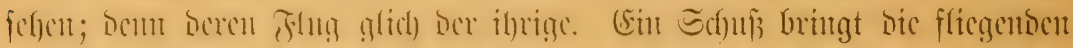

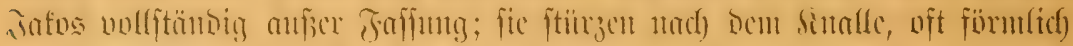

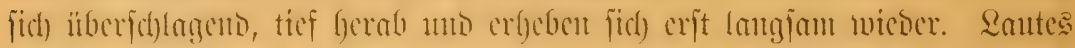

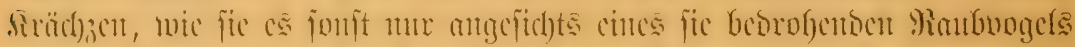

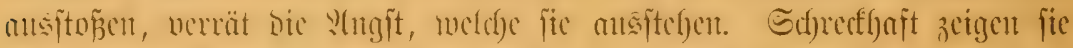

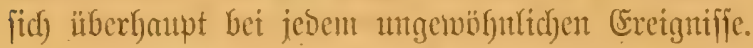

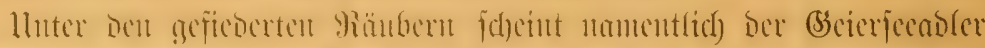

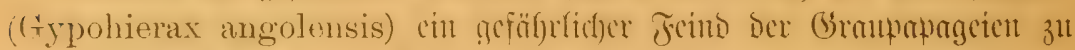

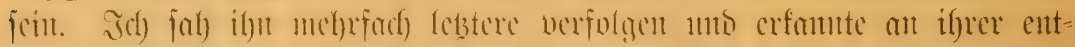

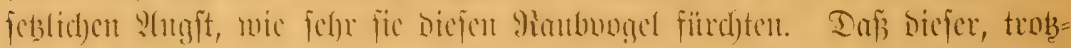

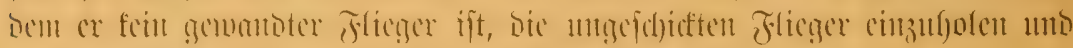
żl

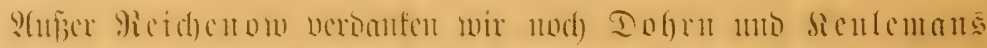

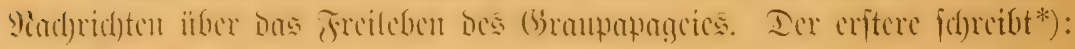

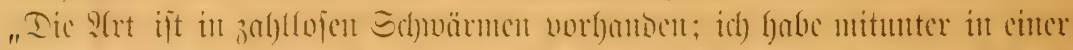

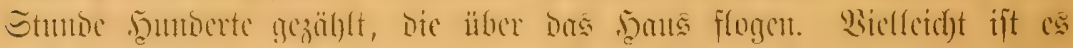

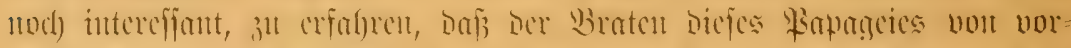

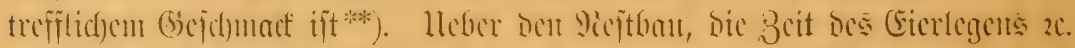

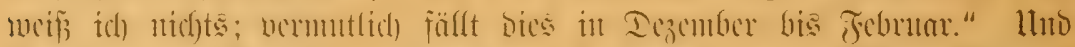

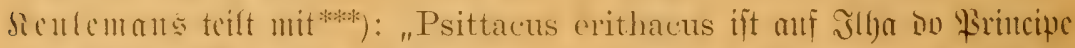

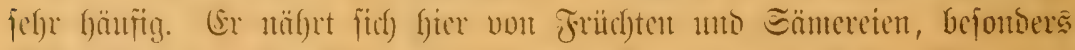

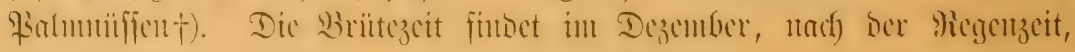

*) Finj(), Dic \$apagcicn 1868. B3and II, S. 312.

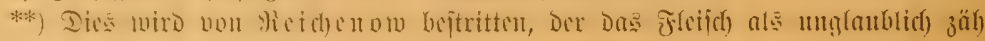

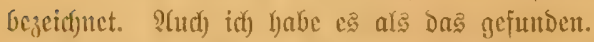

***) Fiuj(h), Dic \$awageien 1868. Band II, S. 314.

†) Das habe idf) auf Dem Feftlande ute beobad)ten fömen. ?(ud) habcu meine gefangenen \$apageien \$almuiijie nid)t angerïgrt. 


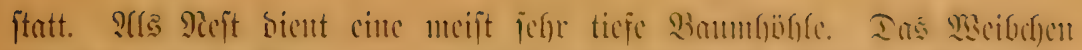

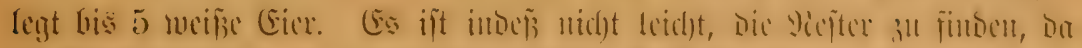

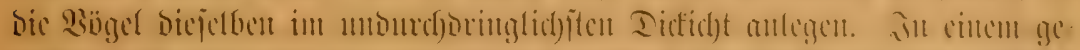

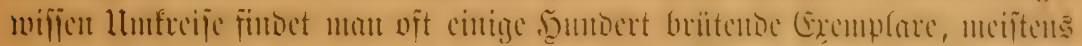

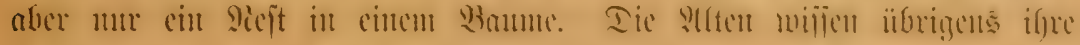

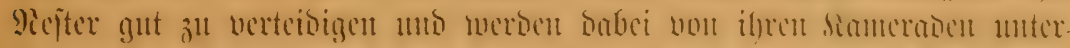

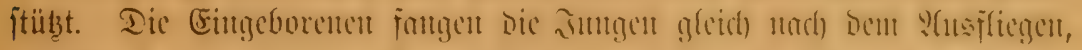

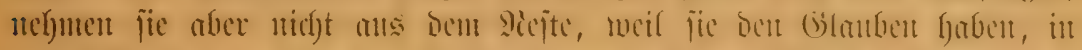

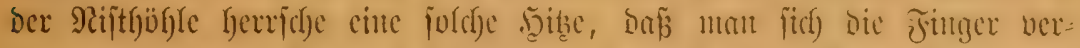

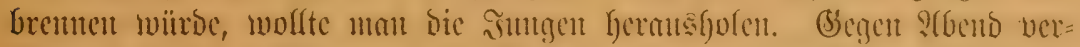

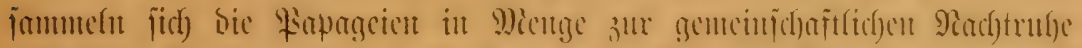

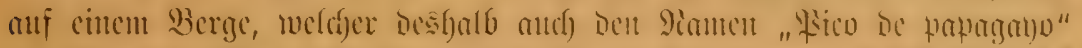

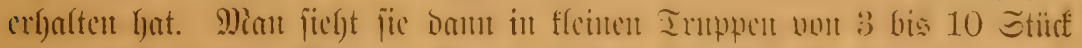

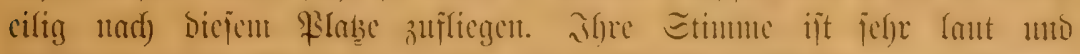

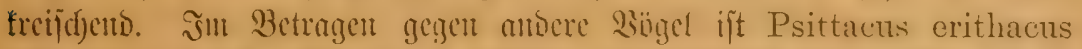

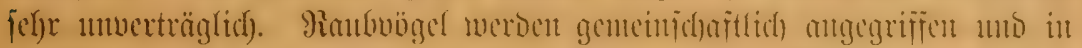

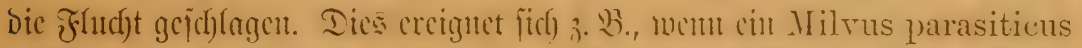

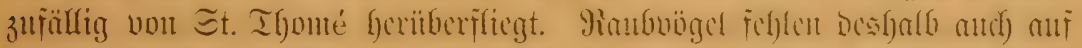

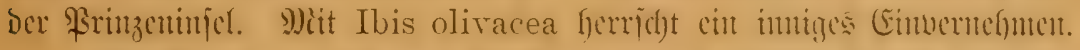

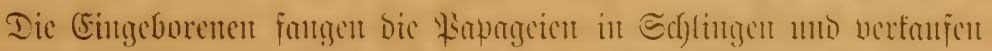

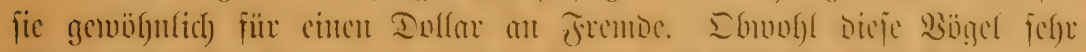

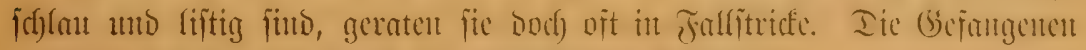

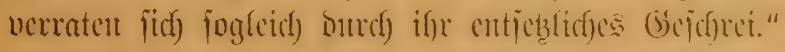

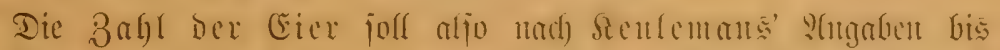

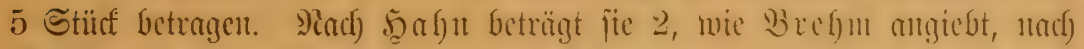

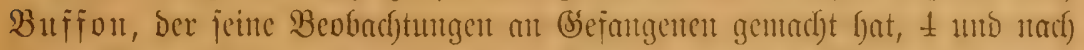

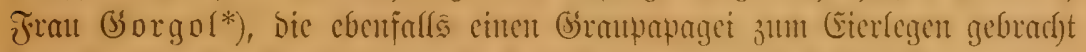

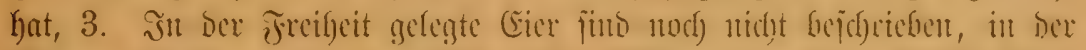

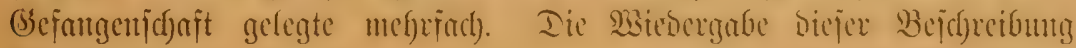
folgt ipäter.

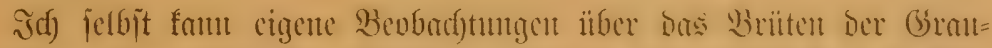

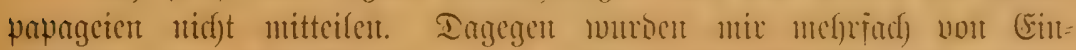

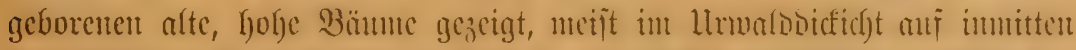

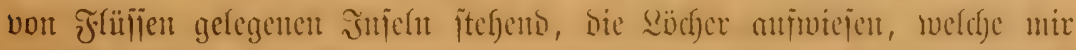
als Bruthöhlen Des Braupapageics bezeichnet rumben. So crimtere idf) mid) nod) lebfaft cines alten "Banmmollbaumes", weldser mix auf

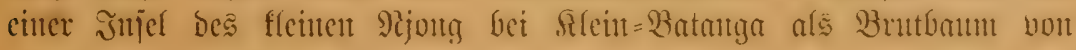

*) Brefiederte $\$ e l t ~ 1894$, ธ. 13. 


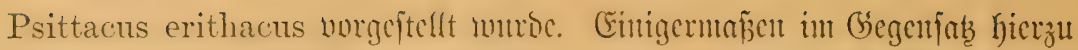

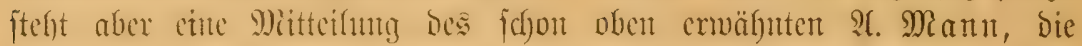

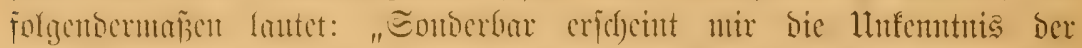

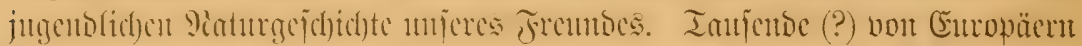

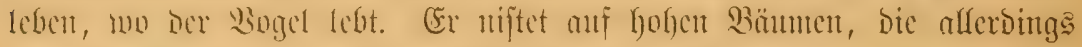

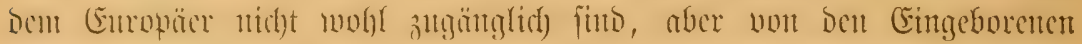

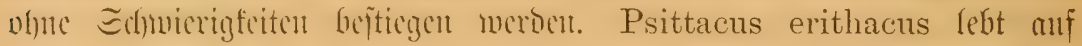

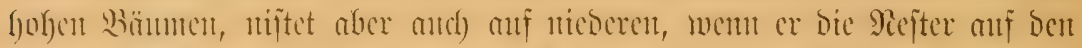

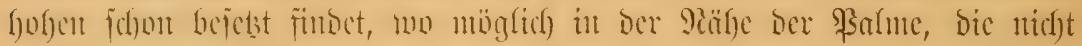

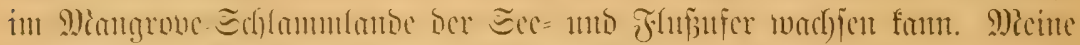

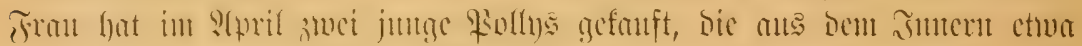

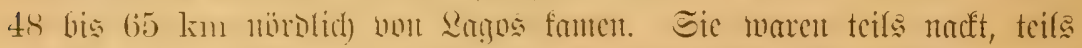

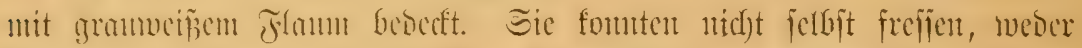

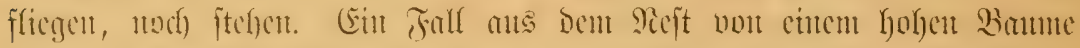

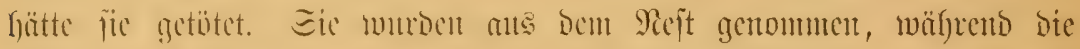

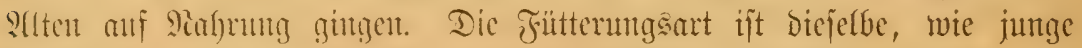

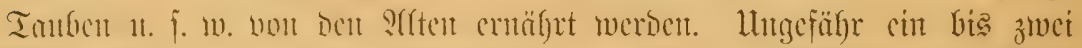

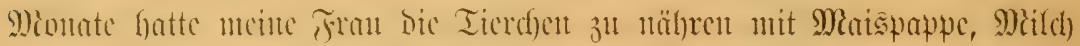

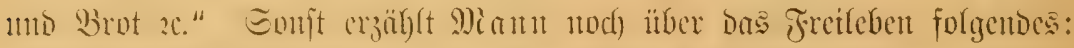

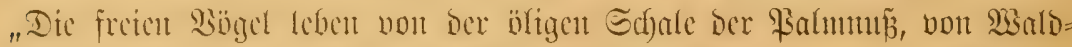

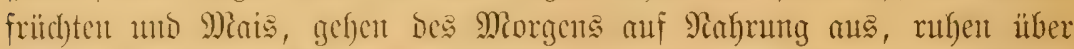

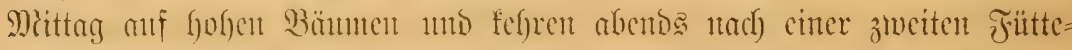

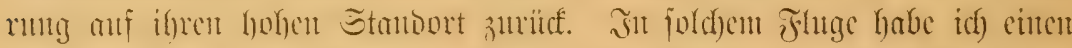

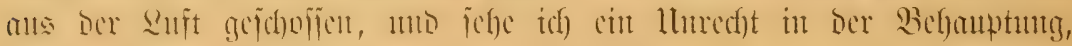

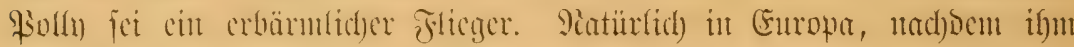

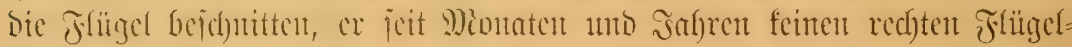

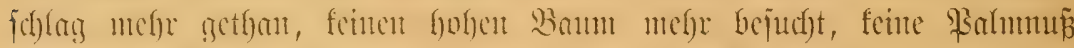

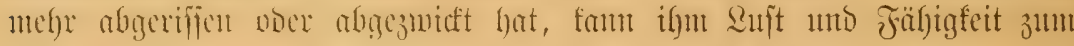

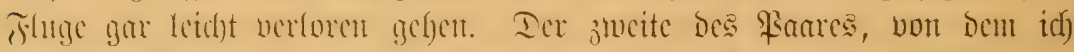

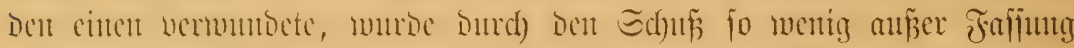

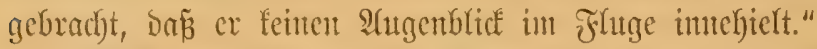

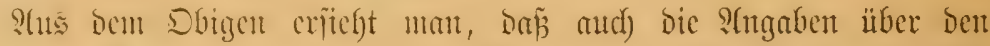

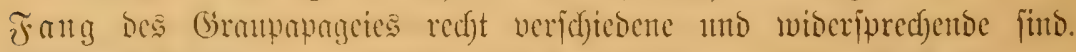

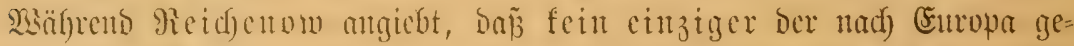
langenton (brantapageicu alt gefangen fet, fondorn affe aus bem Sejt

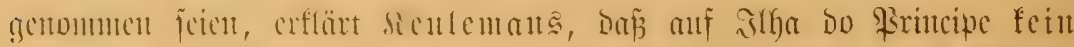
ciuziger aus bem sect gendumen werde. Sd) glaube, bas Ridjtige

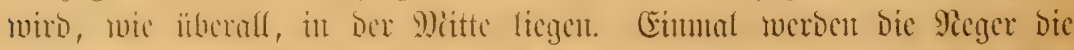

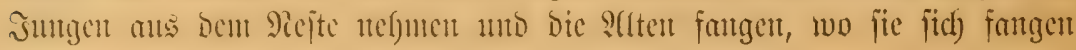




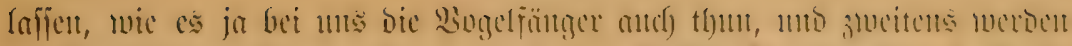

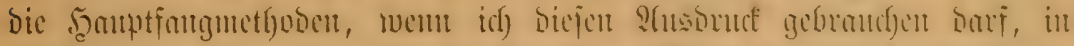

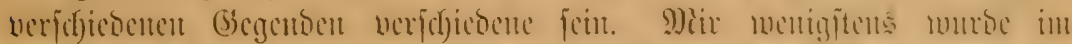

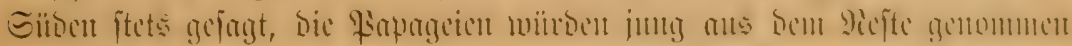

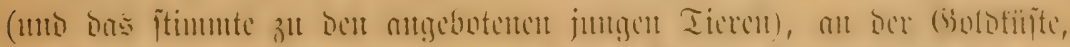

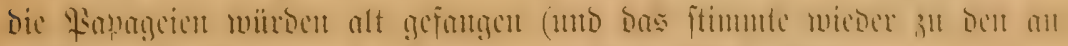

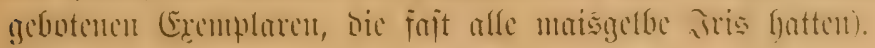

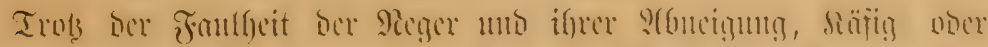

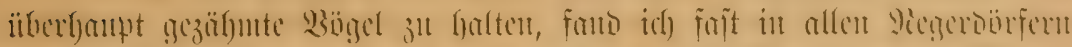

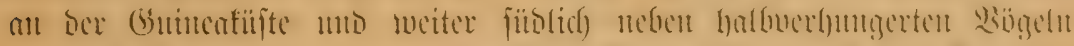

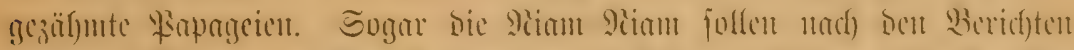

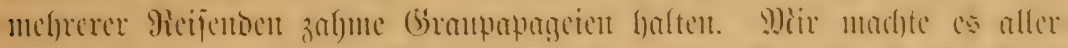

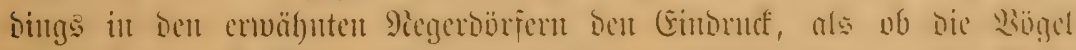

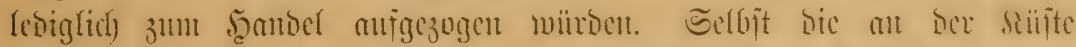

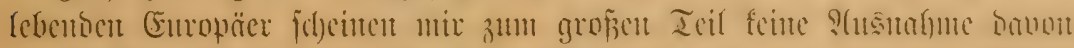

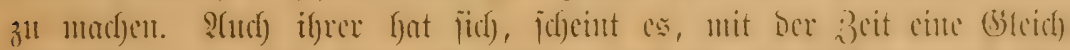

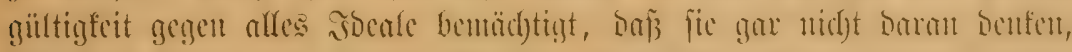

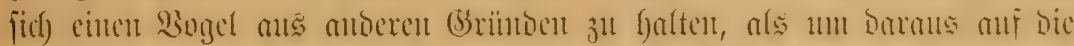

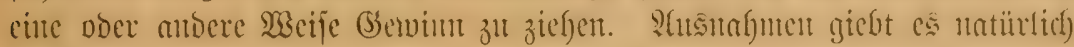
autd) lict.

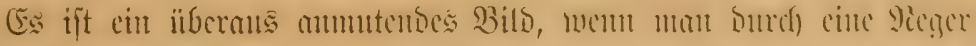

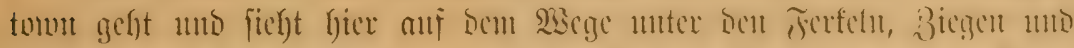

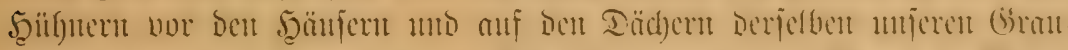

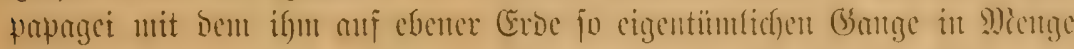

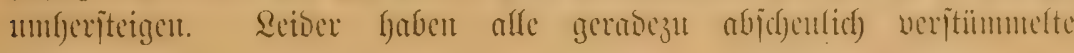
S(j)wingen.

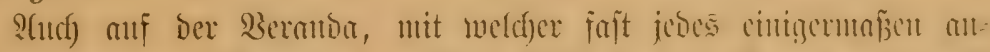

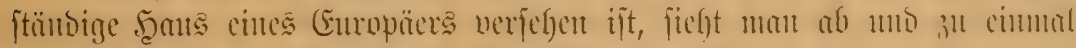

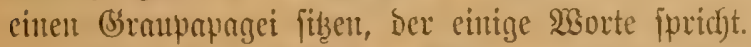

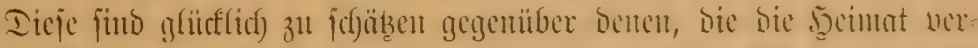

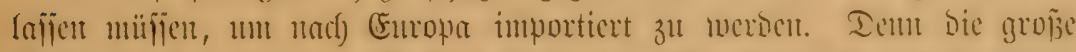

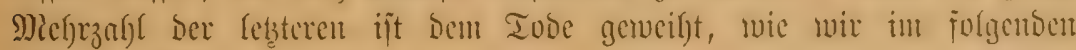
fefjen werben. 


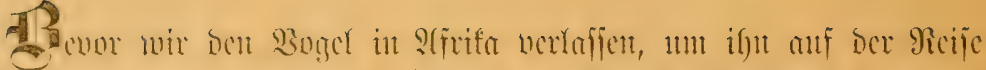

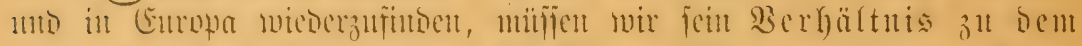

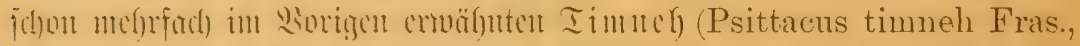

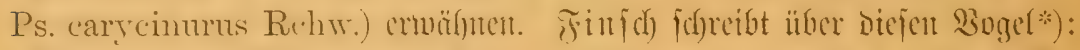

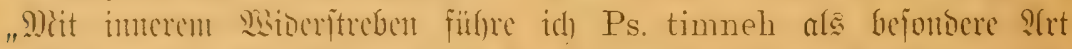

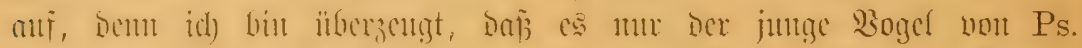

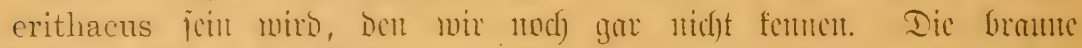

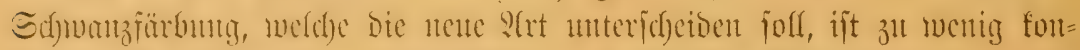

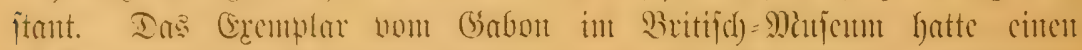

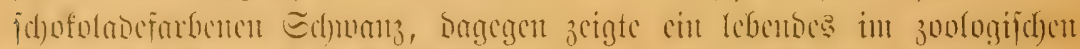

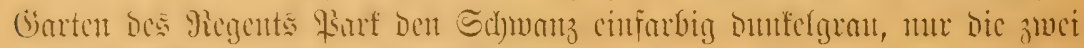

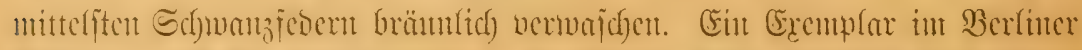

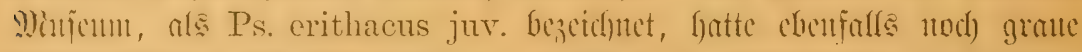

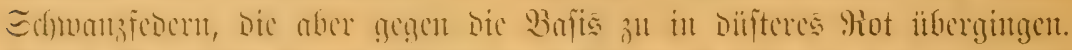

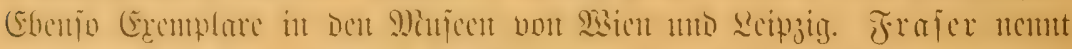

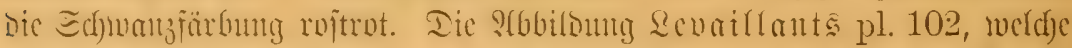

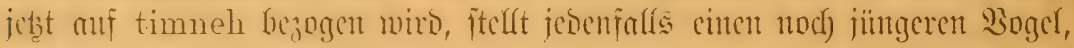

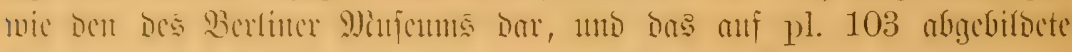

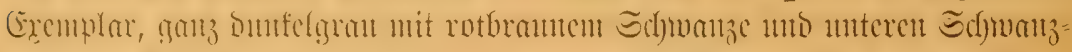

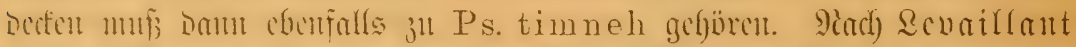

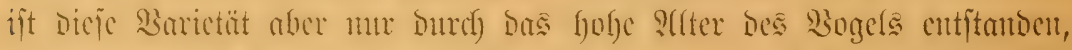

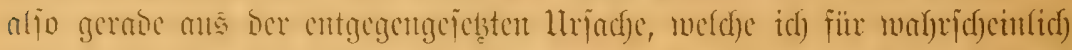
Galte. De Souratcé nemut Ps. timneh eine "fer)r gute" S(rt. Riad)

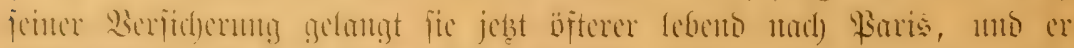

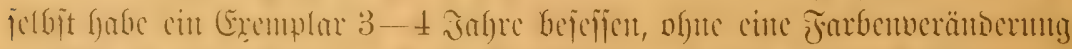

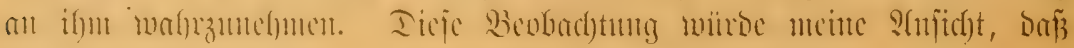




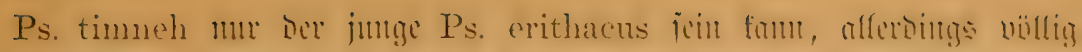

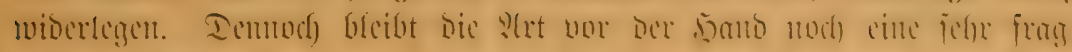
liche fït micl).

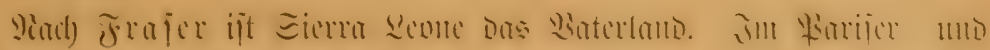

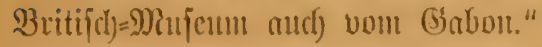

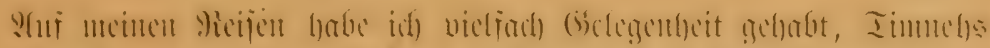

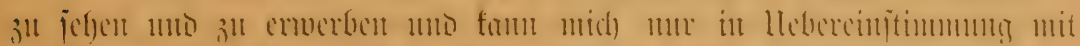

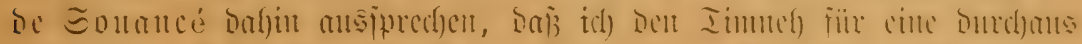

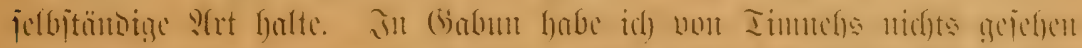

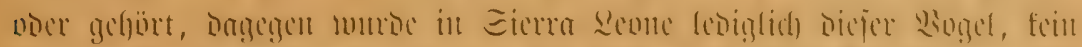

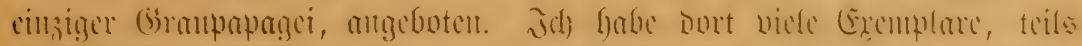

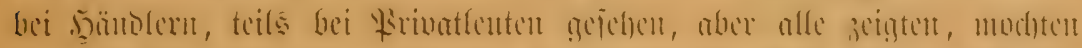

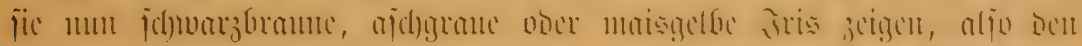

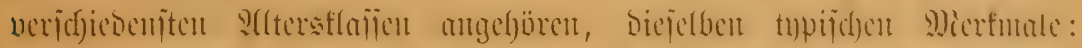

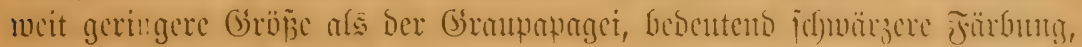

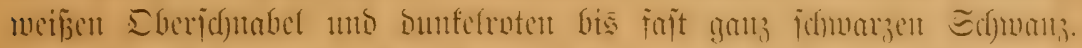

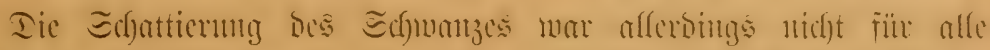

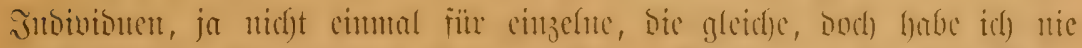

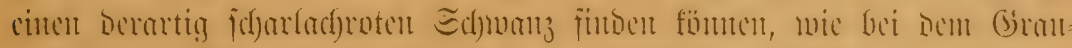

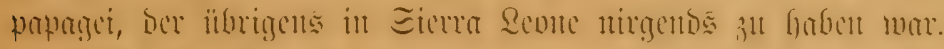

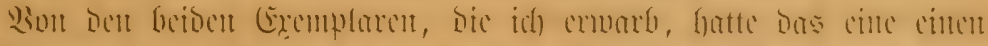

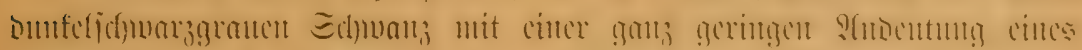

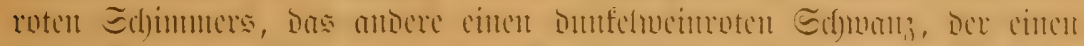

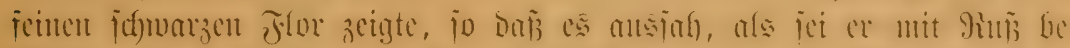

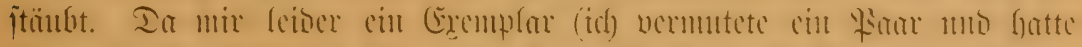

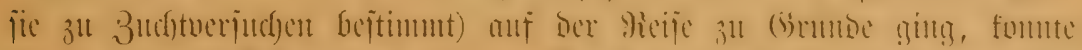

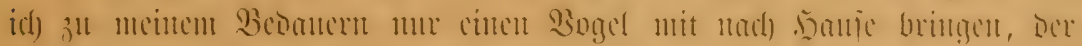

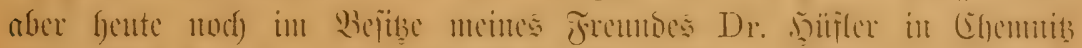

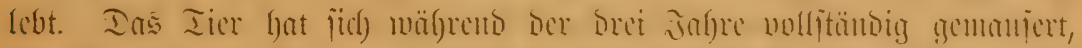

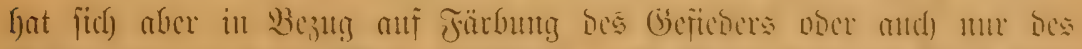

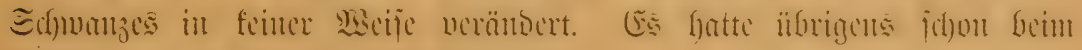

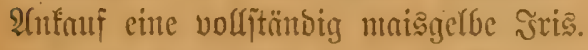

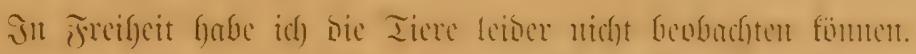

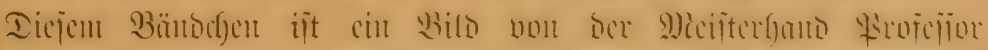

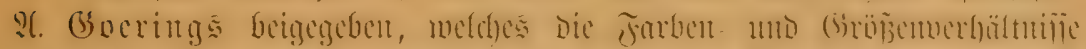

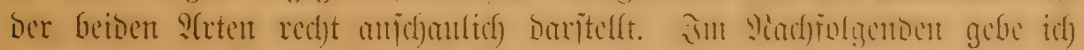

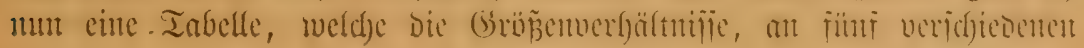
Ȩremplaren gemejient, entfä́lt. 


\begin{tabular}{|c|c|c|c|c|c|c|c|}
\hline & \multicolumn{4}{|c|}{ Psittacus eritbacus } & \multicolumn{3}{|c|}{ Psittacus timneh } \\
\hline & 1. & 2. & 3. & $\begin{array}{l}\text { Dutrd) }= \\
\text { (id)uitt }\end{array}$ & 4. & 5. & $\begin{array}{l}\text { Durdf)= } \\
\text { iffutitt }\end{array}$ \\
\hline & $\mathrm{mm}$ & $\mathrm{mm}$ & $\mathrm{mm}$ & $\mathrm{mm}$ & $\mathrm{mm}$ & $\mathrm{mm}$ & $\mathrm{mm}$ \\
\hline 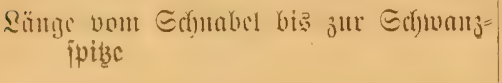 & 340 & 340 & 340 & 340 & 300 & $29 \check{5}$ & 297,5 \\
\hline IIaftertucite & 800 & 750 & 800 & 775 & 700 & 690 & 695 \\
\hline 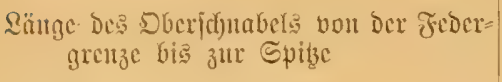 & 37 & 36 & 37 & 36,7 & 35 & 35 & 35 \\
\hline 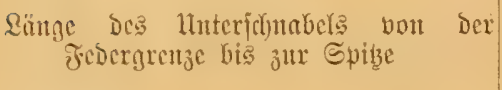 & 23 & 22 & 23 & 22,7 & 20 & 19 & 19,5 \\
\hline 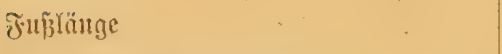 & 71 & 70 & 70 & 70,3 & 60 & 61 & 60,5 \\
\hline Qüngfte Sdjuntzfedern & 94 & 93 & 93 & 93,3 & 90 & 90 & 90 \\
\hline Frïgel vont Butg bis zur Epißze & 236 & 230 & 233 & 233 & 210 & ? & 210 \\
\hline (Gsowidft & $400 \mathrm{~g}$ & $80 g$ & $390 \mathrm{gr}$ & $390 g_{3}$ & $30 \mathrm{gr}$ & $?$ & 330 x \\
\hline
\end{tabular}

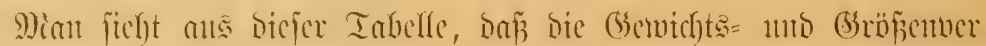
bältuific ocrartig funb, Daf bor Psittacus erithacus ben Timmel) in bei=

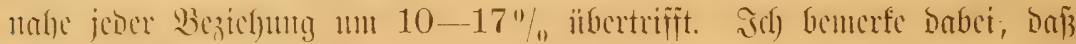
alle bie betreffenton Tiere bis anf sir. 5 bercits feit ca. 3 sabren in

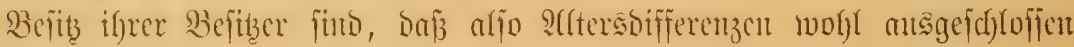

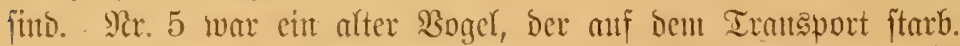

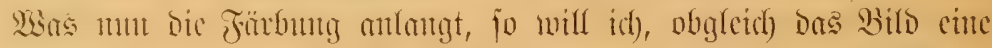

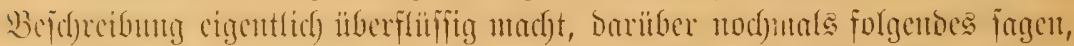

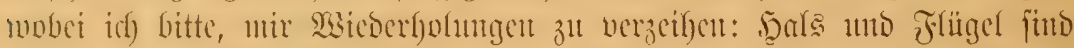

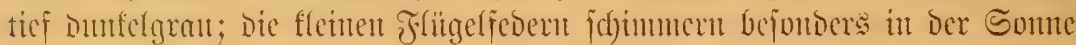

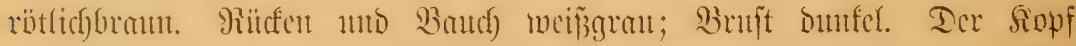

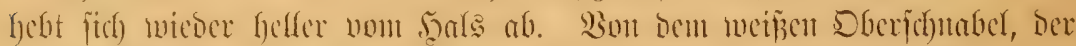

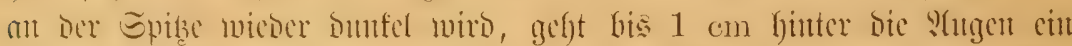

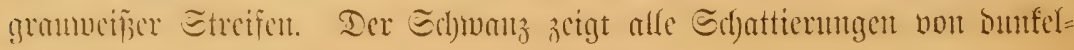
rot bis fdjofolabenbraun, grat und fdjwarz.

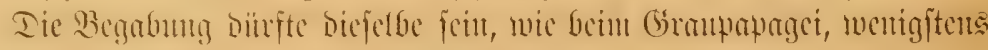
Gabe idf etroas abrweidyentos ntidyt benerft. 


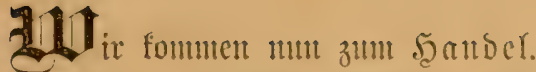

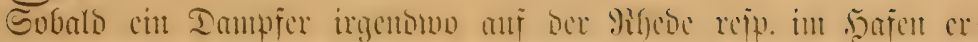

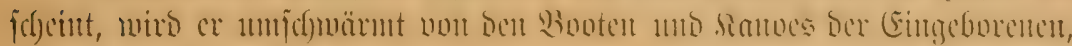

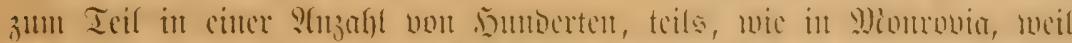

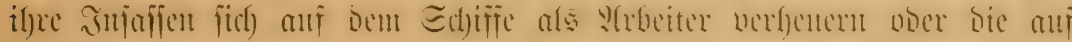

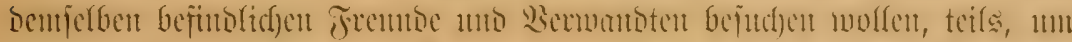

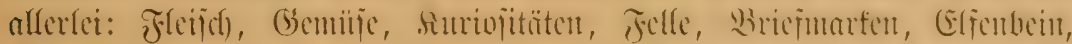

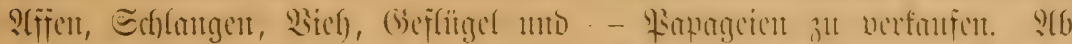

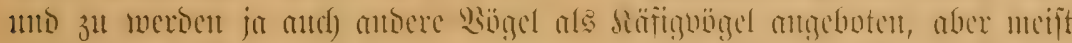

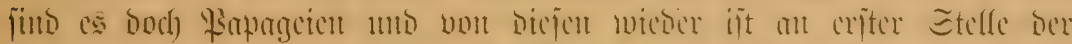

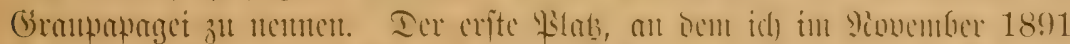

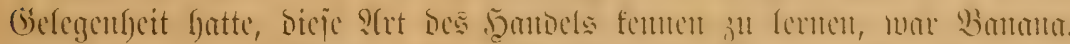

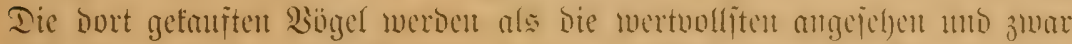

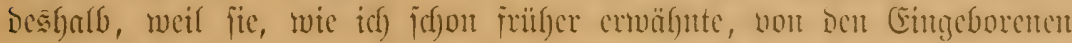

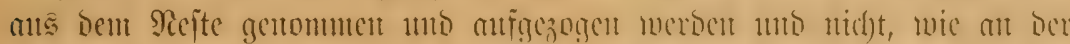

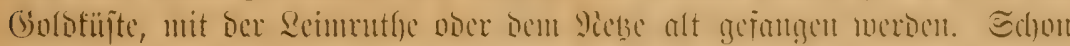

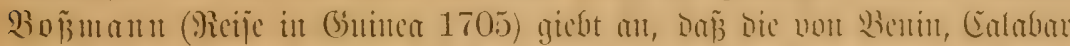

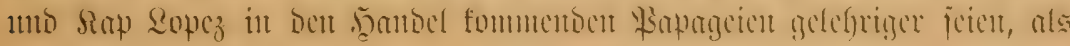
Sic von Der Silifte von Bruinea ftammentoen.

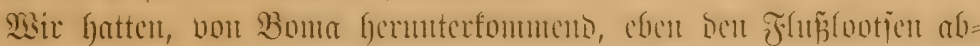

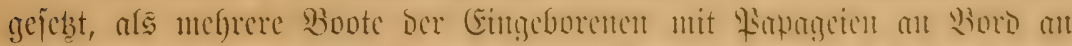

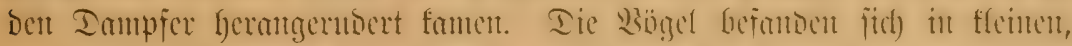

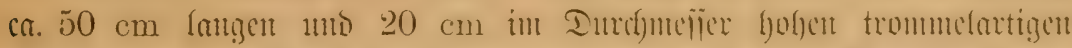

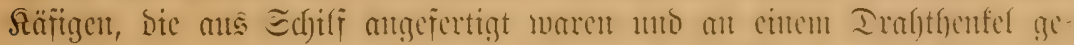

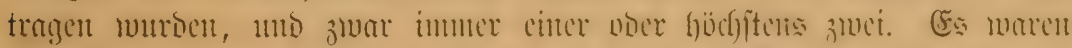

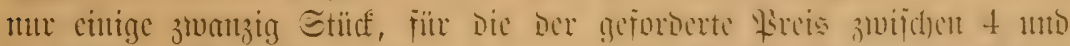

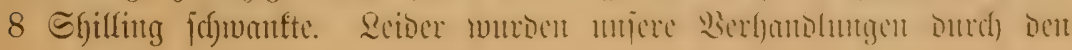




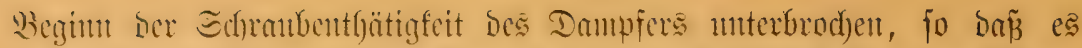

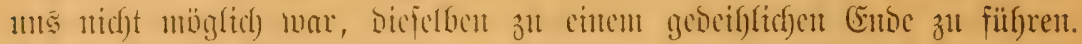

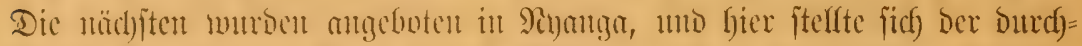

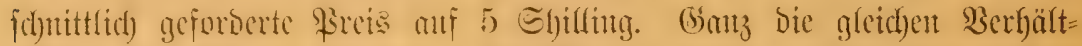

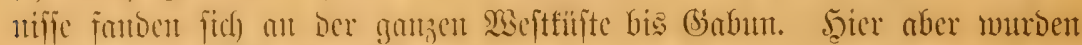

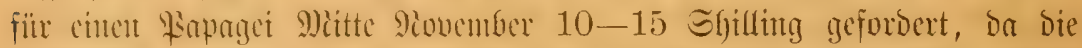

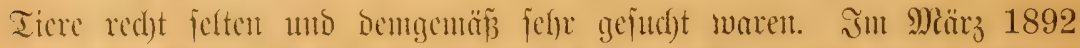

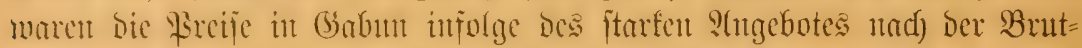

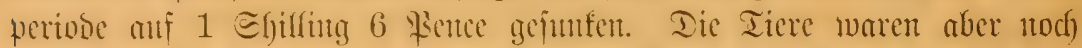

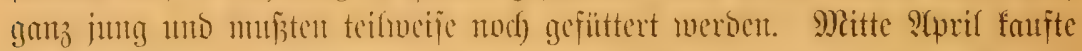

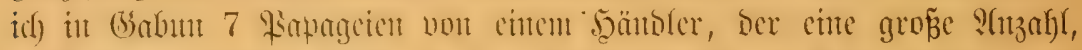

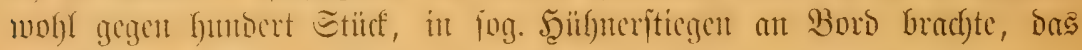

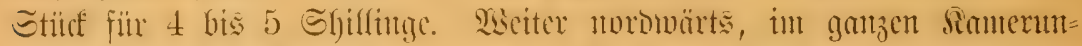

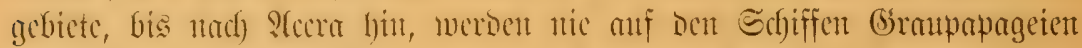
angeboten. Eigentiumlich), Denn ber (Srantapaget ift in Samerum nicht meniger bäufig als füD= แnto norsmärts. Die Sanffente in Samerun,

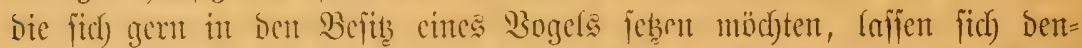

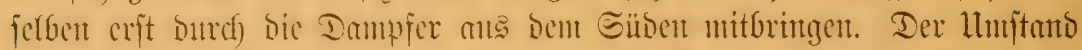

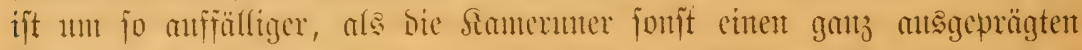

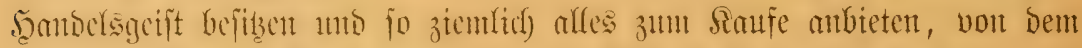

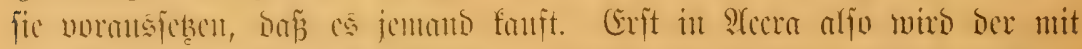

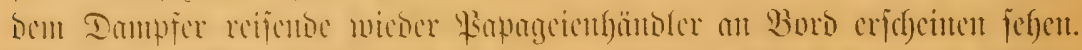

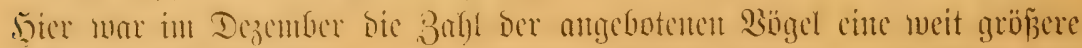

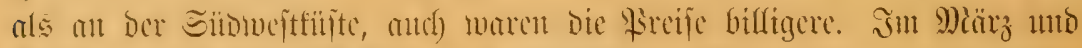

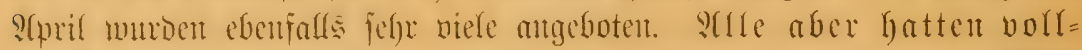
fommen maisgelbe sris, fomoly bie im Dezember, wie bie im März

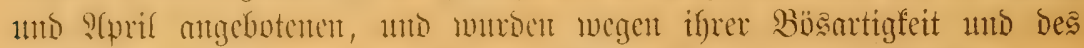

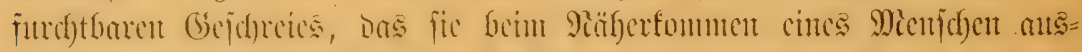

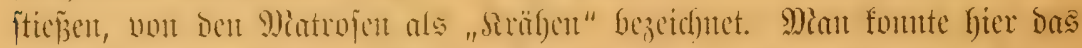

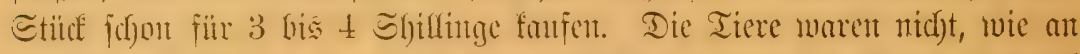

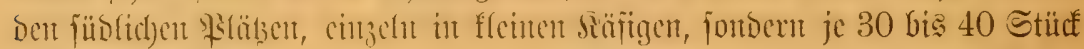

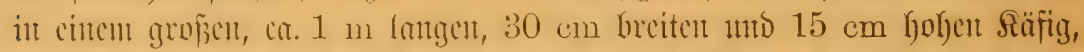

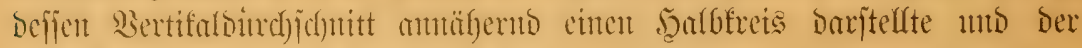

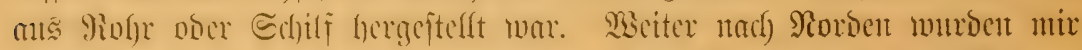

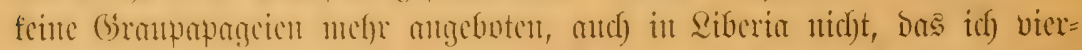

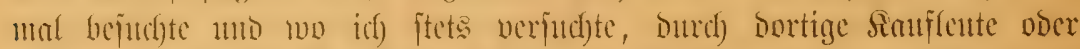

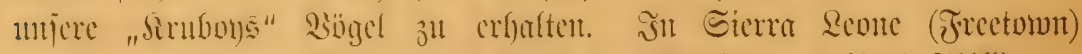

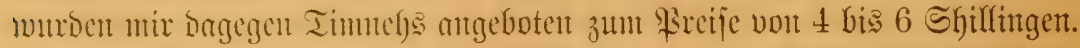

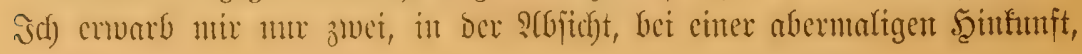




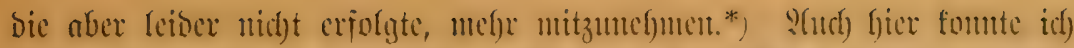

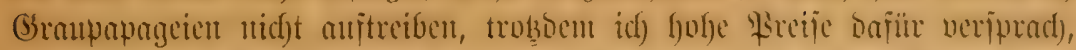

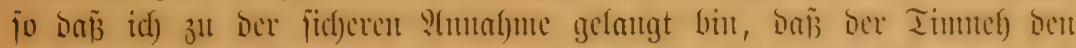

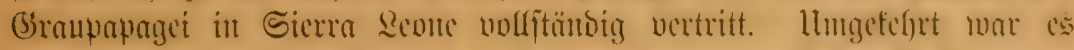

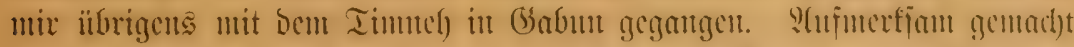

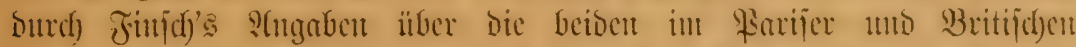

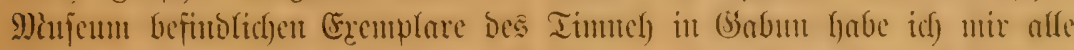

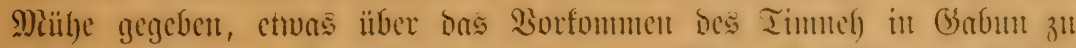

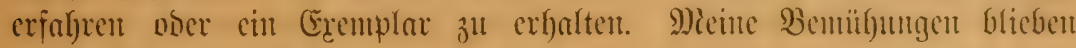
vollfoument olnte Ěrfolg.

Dod) Das nebenbei.

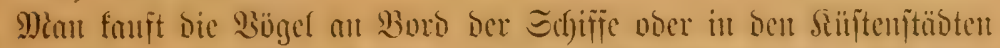

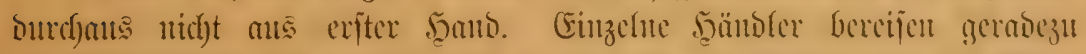

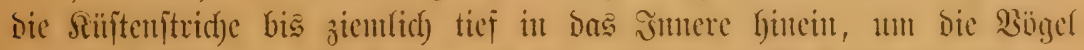

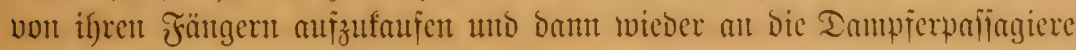
ober bie Seeleute zll berfaufen.

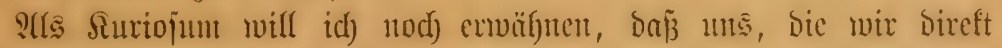

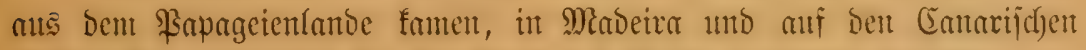

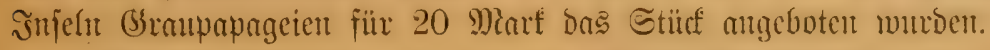

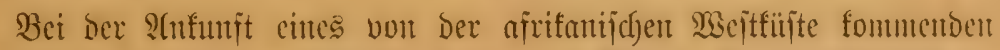

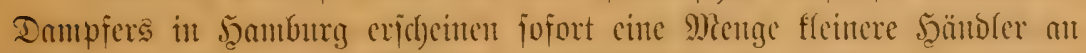

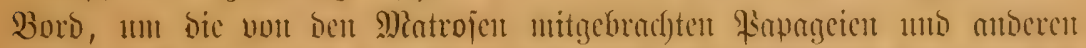

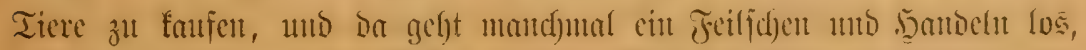

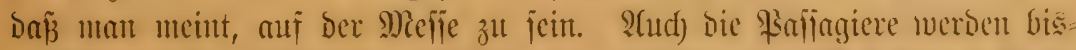
meifen von Den Şänd

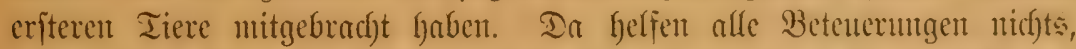

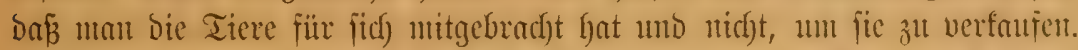
Mit einer Bungenfertigfeit uno ?(usbauer, bie ciner befferen End)e wert

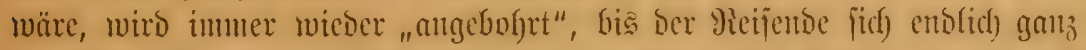
energijd) afle weiteren Serfantolungen verbittet. Die Preije, Die gezahlt werben, jd)wanfen zwijchen 8 bis 10 Miarf für einen frijch importierten

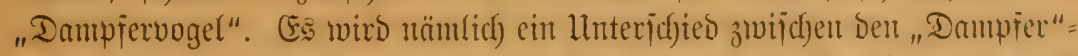

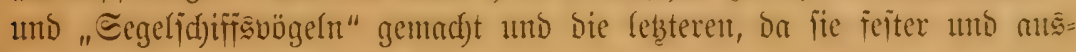
bauernber jein joffen, tenerer bezafit.

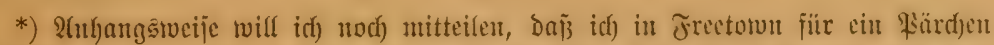
Mofrenfopf (Poeocephalus senegalus) 10 Shilling, fïr cin Crumplar des llu= zertrennlid)en (Agapornis pullaria) in 2(ccra und Euttha 6 Pence bezahlte. Tatocre

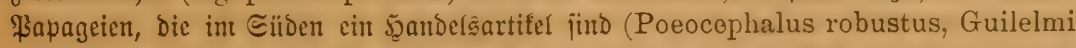
und fuscicollis) wurben mir nidjt angeboten und waren aud) nidjt zu ex(angen. 


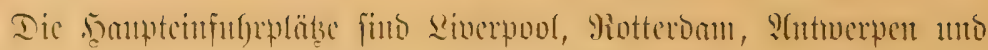
Бุamburg.

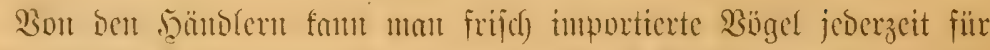

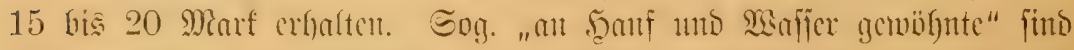

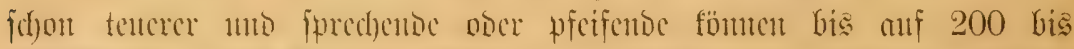

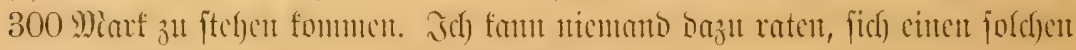

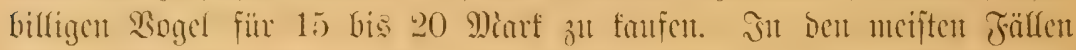

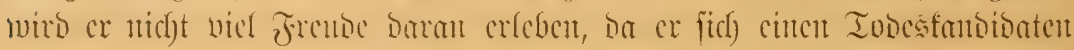
erworben hat.

Morm licgt bics mut? 


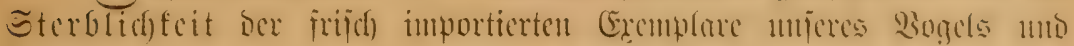

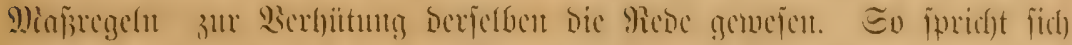

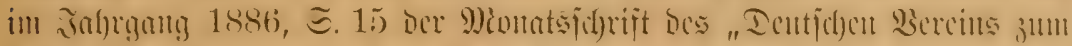

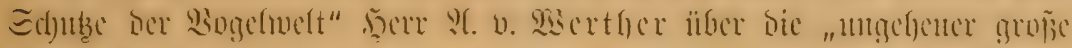

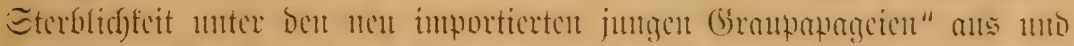

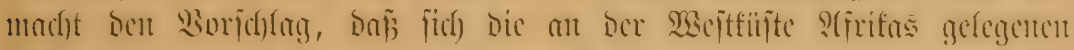

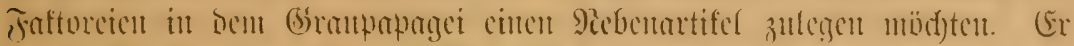

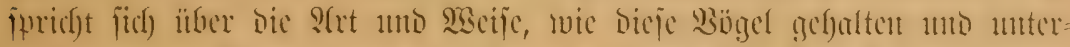

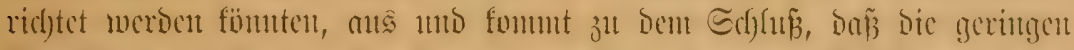

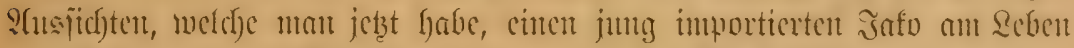

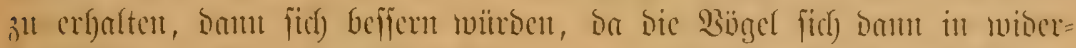

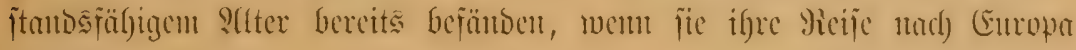
anträten.

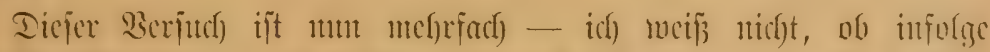

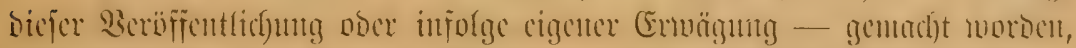

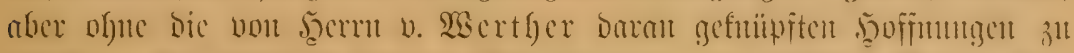

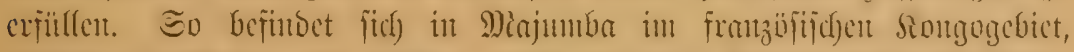

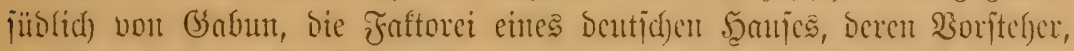

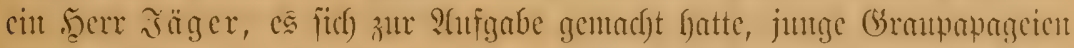

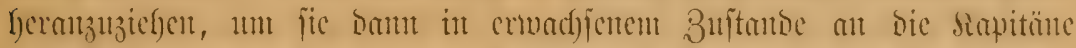

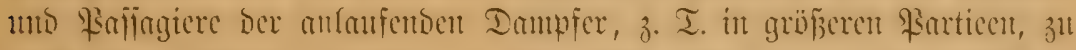

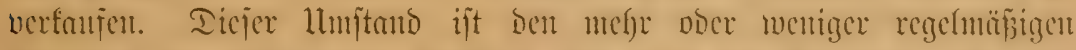

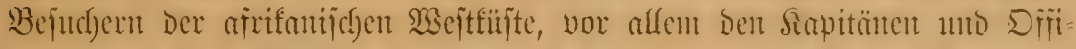

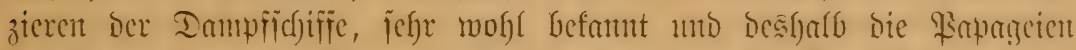

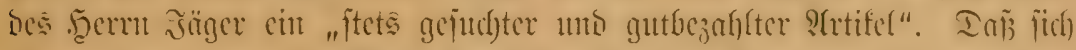

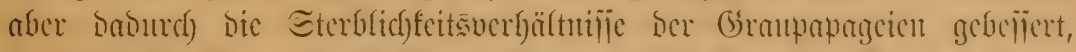

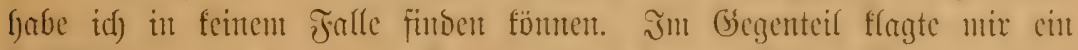

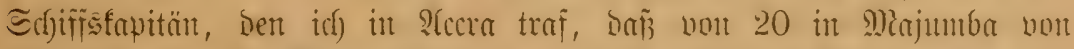

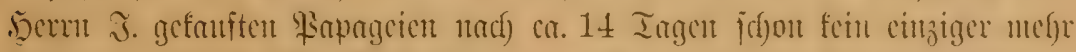

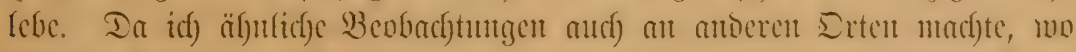

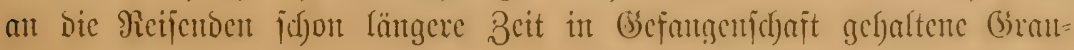




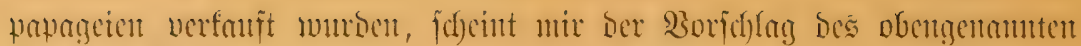

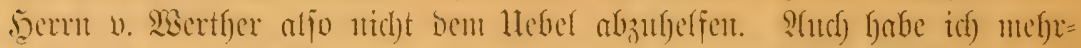

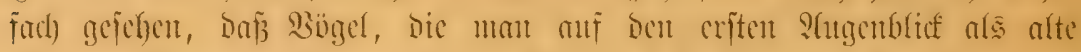

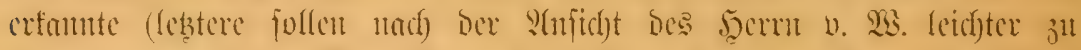

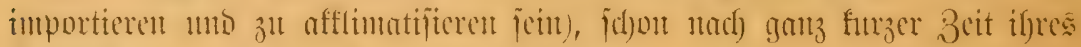

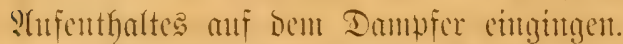

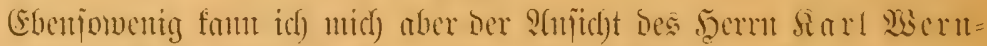

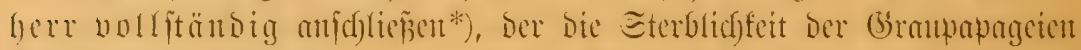

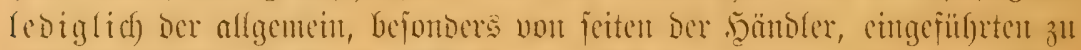

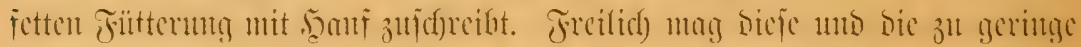

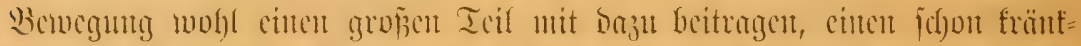

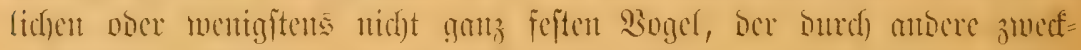

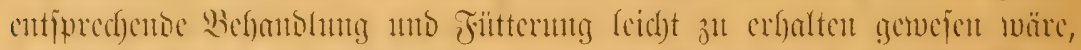

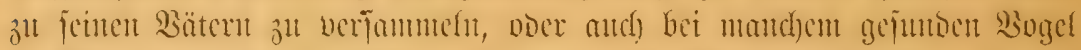

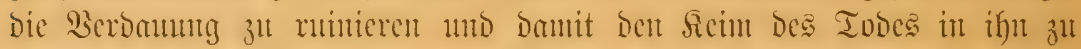
legen, aber in alfgemeinen liegt nad) memer lteberzentgutg Der Fefler: Dod) two anders.

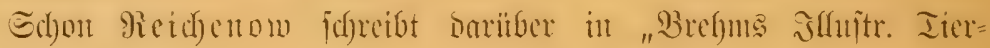
leben1 $" * * *)$ :

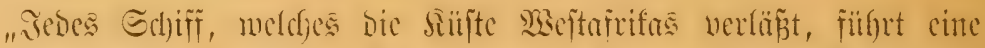

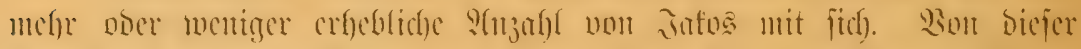

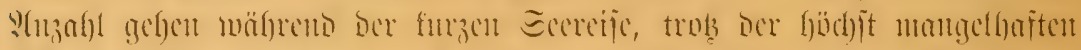

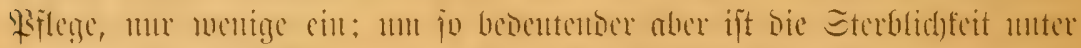

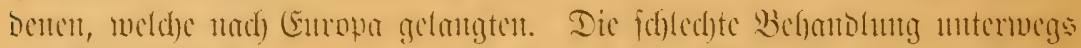

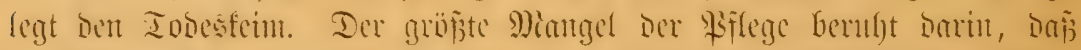

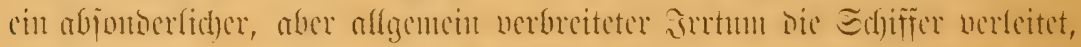
Den Papageicu unterwega Irinfuaffer vorzuentbalter. Da mu

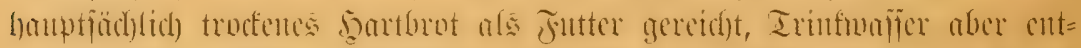

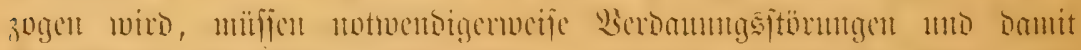

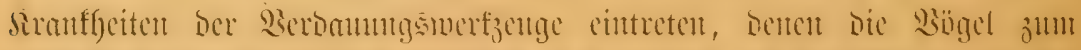

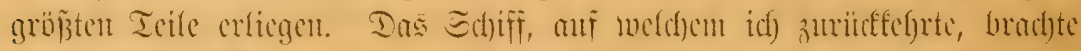

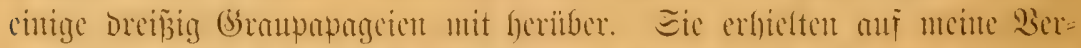

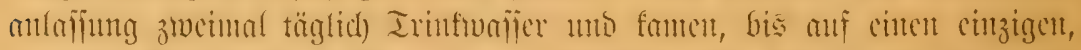

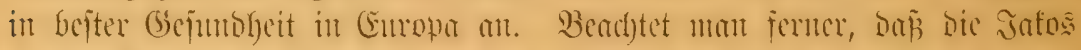

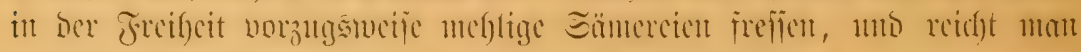

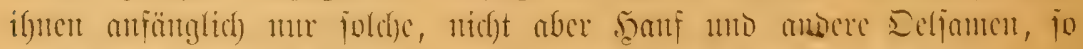

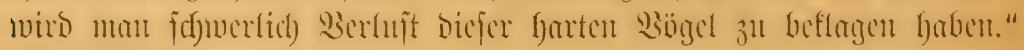

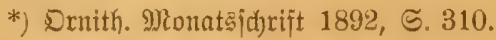

**) 1878. 23and IV, ऽ. 62. 


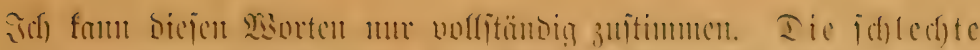

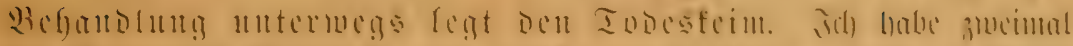

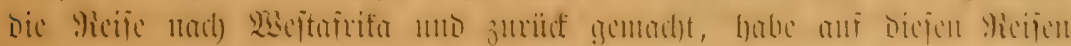

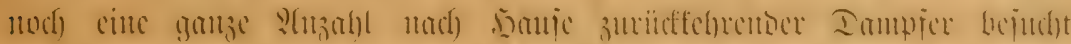

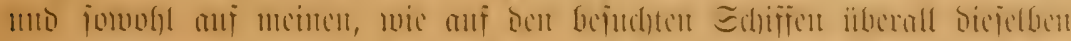

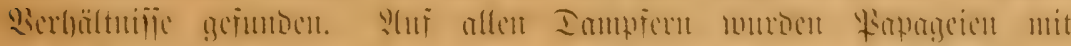

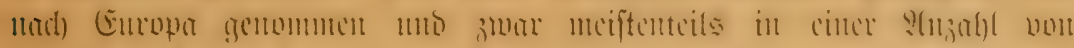

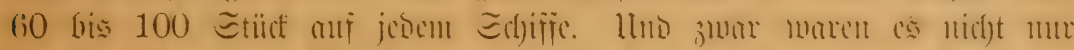

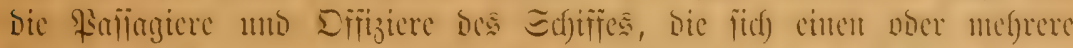

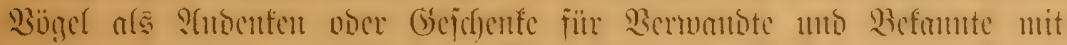

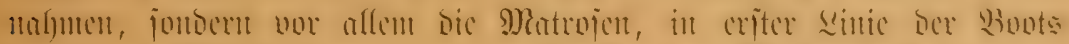

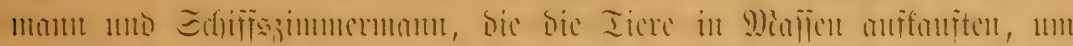

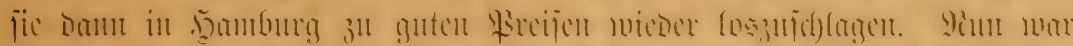

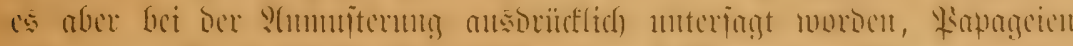

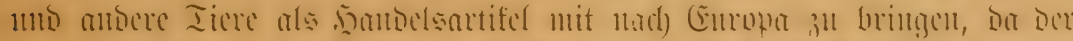

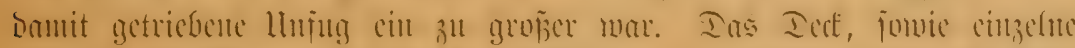

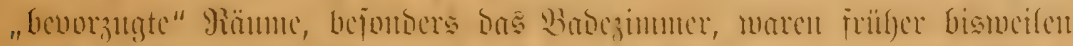

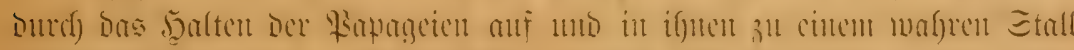

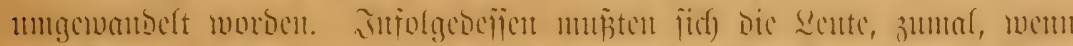

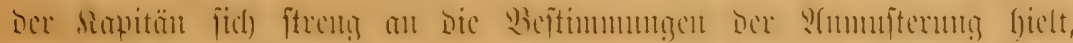

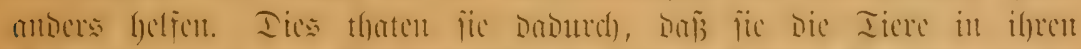

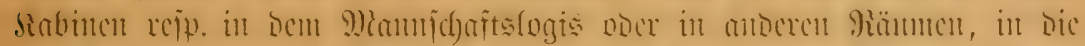

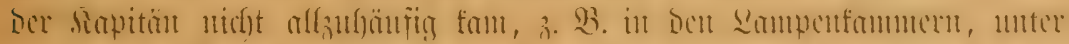

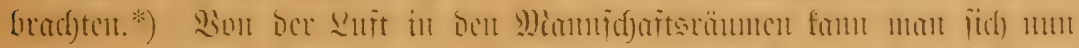

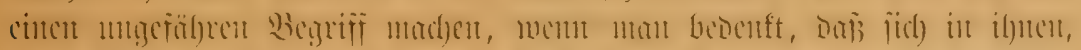

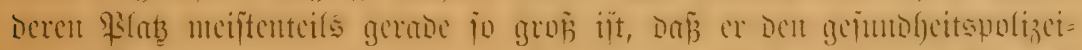

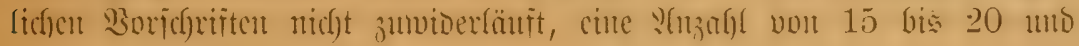

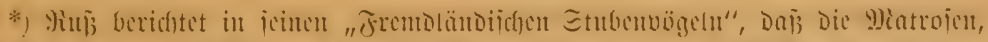

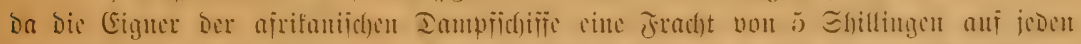

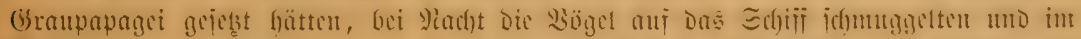

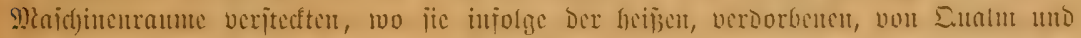

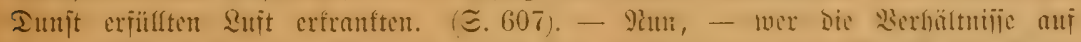

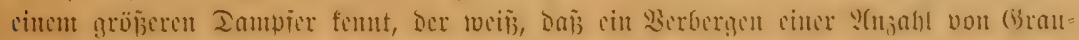

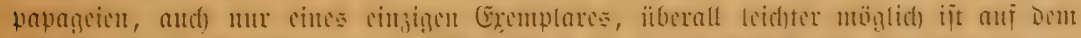

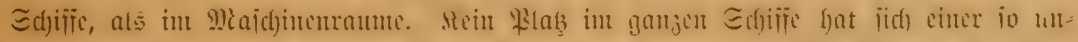

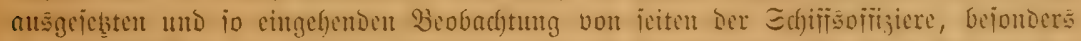

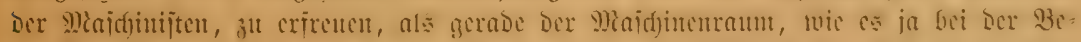

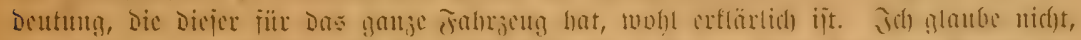

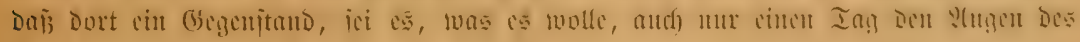
Den Diemít Kabenben Beanten entgegen f̈önte. 


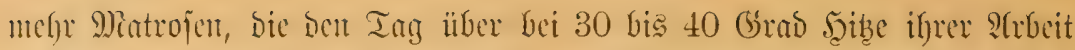

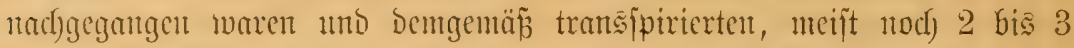

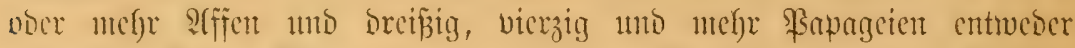

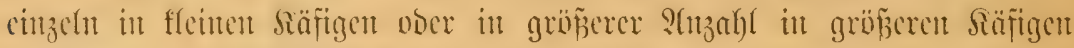

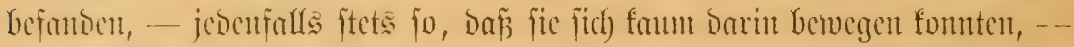

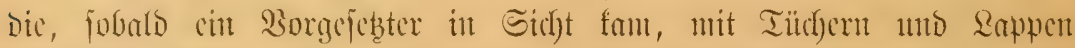

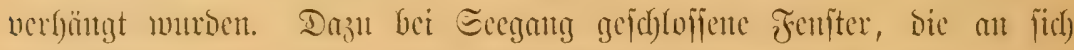

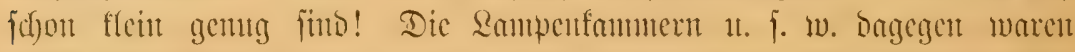

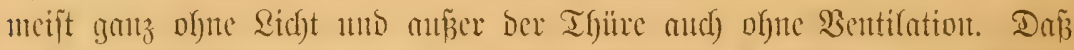

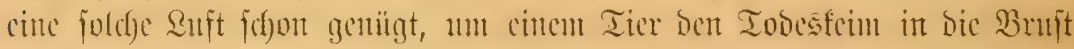

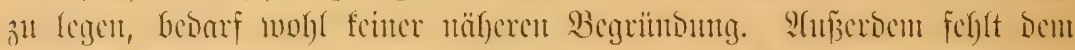

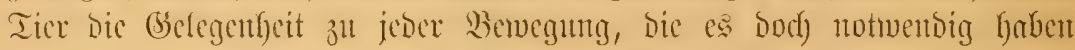

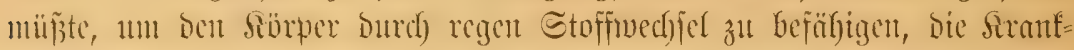

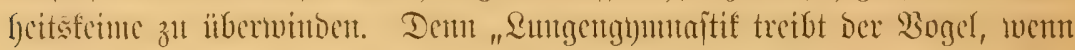

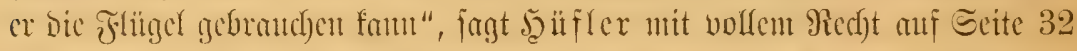

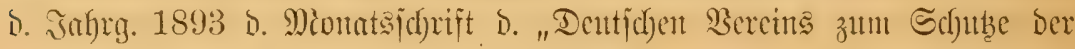

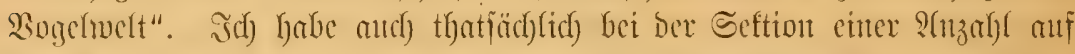

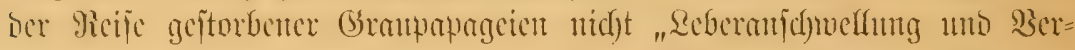
ftopfung ber Durchgaugstanüle", wie berr Tiecargt Dunfer bei beu

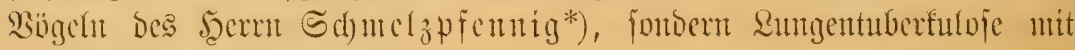
grổett Cànernet gefundent.

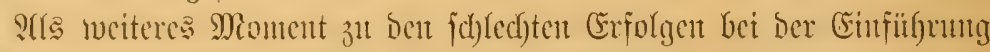

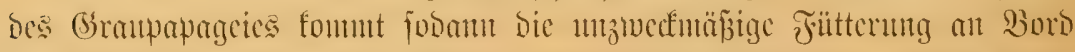

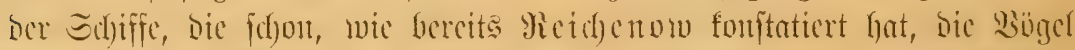

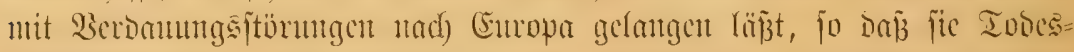

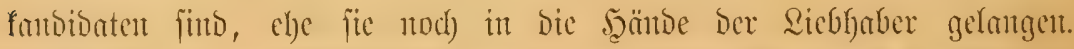

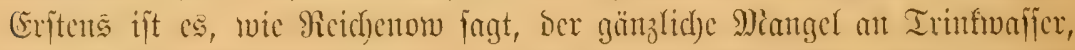

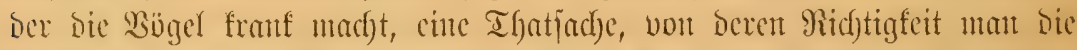

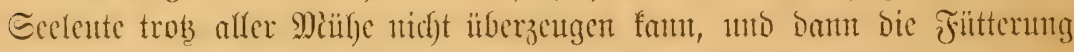

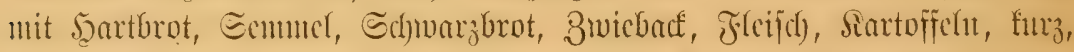

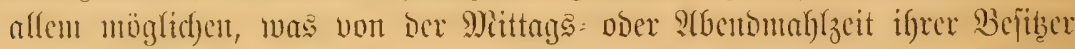

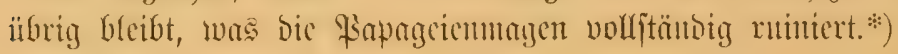

*) Drnith. Monatşifyrift 1892, ธ. 311.

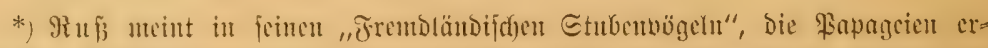

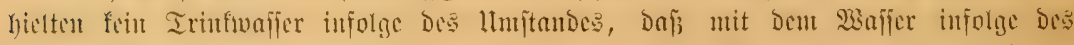
Mangels iparjant umtgegangen werben mitije. Der (brumb ift abor cin gam anderer.

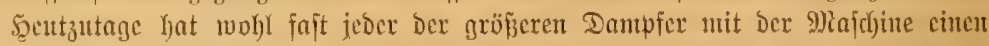

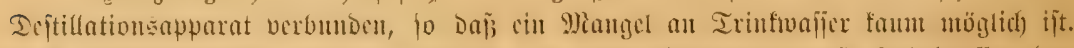

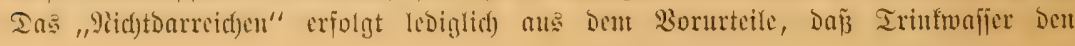




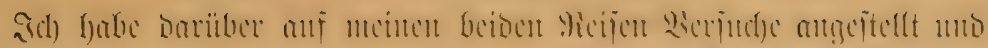

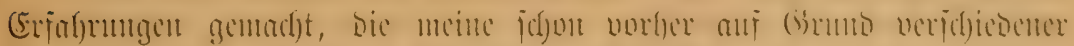

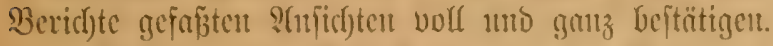

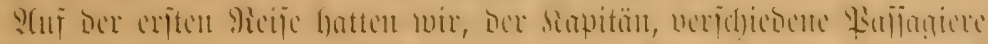

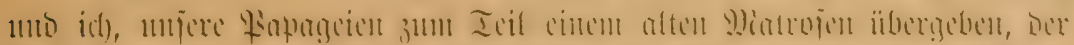

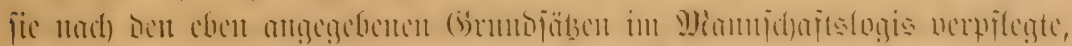

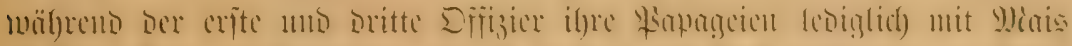

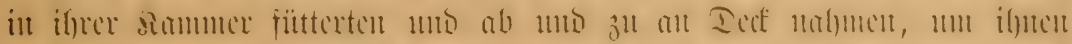

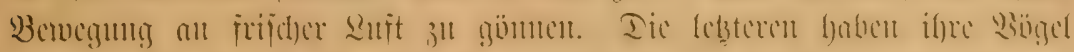

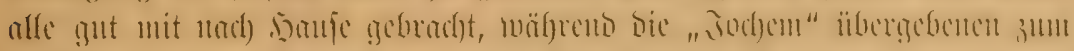

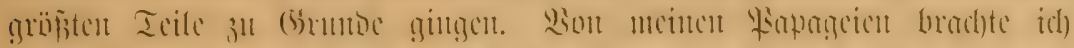

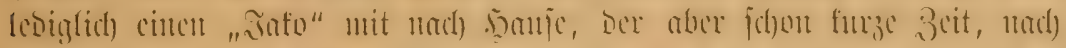

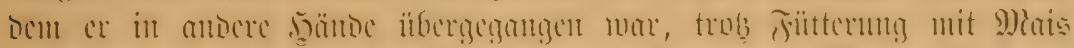

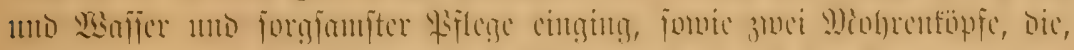

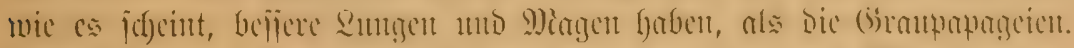

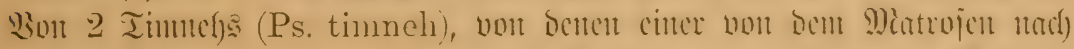

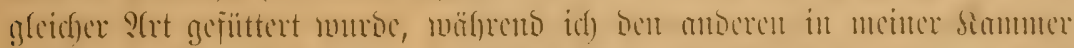

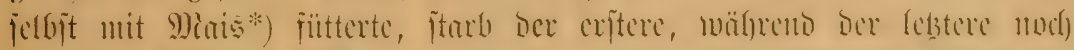

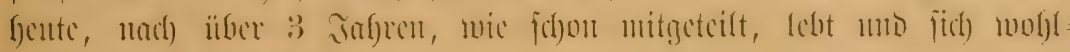
befintoet:

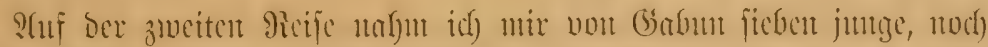

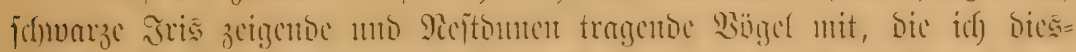

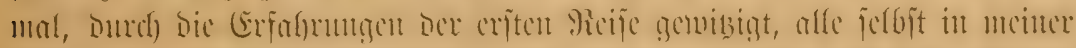

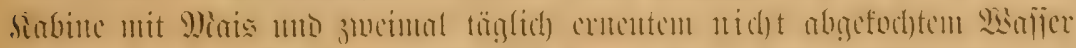

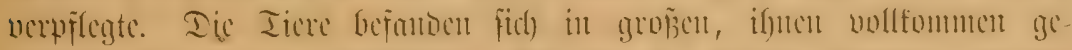

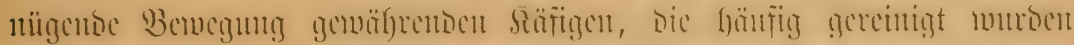

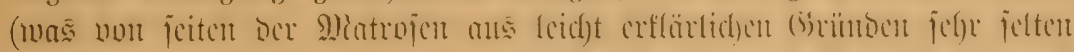

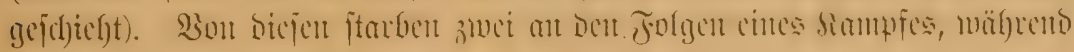

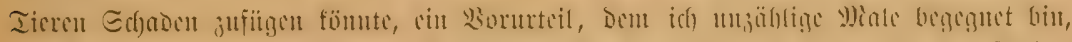

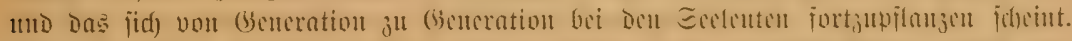

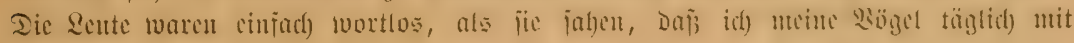
ほ̊ajer verjorgte.

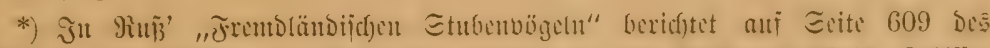

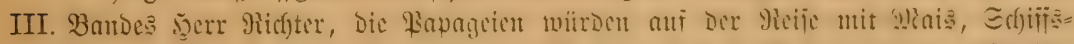

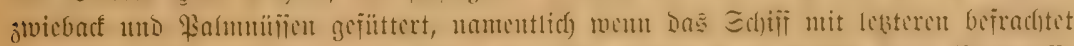

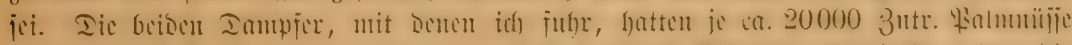

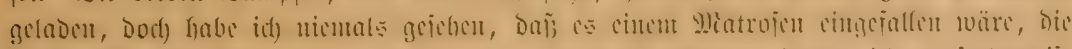

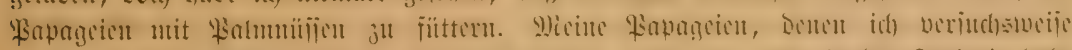

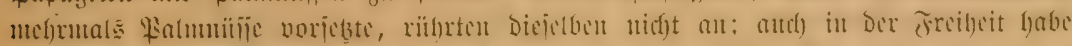

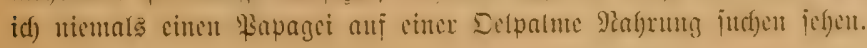




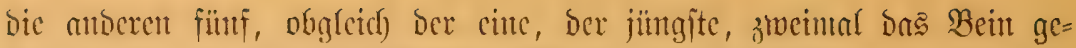

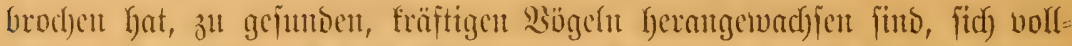

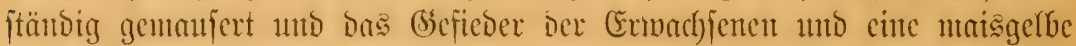

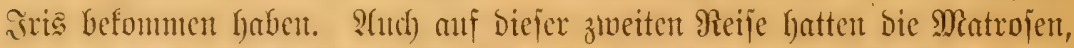

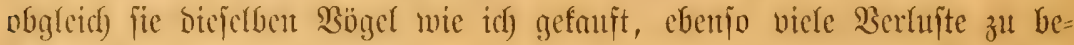
flagen, wie auf ber criften, ba fie bei Dem arthergebractent Berfalyren fteben gebficben waren, won ben fie wohl überhaut nicht abzubringen fein werben, ba fie berartige Dinge "viel bejfer verjteljen", wälrent bic= jentgen unjerer Bajiagiere, welche gleich mix bie Bögel Kebiglich mit Maris

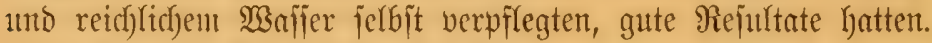

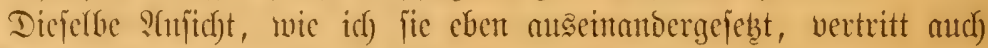
ber fdjon melyrfach erwälynte î. Mann. Er fabreibt:

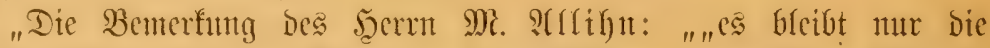

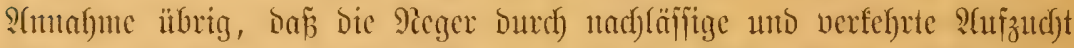
Der juntgen Tiere ben Iodesfein in fie finemlegen*)," entbef)rt Der

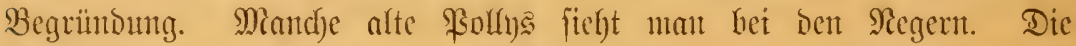

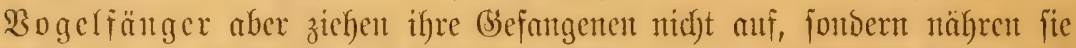
mux, bis fie foldye an ein Exbiff verfaufen, was gewöhnlidy fdyon nad)

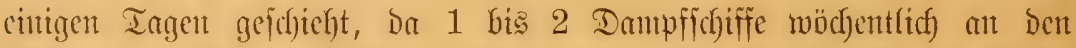

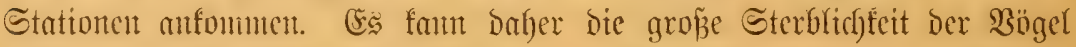

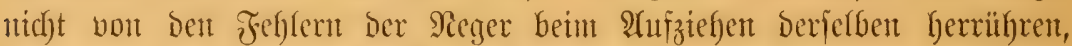

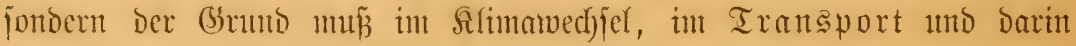

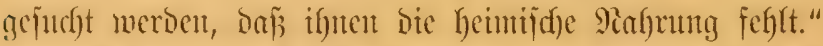

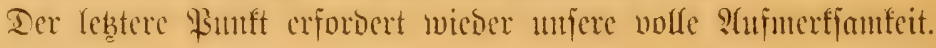

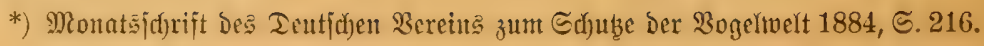


Inl Der fremold. - w 



\section{Z11 ic fort man ben Grampapagei fïttern?}

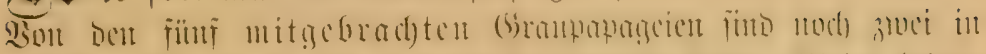

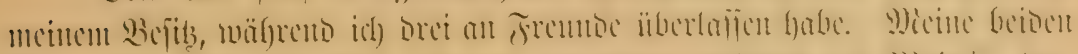

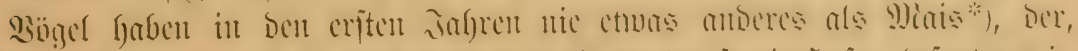

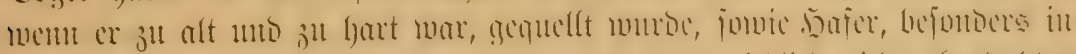

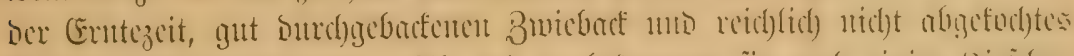

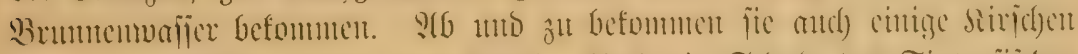

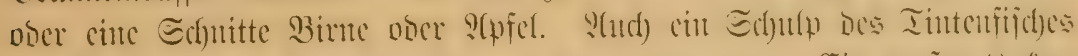

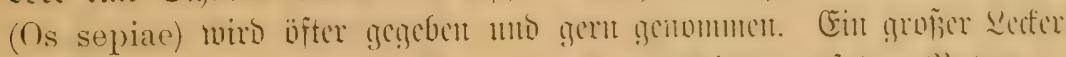

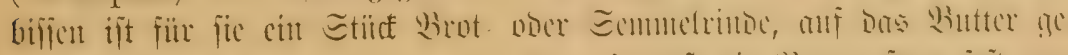

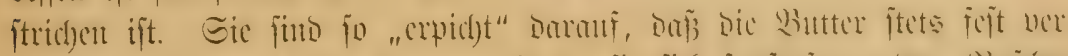

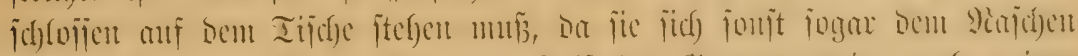

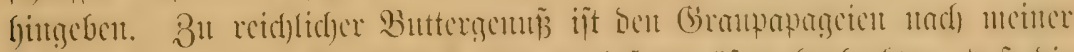

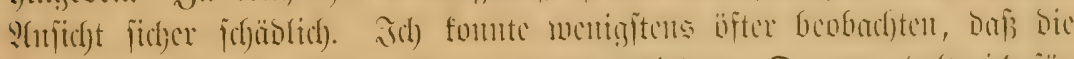

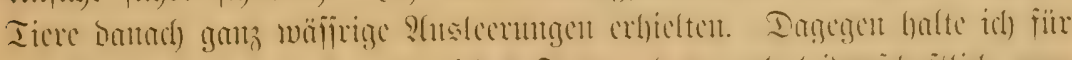

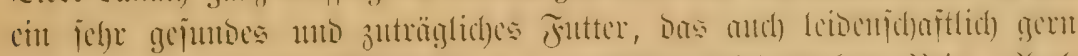

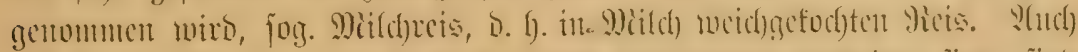

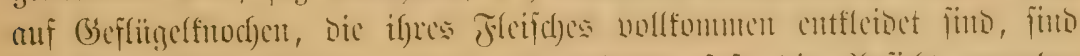

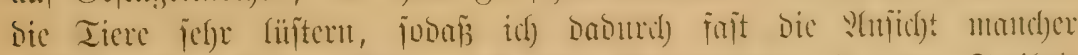

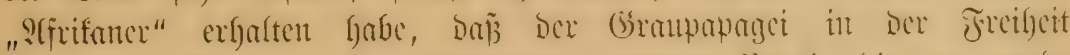

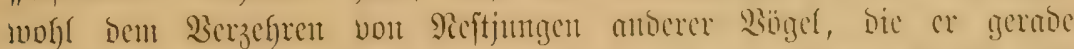

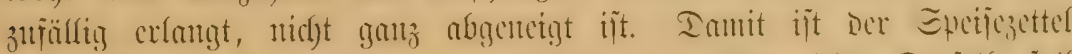

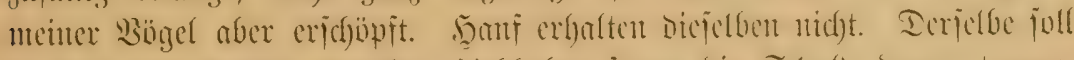

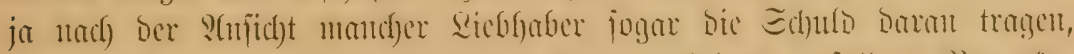

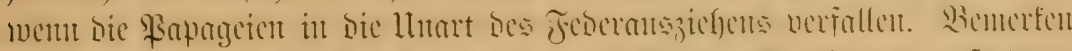

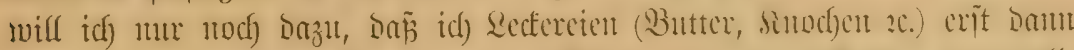

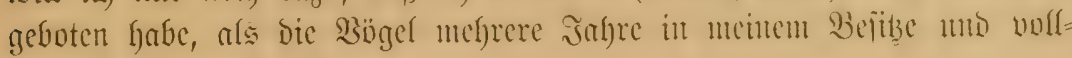
itönbig afffimatifiert waren.

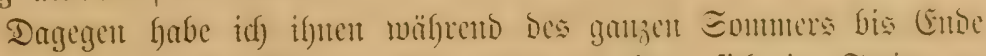

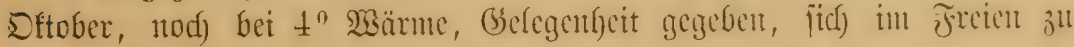

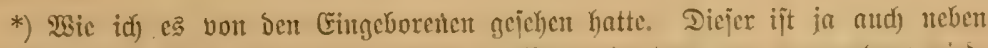

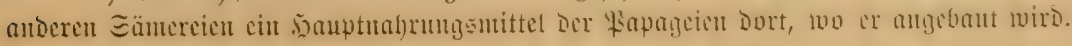




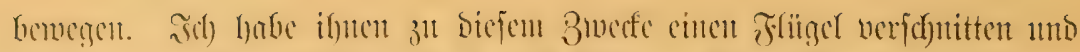

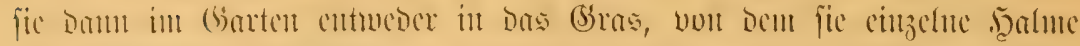

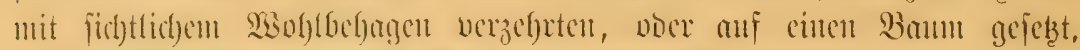

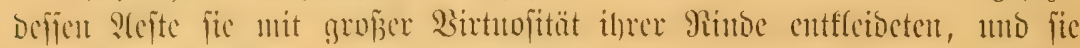

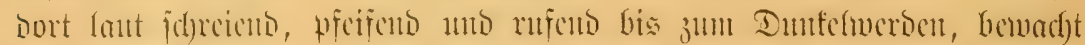

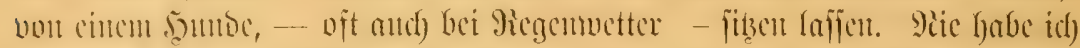

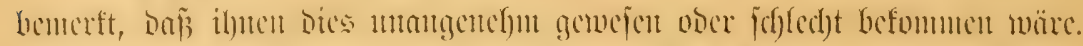

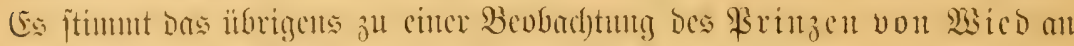

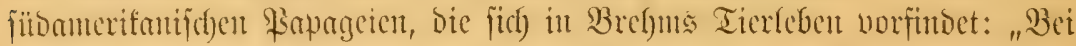

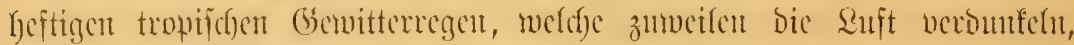

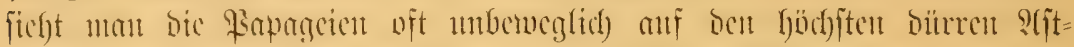

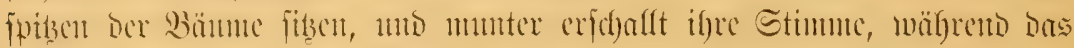

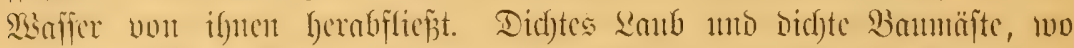

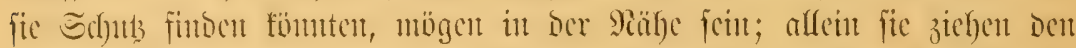

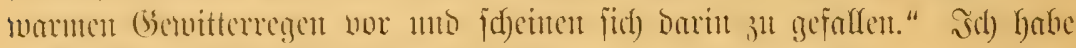

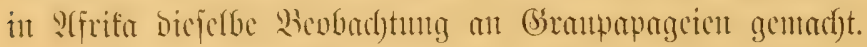

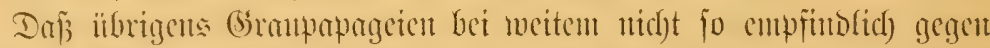

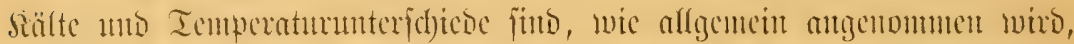

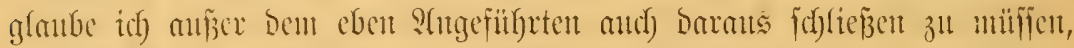

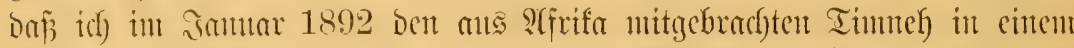

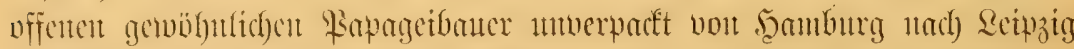

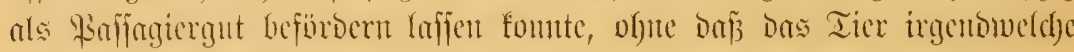
2(uzeidben won llutwohlfein z̆t erfentent gab.

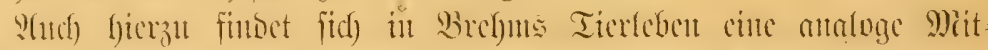

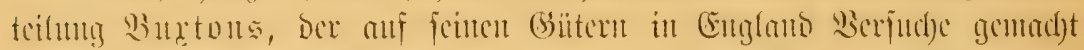

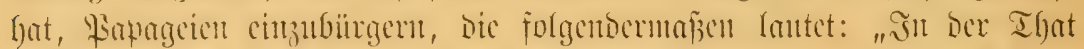

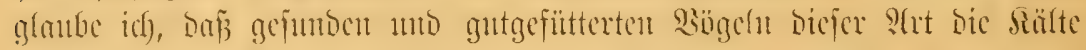

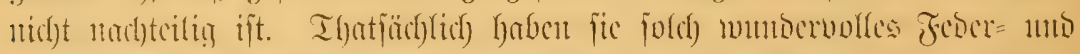

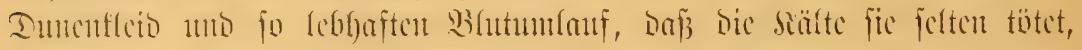

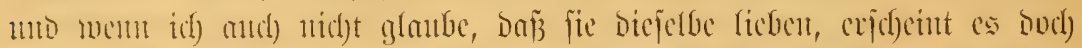

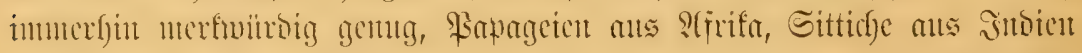

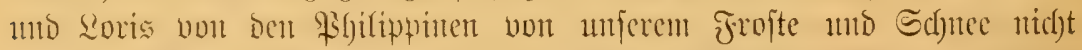

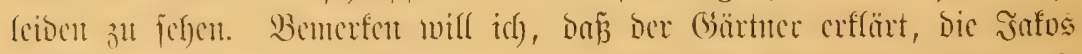

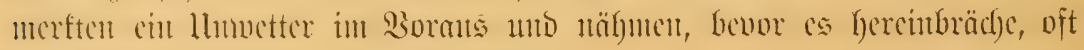

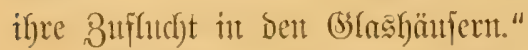

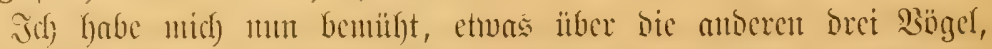

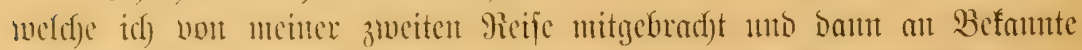

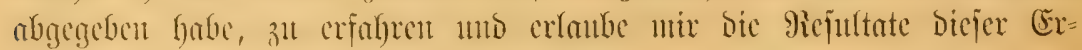
funtigutgen in nachjtehenden mitzuteilen: 


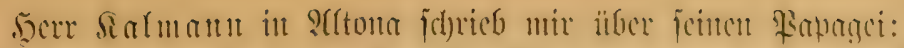

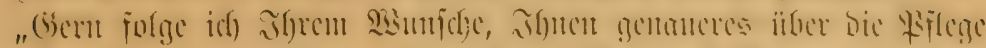

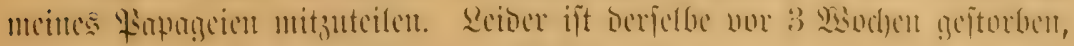

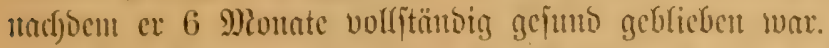

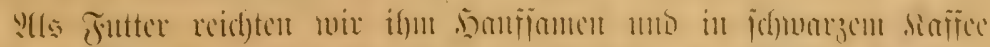

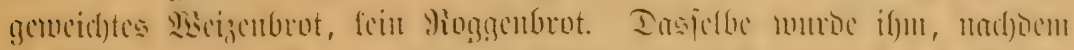

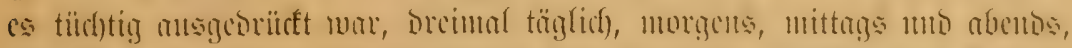

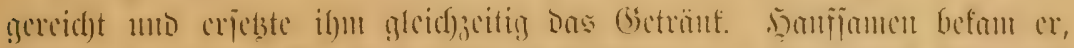

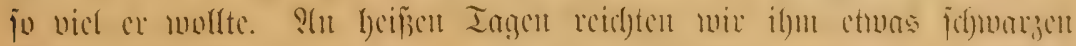

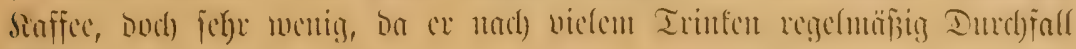
beffall.

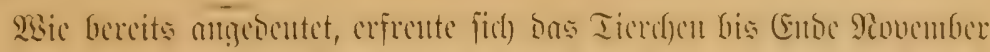

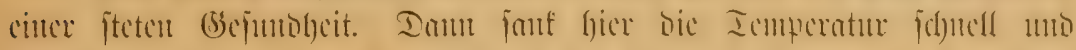

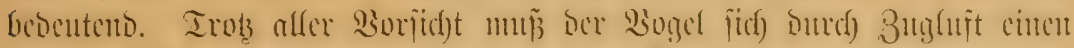

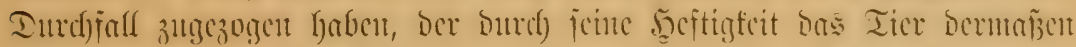

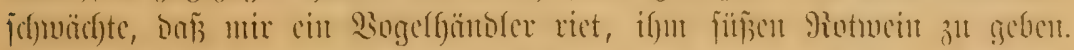

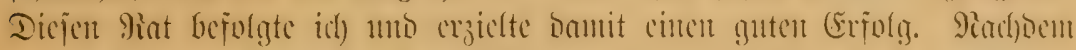

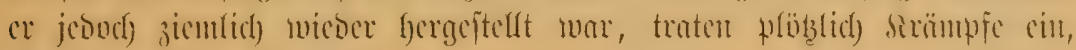
benen bกร Tier erlegen ift.

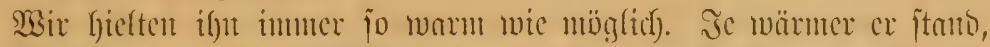

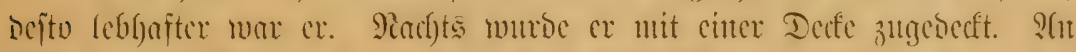

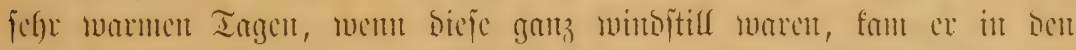

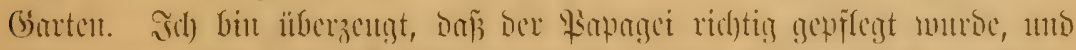

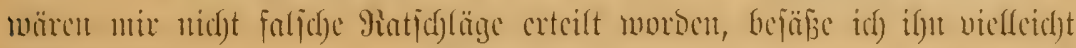
nod) heute."

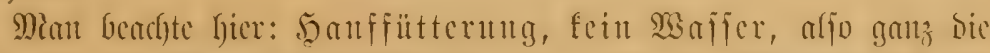

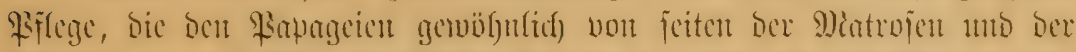

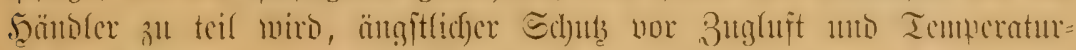

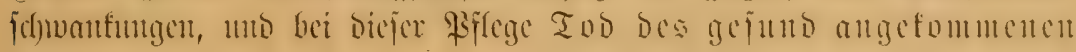
Bogel:

Secr 2ubolot in Cuba bei Gera beridgtete:

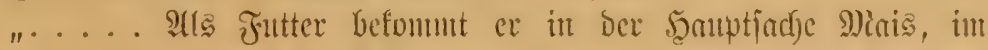

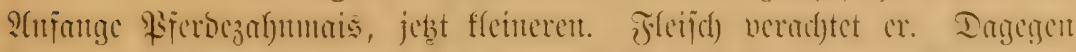

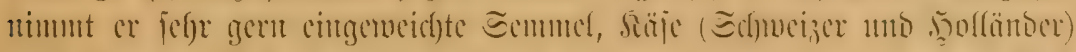

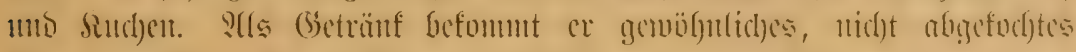

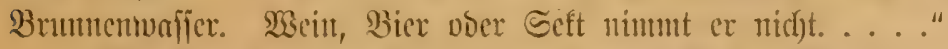

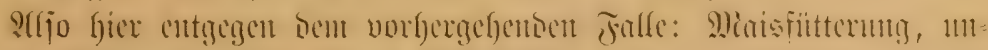

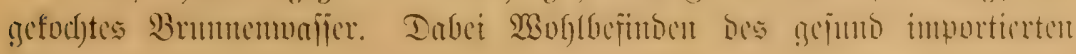
Papageiett. 


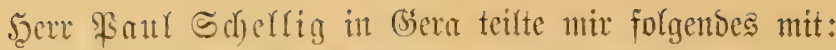

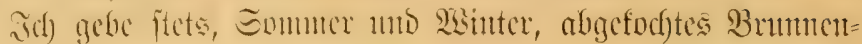

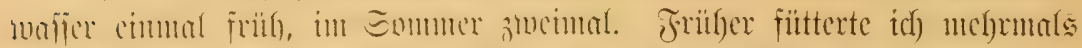

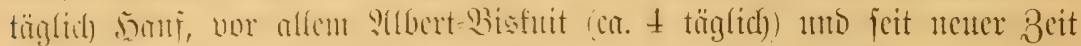

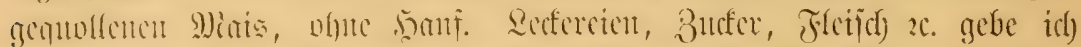

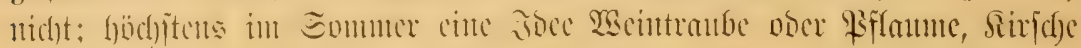

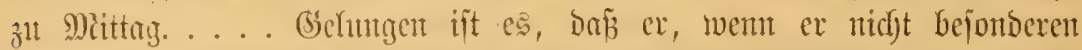

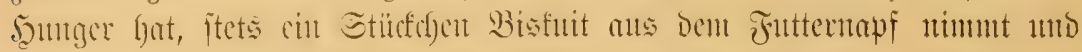

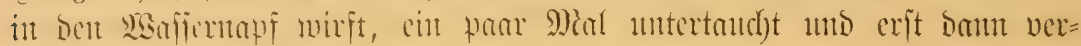
incti)nt.

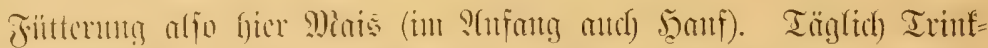

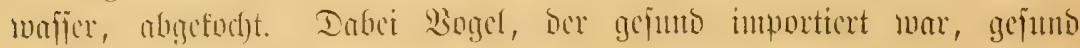
geblicben.

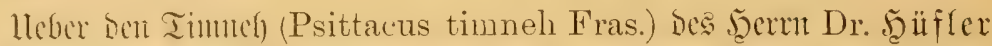

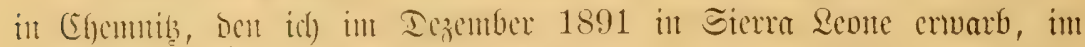

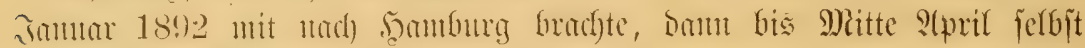

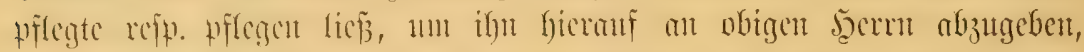

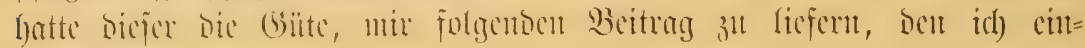
fiditite:

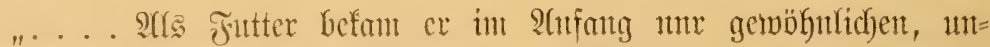

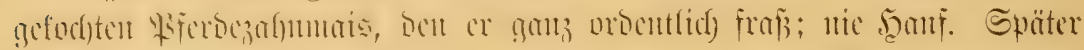

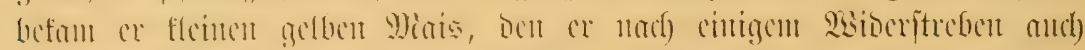

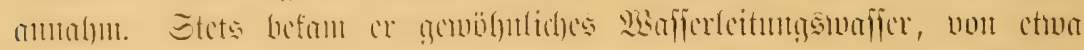

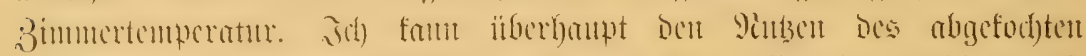

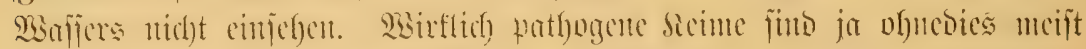

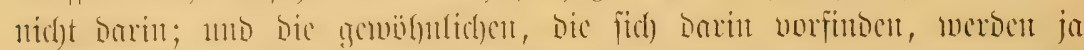

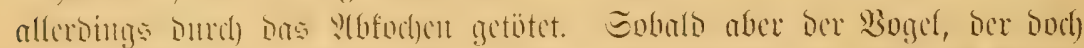

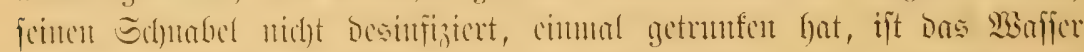

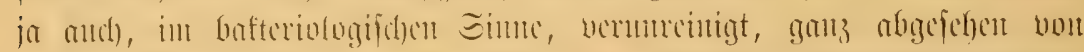

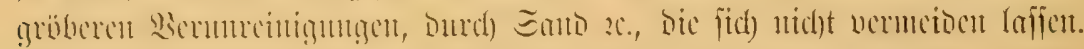

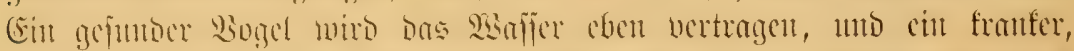

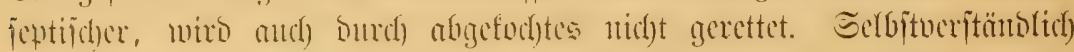

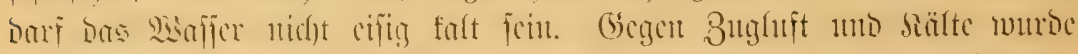

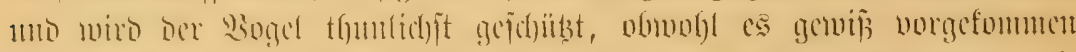

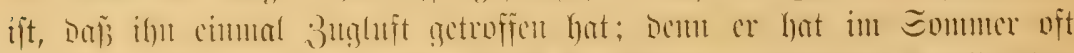

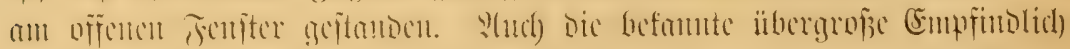

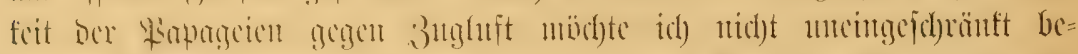

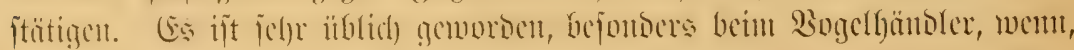

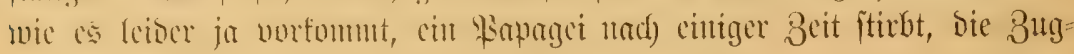




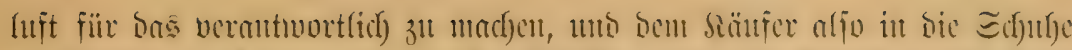

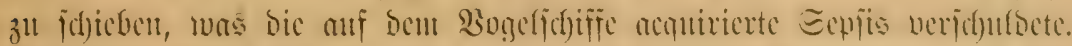

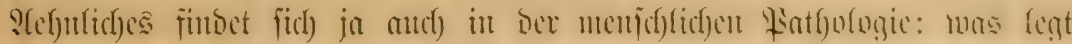

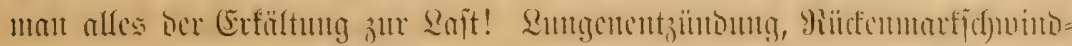
jucht, Diphtheritis, Sicudbluteu $2 c$.

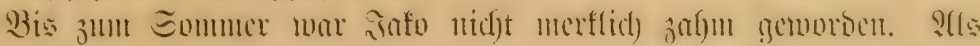

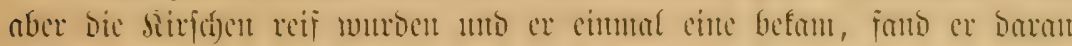

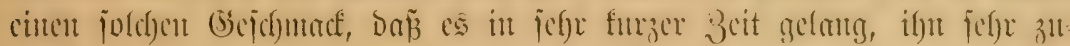

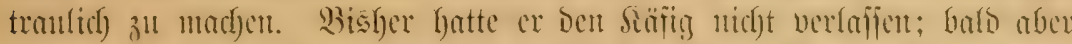

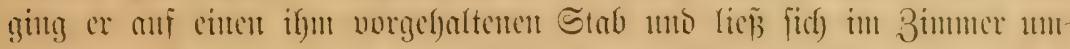

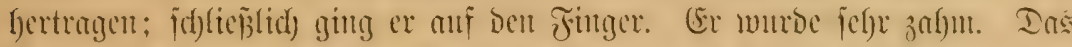

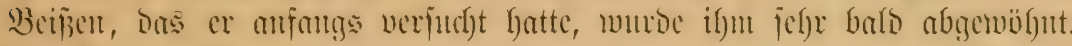

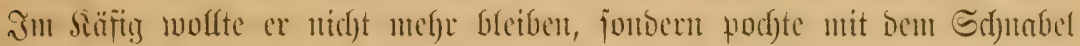

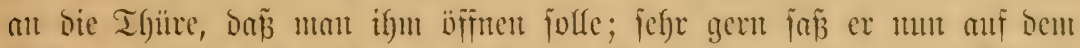

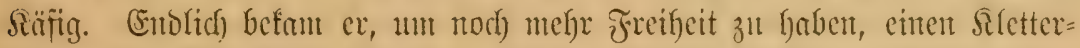

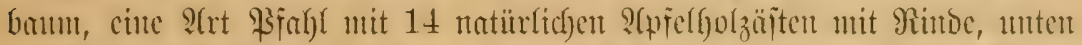

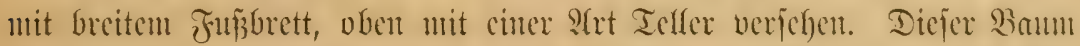

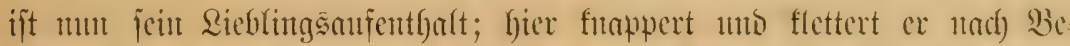

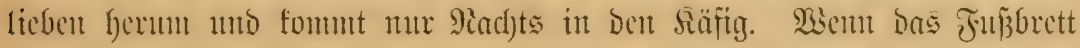

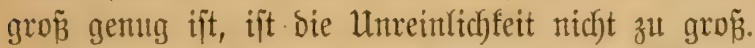

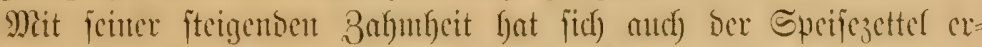

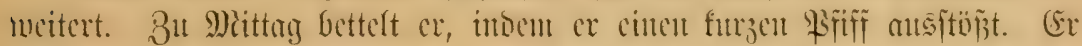

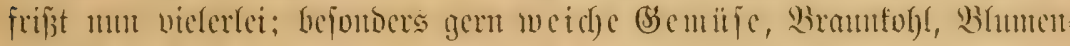

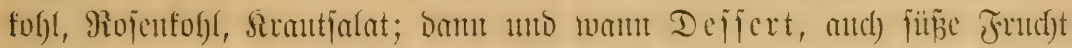

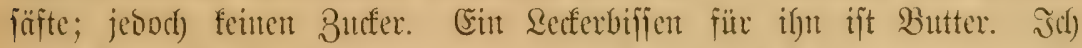

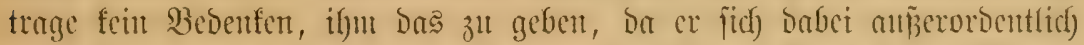

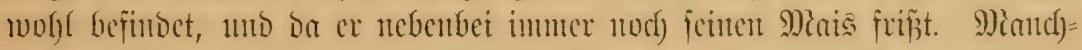
mal erfä̈t ex aud) cine Eepiaj(buppe, bie er in furger Beit bertilgt."

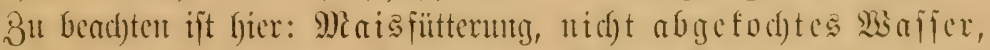
zwar ïbertriebeu ängitlid), gejund angefommener $30 g e l$, der bei biefer Pflege and) gejund brieb.

Bon ben auf ber Reije von uir felbjt mit Mais und

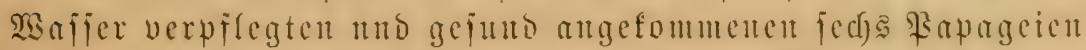

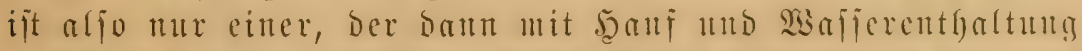
gepflegt murbe, geftorben, währent bic anderen, in der wou

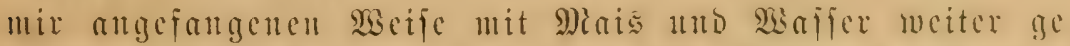

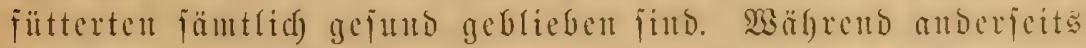

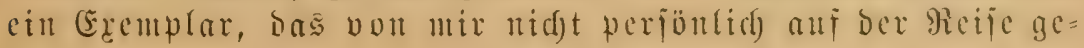


pflegt, fontorn nad) "Matrofenart" gefüttert wurbe, fpäter

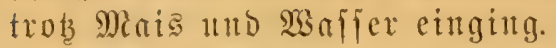

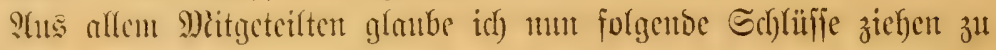
miiijen:

1. Der (strupapage berfangt anf ber Seereife eine gute \$fflege,

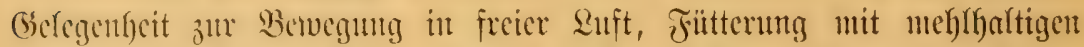

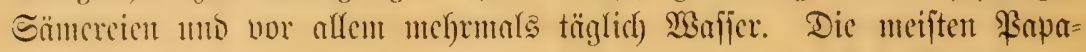
geien gethen cin iujolge ungeeigneter Behantofuntg muj ber Reije.

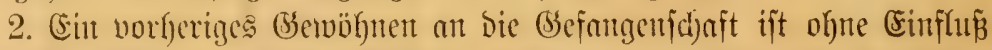

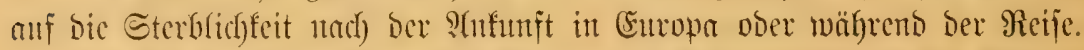

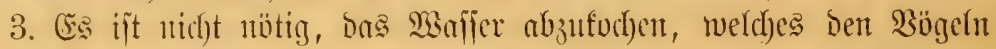

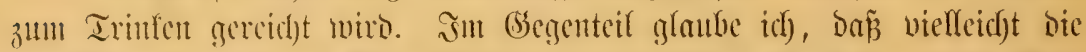

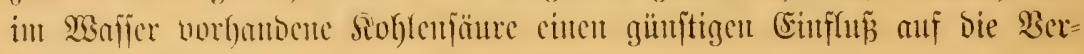
Dontutg atsiürt.

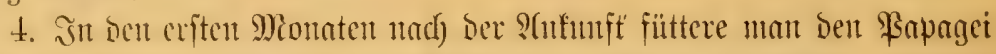

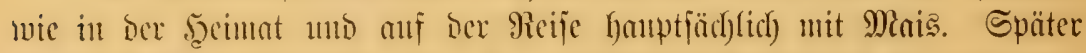

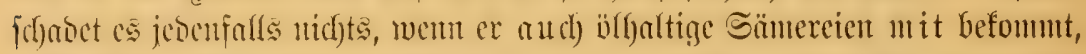

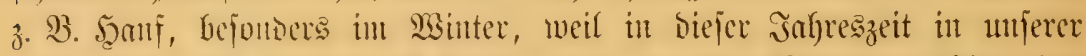

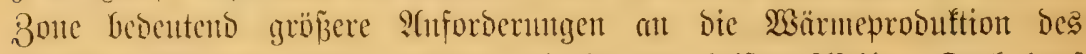

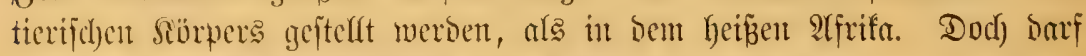

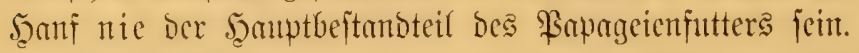

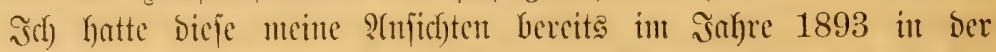

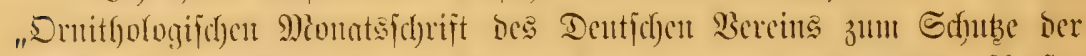

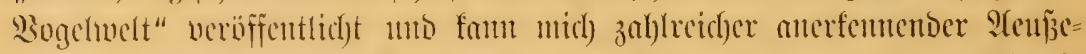

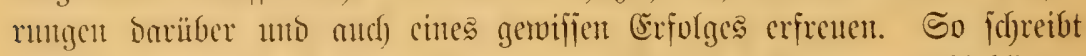

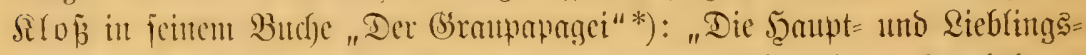

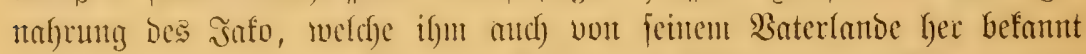

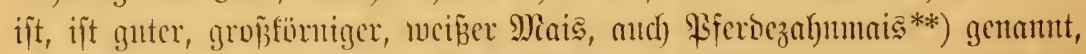

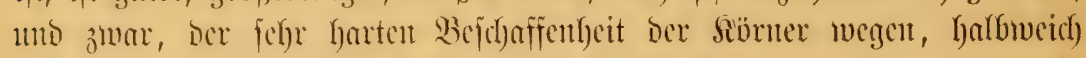

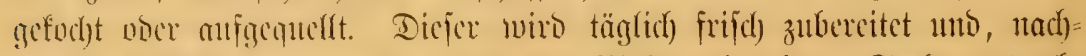

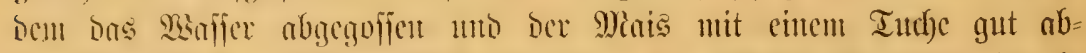

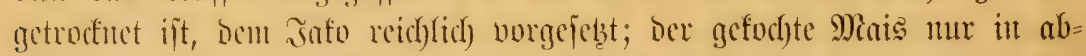

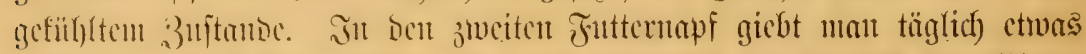

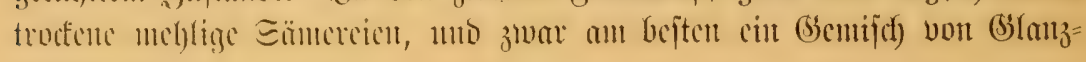

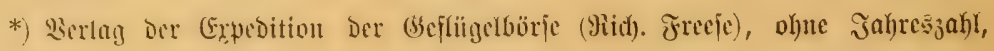
Seite 37.

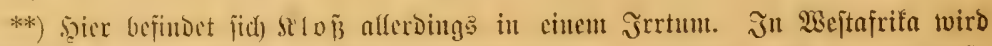

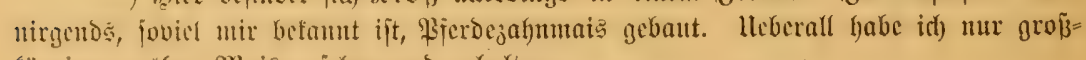
förtigen gelben Miais gejełhen und errjalten. 


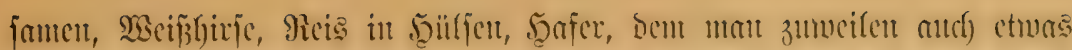

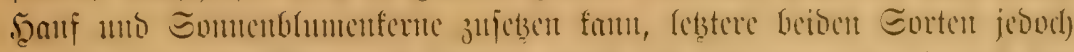

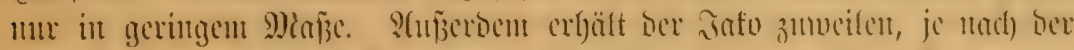

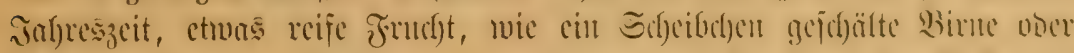

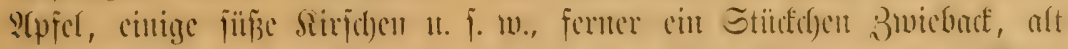

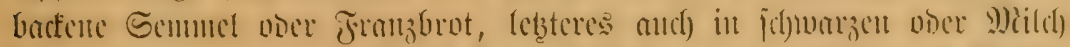

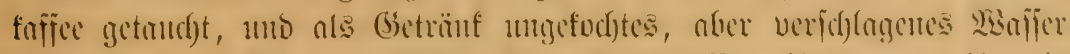

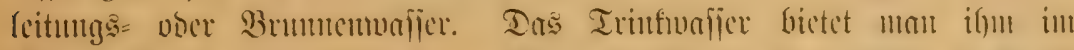

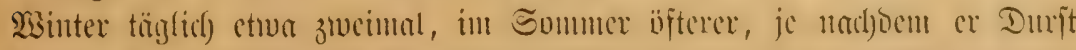

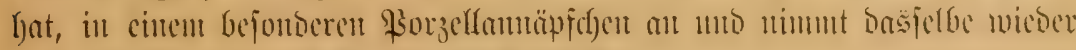
fort, fobald er feincu Durit geftillt loat.*)

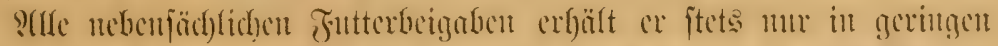
Baben; man bicte ifme licber bifter cimmal ctmos bawon an, als ifnu mit

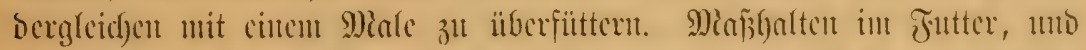

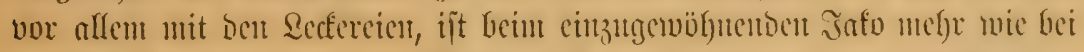

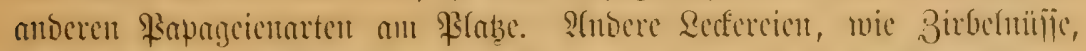

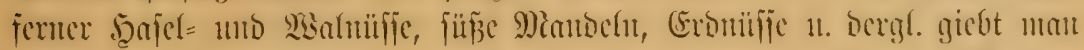

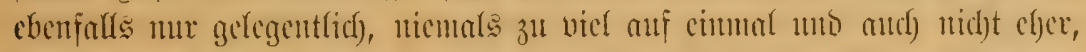
bevor man fid) vou ber untubelfaften Bejd)affenteit bexfelbent überzeugt

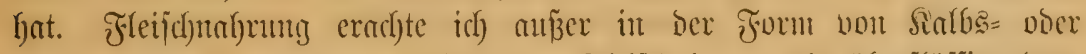

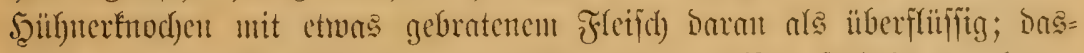

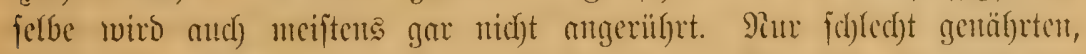

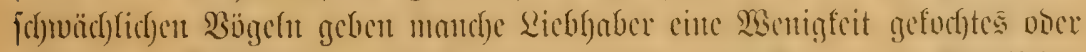

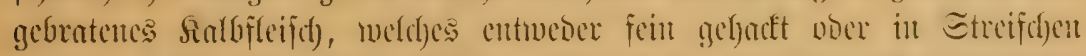

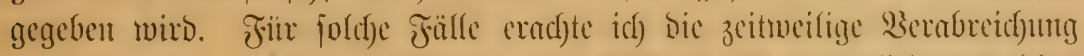

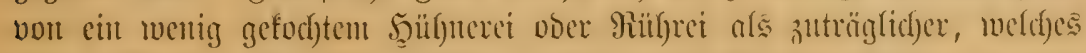

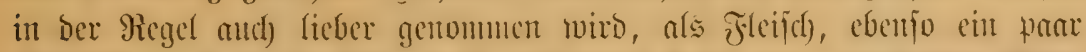

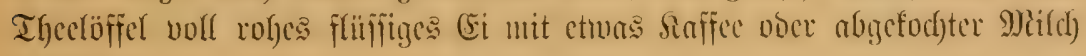
vermifd)t.

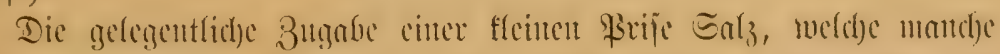

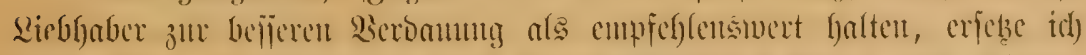

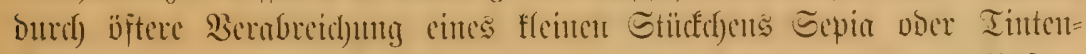

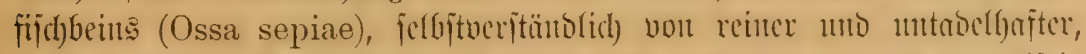

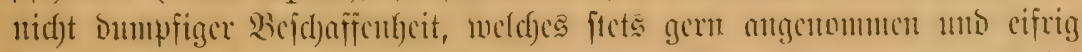

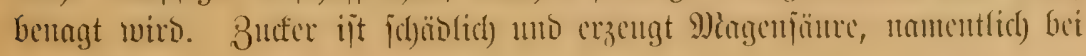

*) Mecine Papageicu haben Irinfwaffer ben ganzou Tan iiber in reteftictler

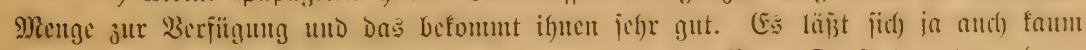

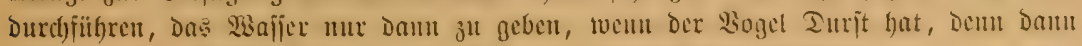
müpte ja eine \$erion fets auf ben Bogel ganz bejonders aufpalien. 


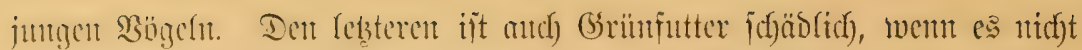

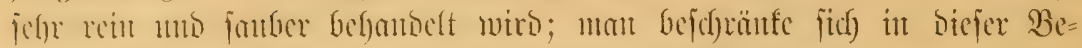

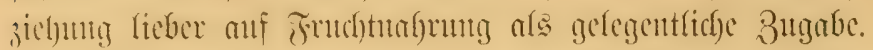

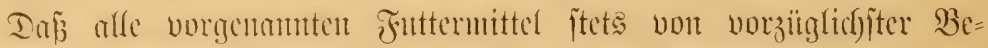

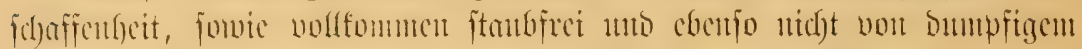

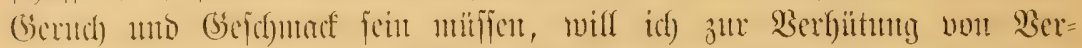

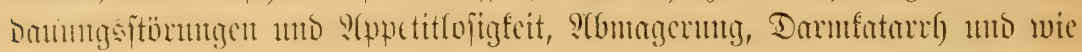

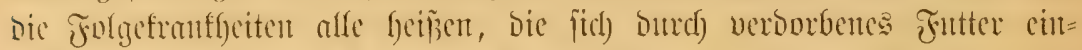
ftellen, nod)uats gatz bejonbers gerworzulfeben micht unterfafien."

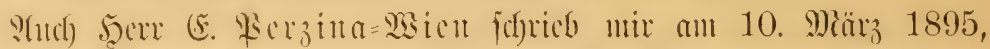

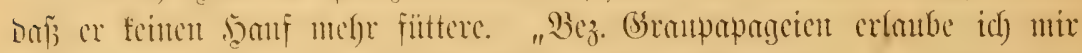

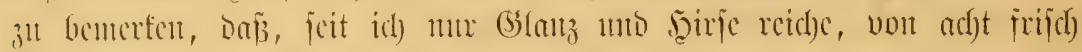

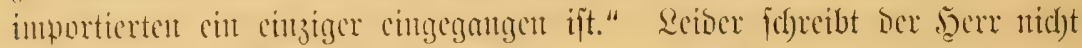

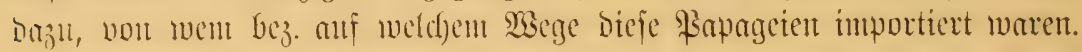

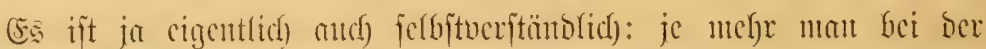

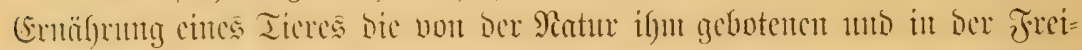

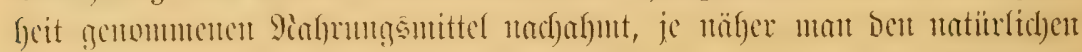

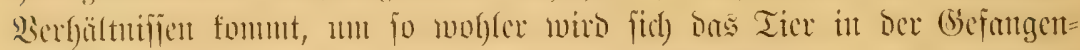

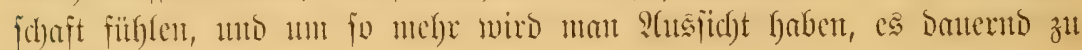
erfaltent.

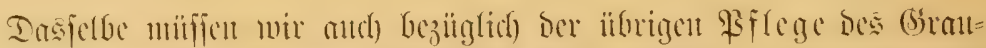

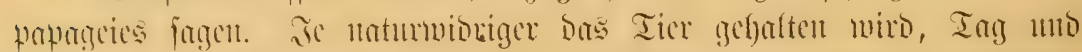

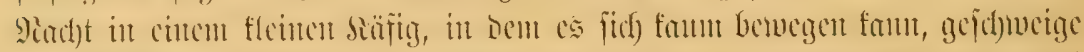

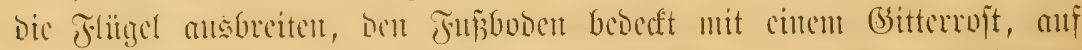

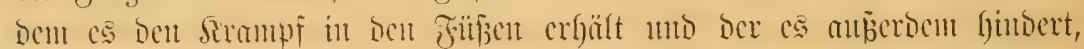

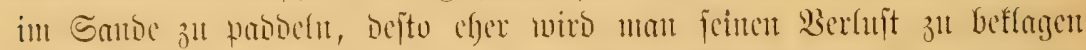

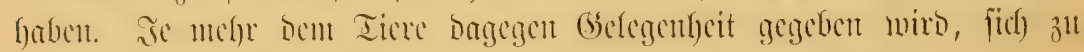
benegen, defto fräftiger nuto gejutber wird es ficl) entwidelu.

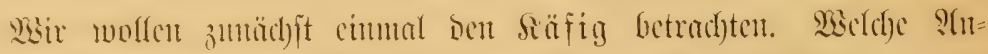

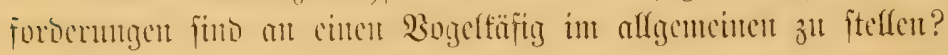

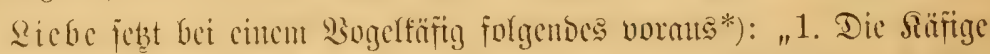

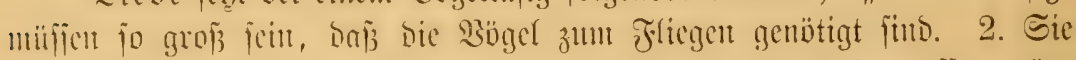

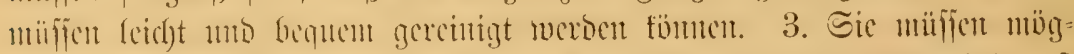

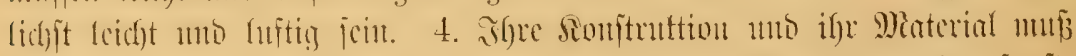

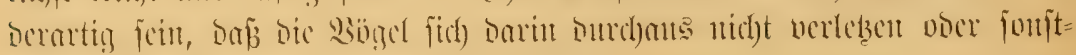
wic zufüllig fchäbigen fümucu."

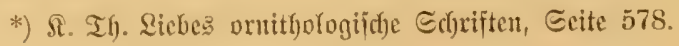




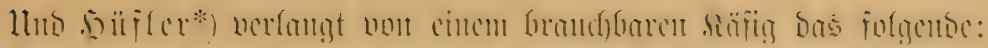

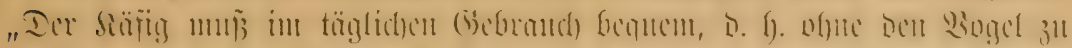

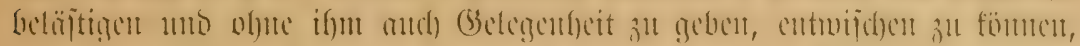

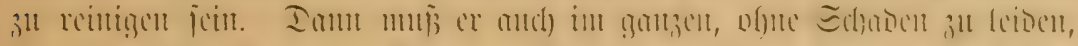

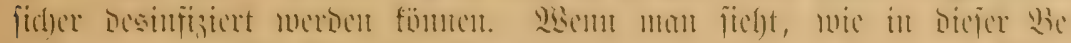

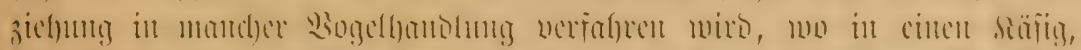

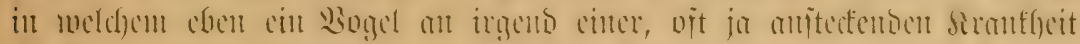

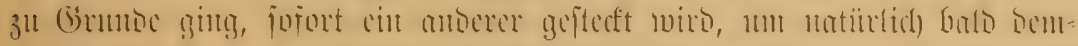

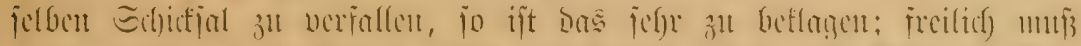

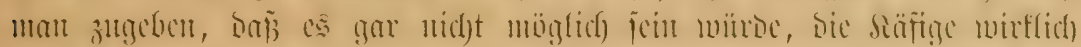

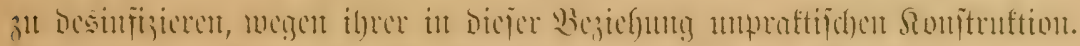

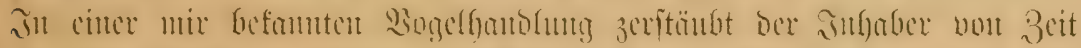

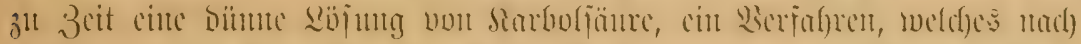

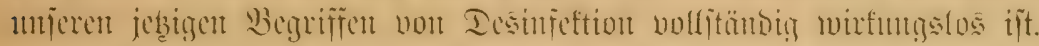

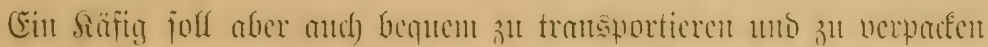

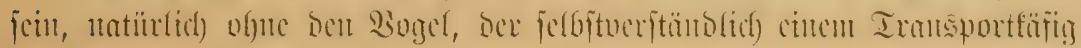
anvertrant weroelt แแนई

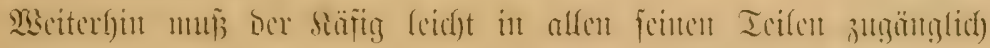

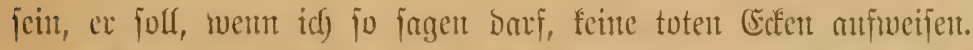

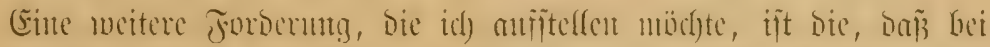

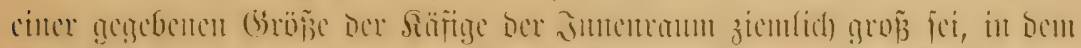

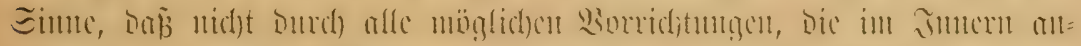

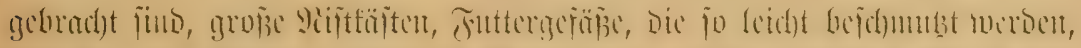

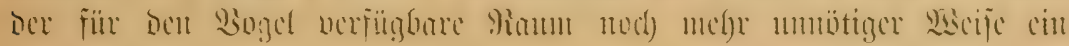
geengt ivitr.

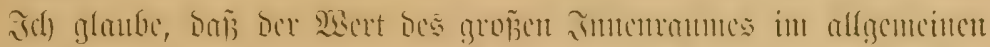

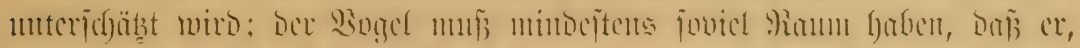

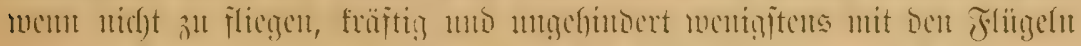

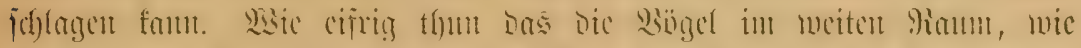

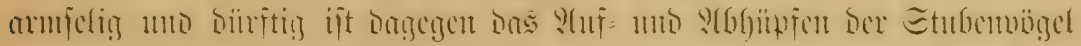

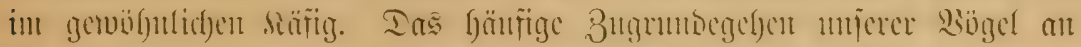

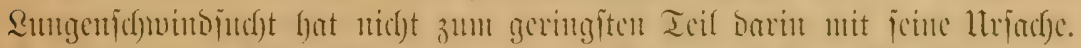

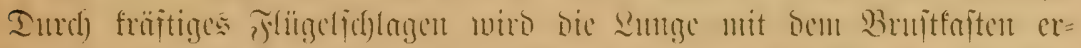

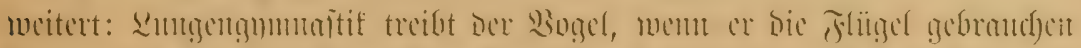

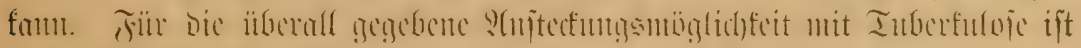

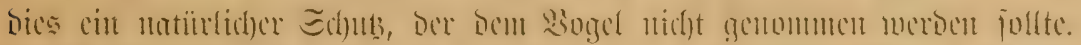

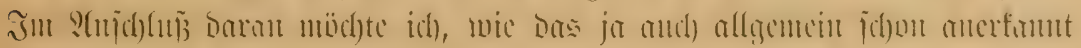

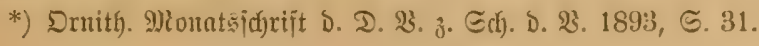




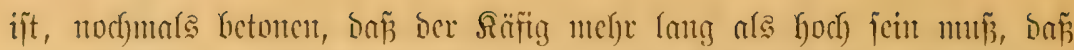

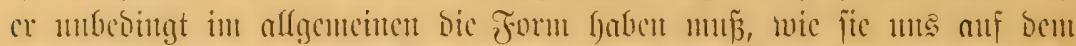

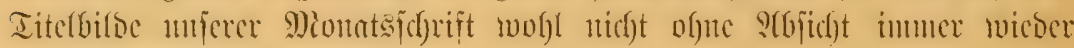
vorgefiilyet witro.

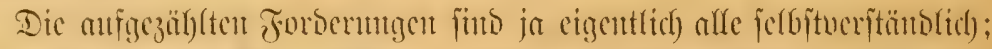

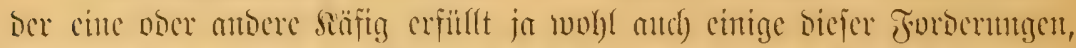

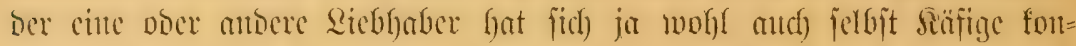

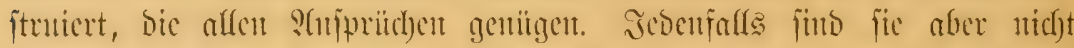

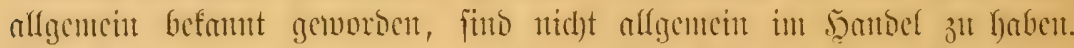

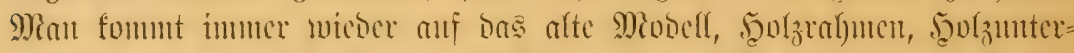

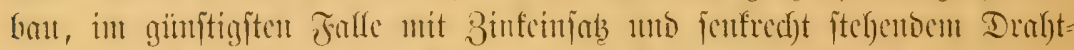

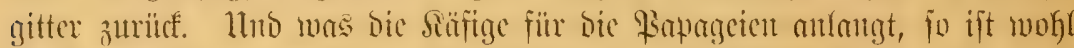

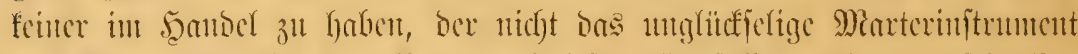

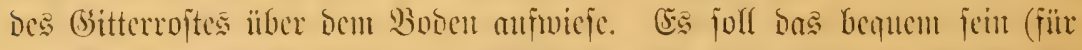

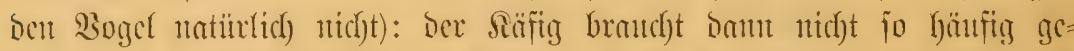

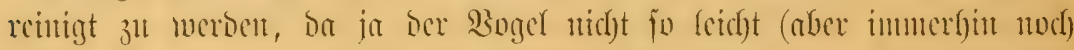

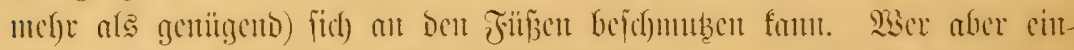

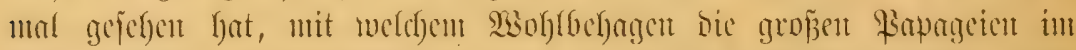

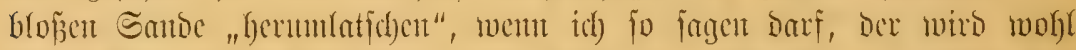

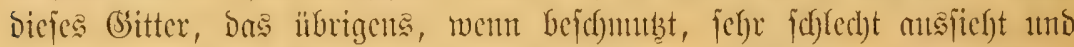

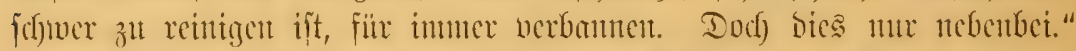

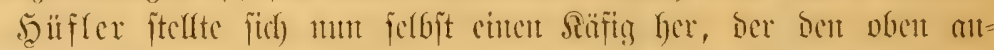

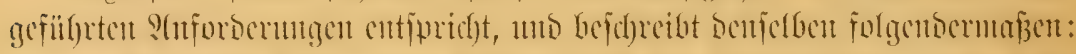

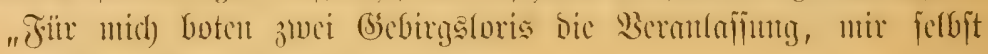
einen paffentoen Säfig. zu fonftrtierent.

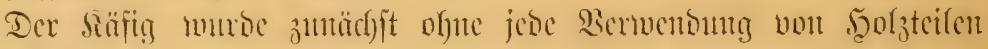

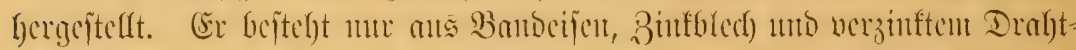

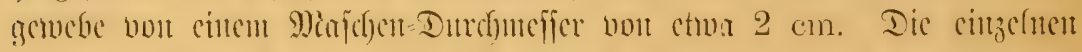

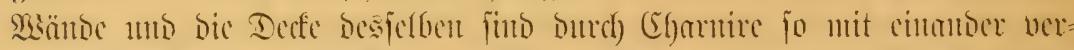

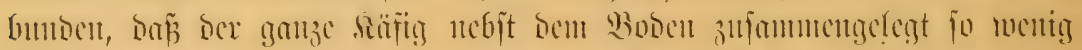

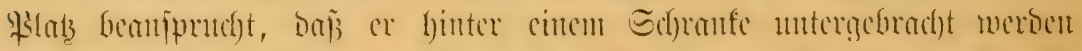

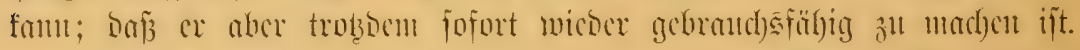
Mecint Säfing ijt ctwa $90 \mathrm{~cm}$ - 1 antg, $65 \mathrm{~cm}$ hod), $50 \mathrm{~cm}$ tief;

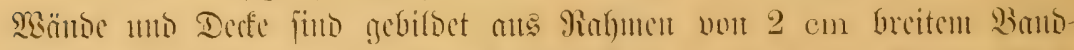

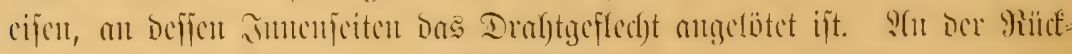

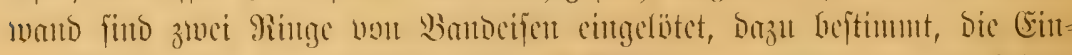

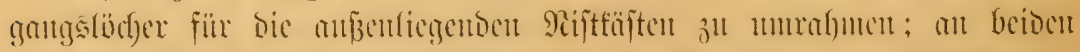

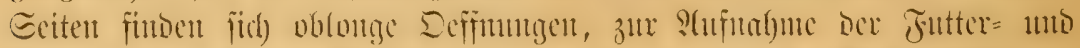

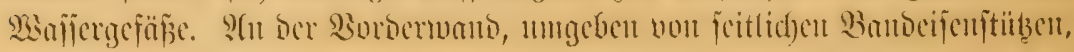




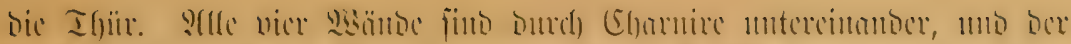

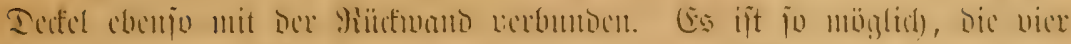

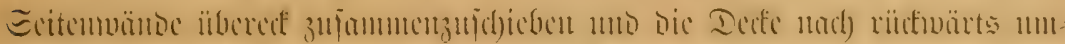

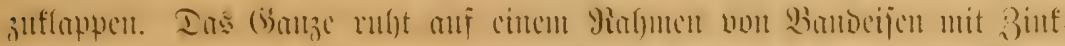

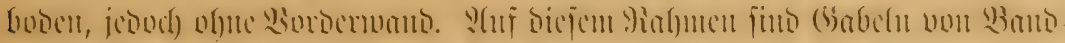

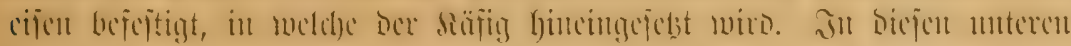

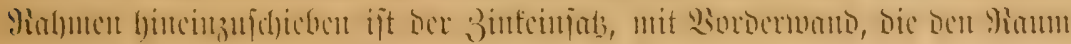
3)

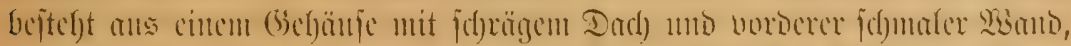

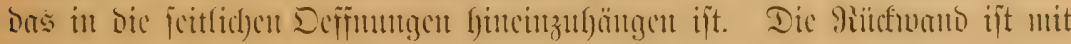

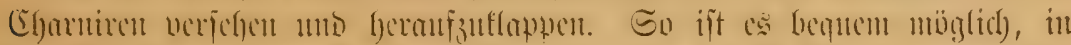

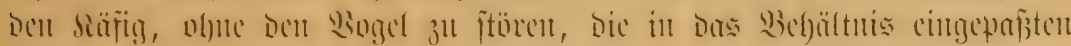

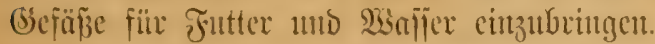

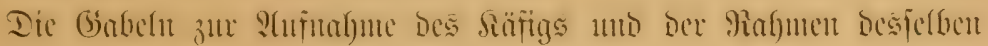

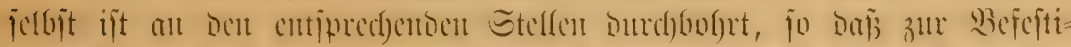

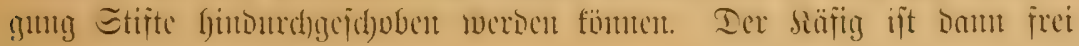
3̆t trantsportierett.

Beifolgende ?lbbiloung wird alle biefe Berfä̈ltuifije crläntern.

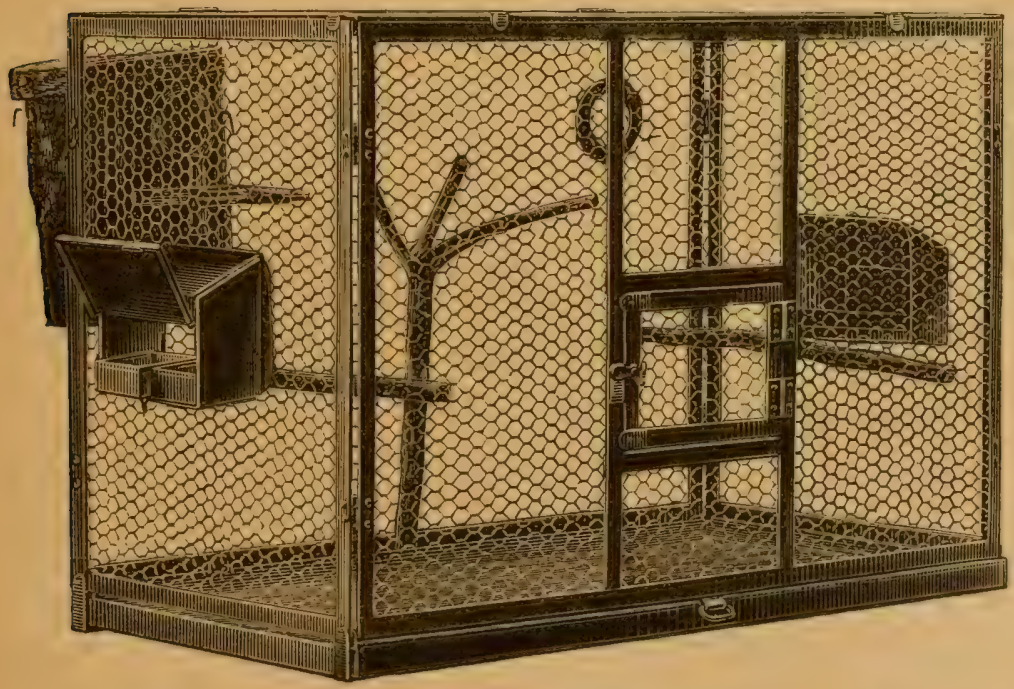

Dieier Säfig entjuridgt volffonment bon oben geftellten Bebingungen,

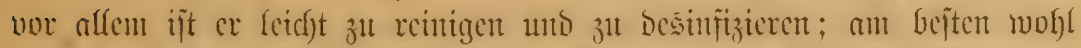

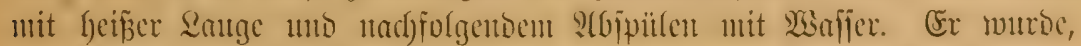

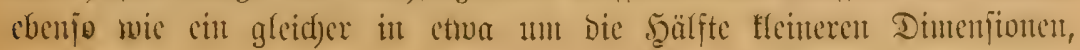




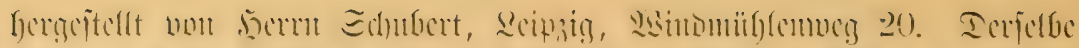

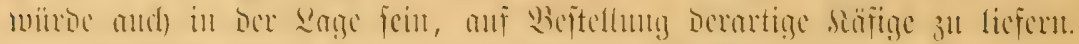

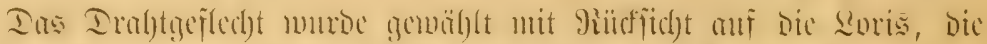

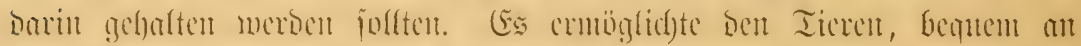

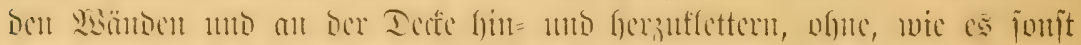

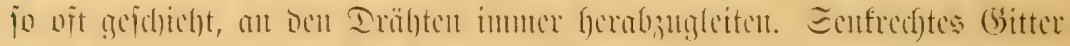

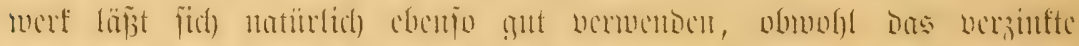

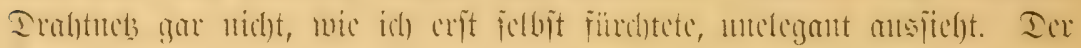

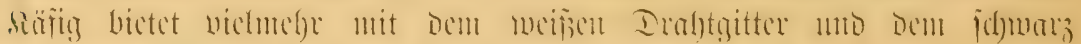

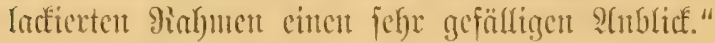

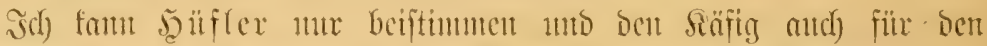

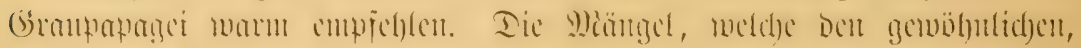

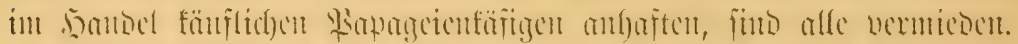

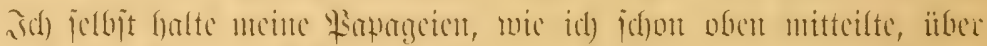

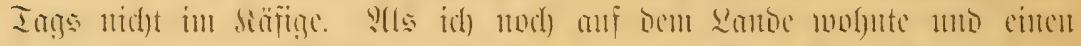

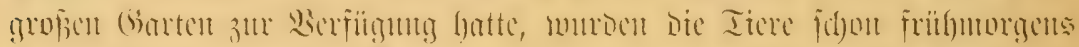

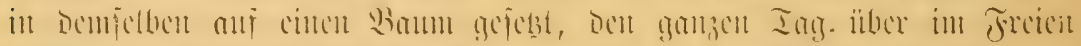

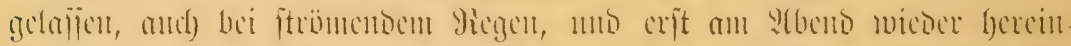

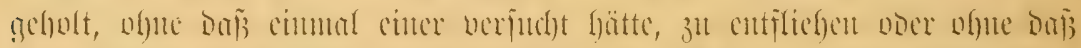

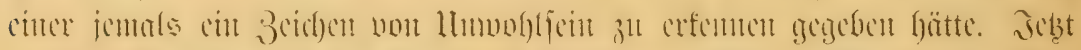

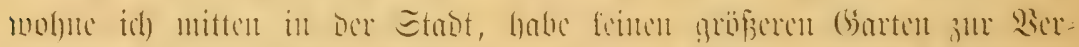

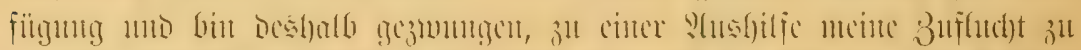

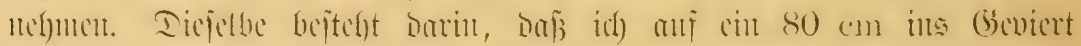

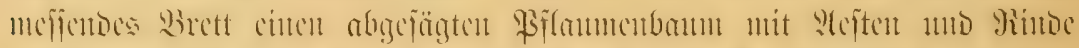

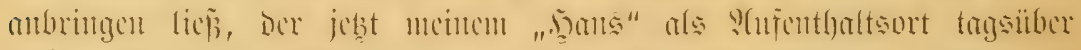

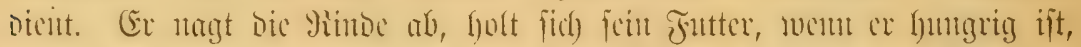

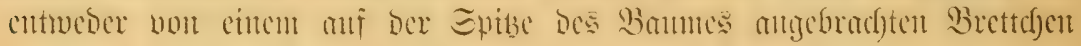

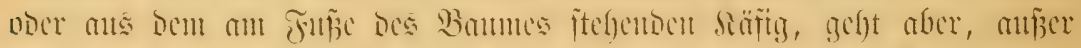

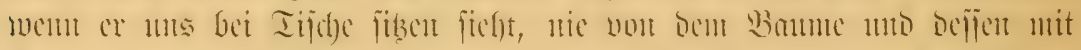

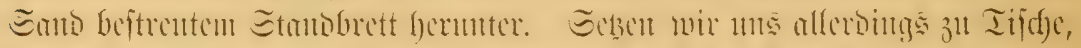

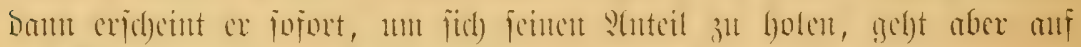

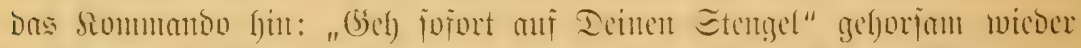

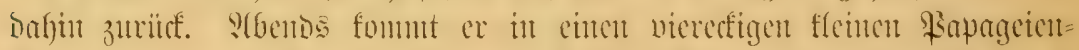

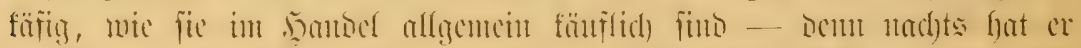

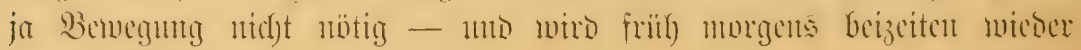
ferantagelafien.

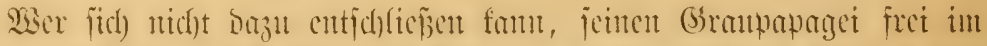

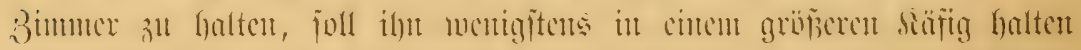

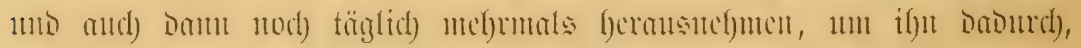




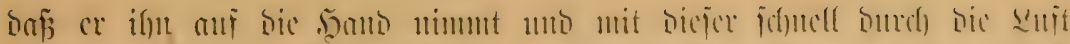

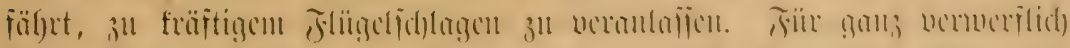

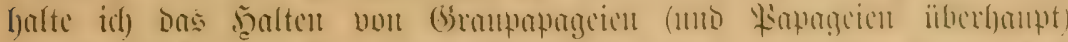

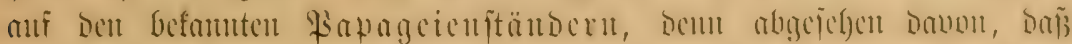

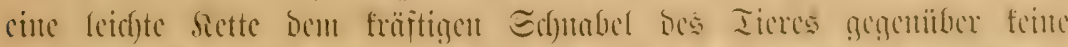

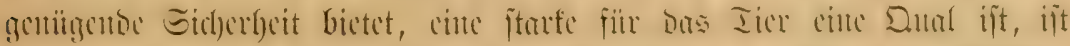

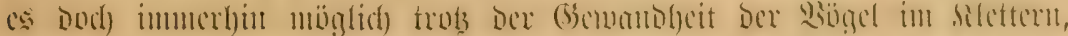

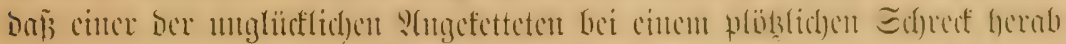

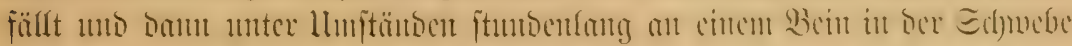

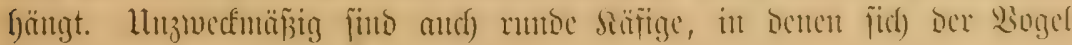
fatm jemata woble fïlylent wiro.

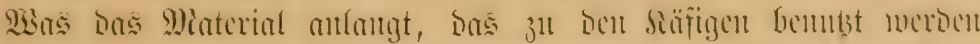

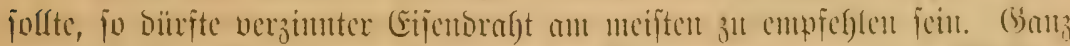

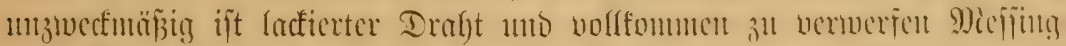

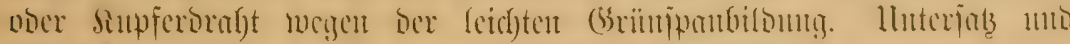

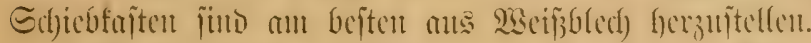

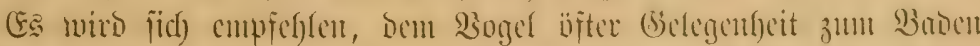

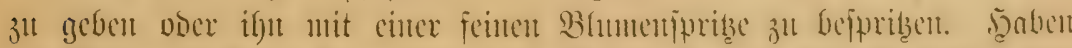

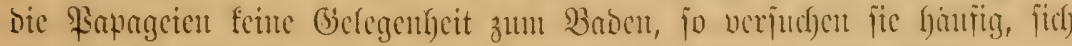

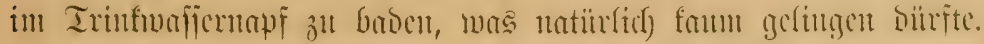

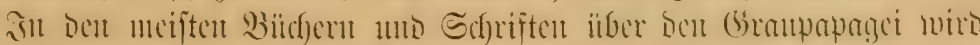

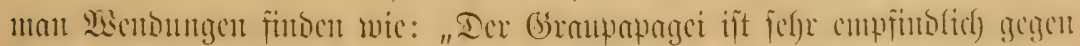

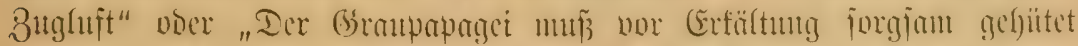

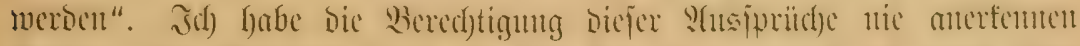

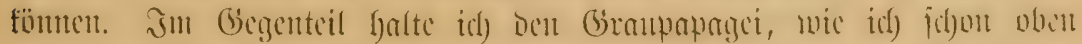

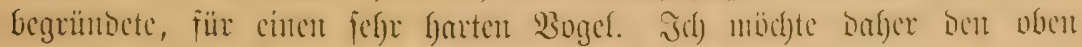
angeführten brei Säßsen nod) bie folgenten ljinzufügen:

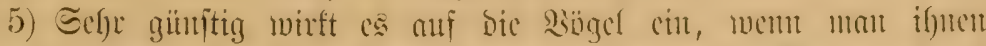

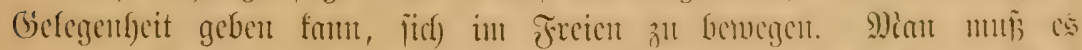

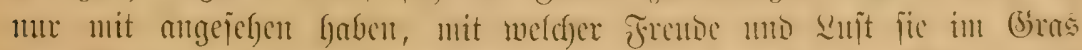

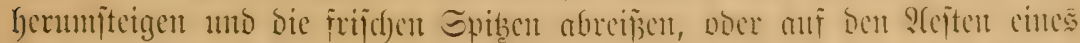

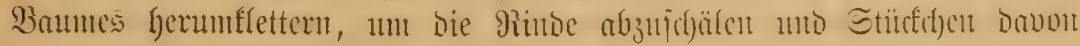

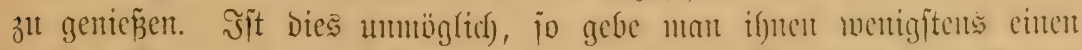

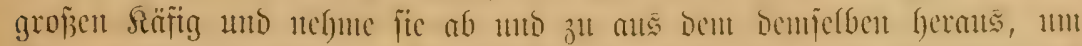

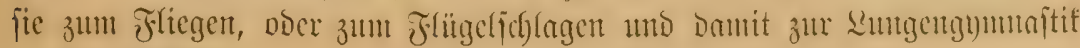
zu veranlafien.

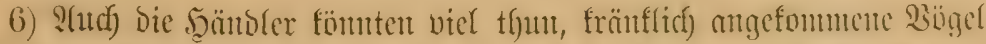

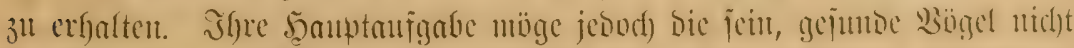

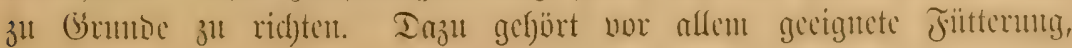




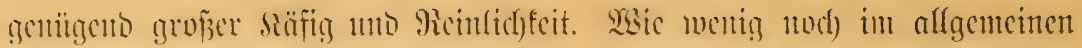

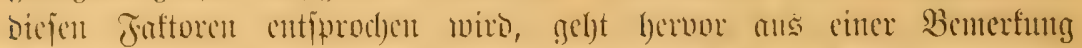

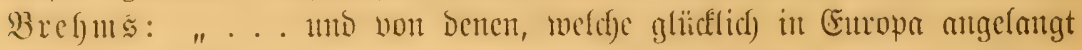

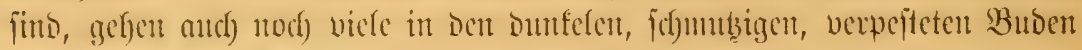

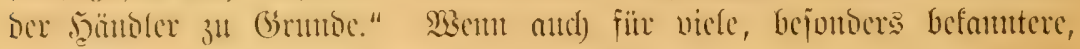

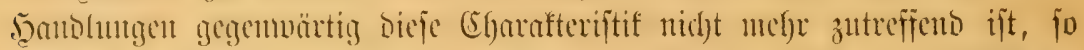

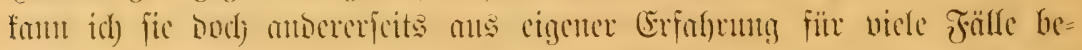

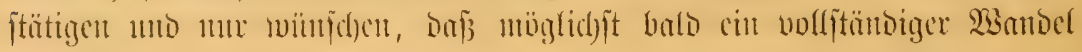
cintritt.

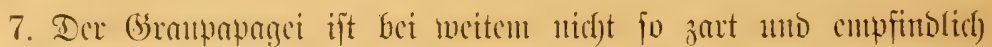
gegent sie 3ugluft, Temperatumbedfol, nicosere Temperatur u. f. w. wie

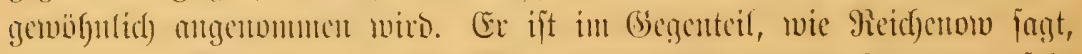

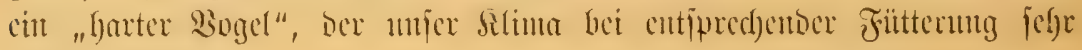
gut verträgt. 


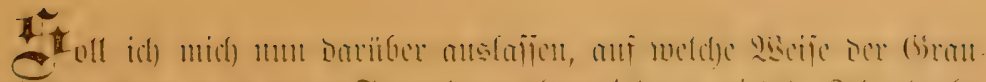

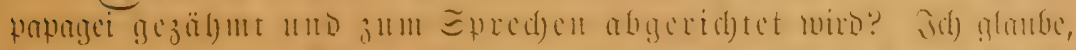

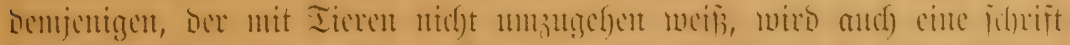

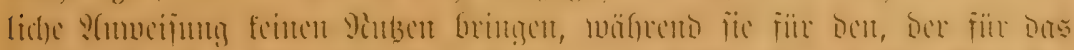

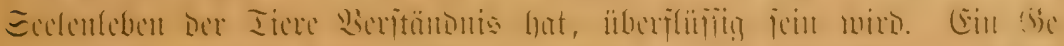

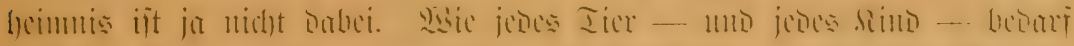

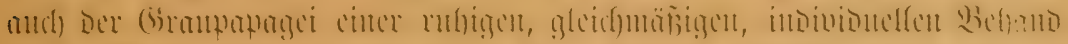

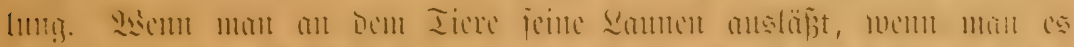

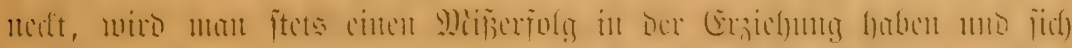

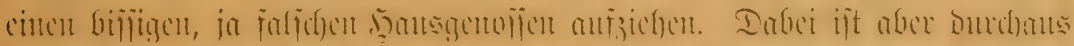

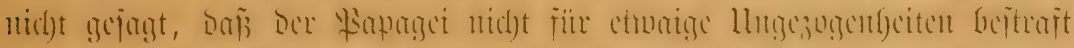

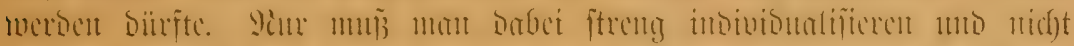

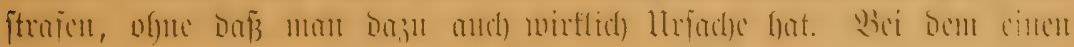

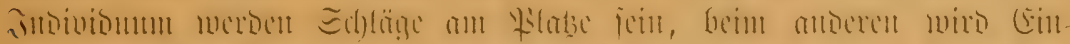

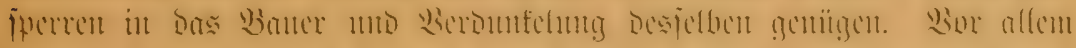

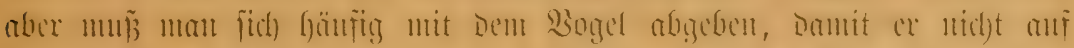

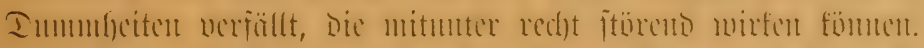

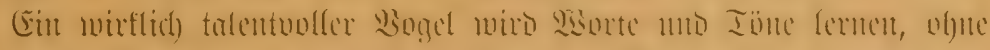

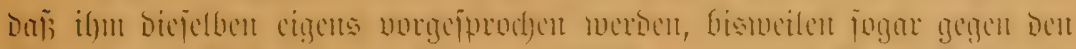

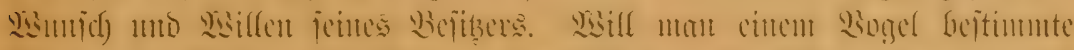

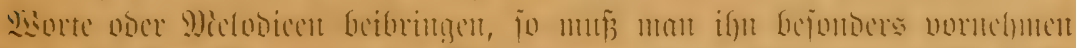

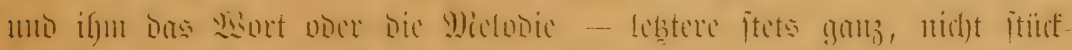

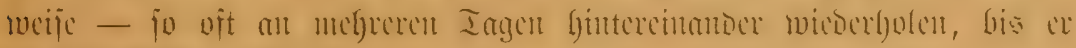

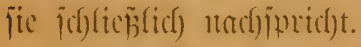

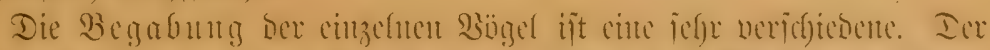

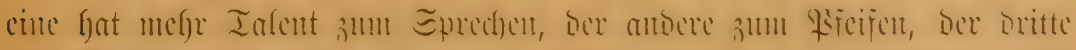

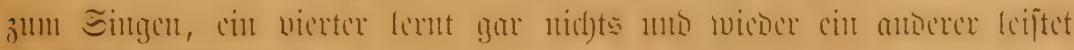
in alfem bedeutembes.

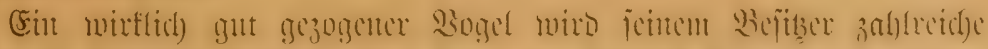

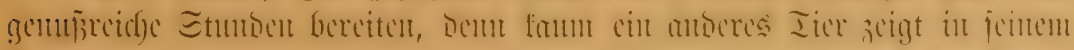

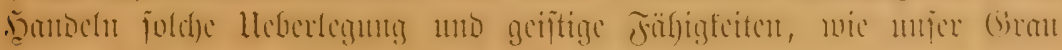
papanget. 


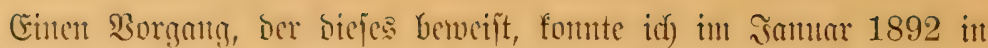

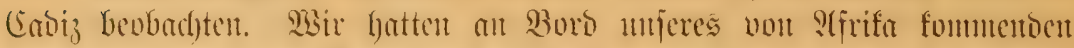

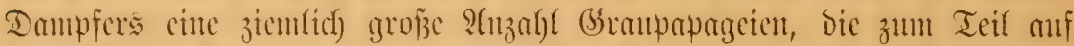

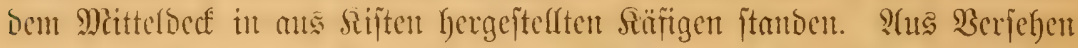

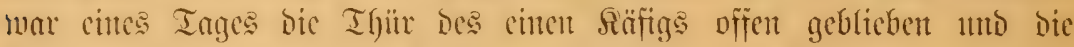

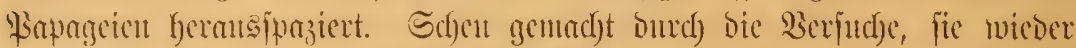

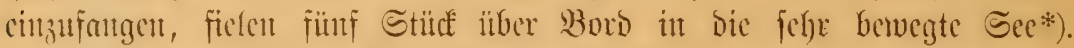

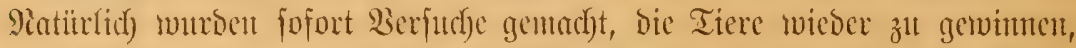

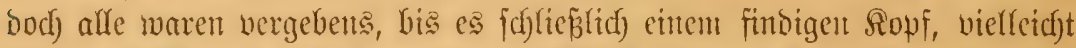

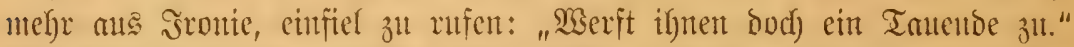

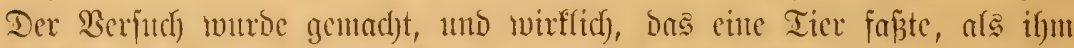

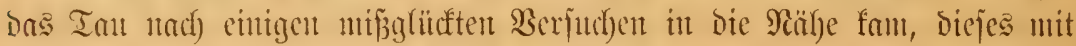

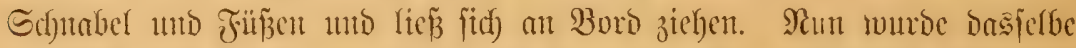

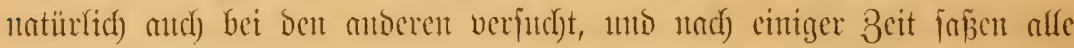

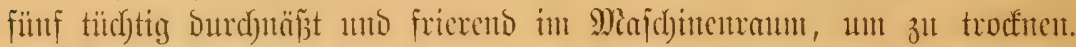

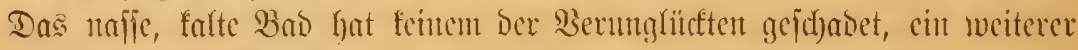

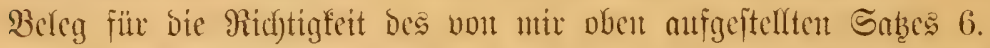

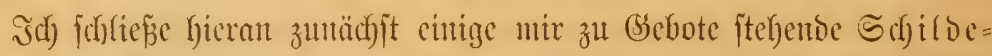
rungen von Gromupapagcien, ba bicie mu beften geeignet finto, cinen Ein=

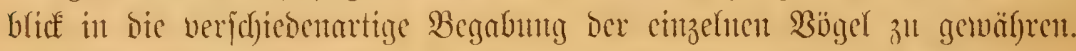

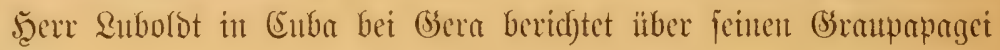
folgettoes:

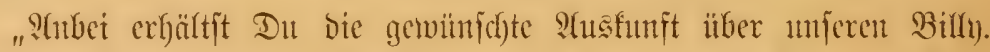

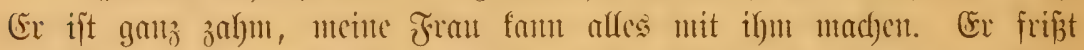

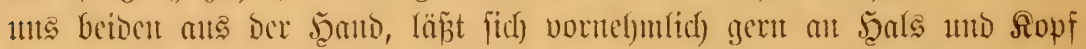

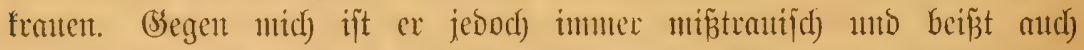
mand)ual, weil er von mir öfters angerautht unb ausgefdyolten

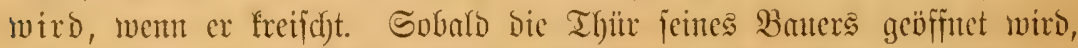
geht er herme mo Gincin, Gleibt aber babei ftets auf Dem Tifde, mif Dem bas Bauer ftebt. FFliegen famu er faum, unto ift bie Becwegutg cher

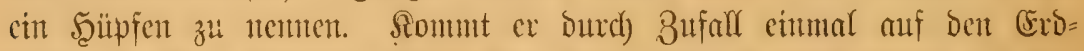

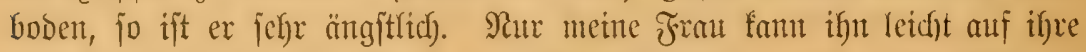

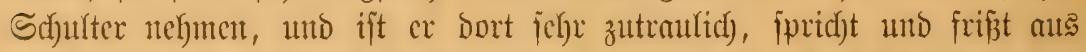

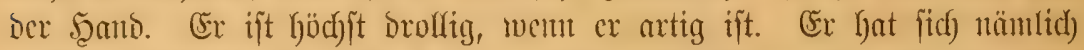

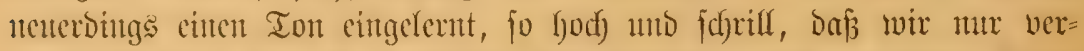

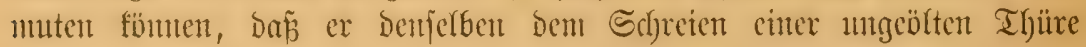

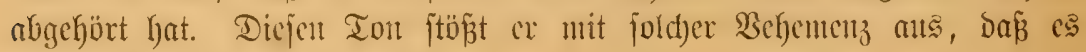

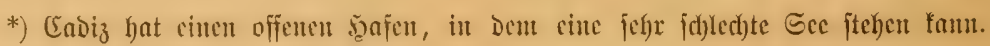




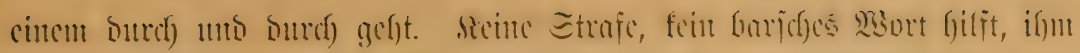

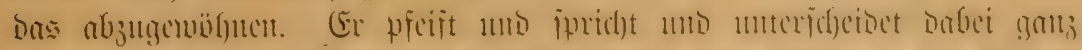

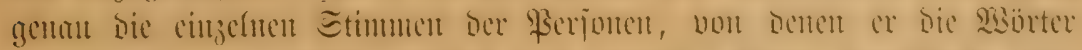

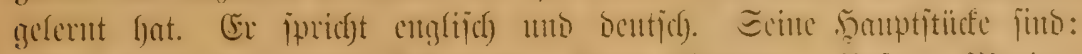

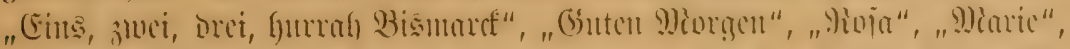

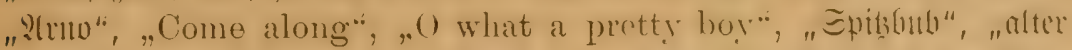

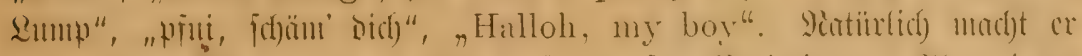

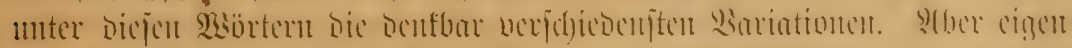

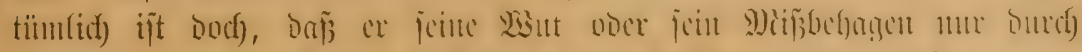

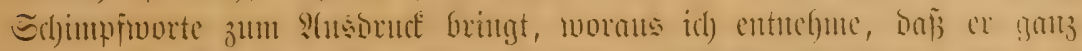

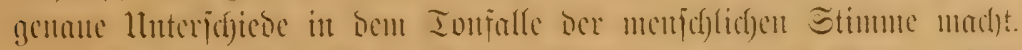

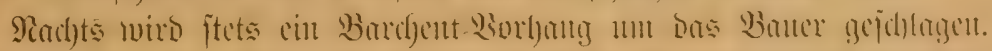

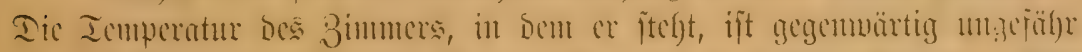

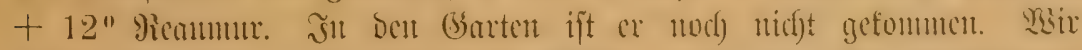

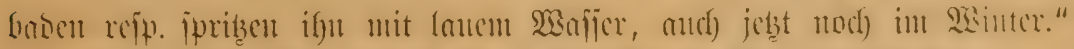

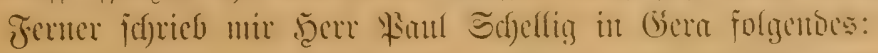

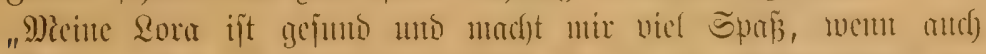

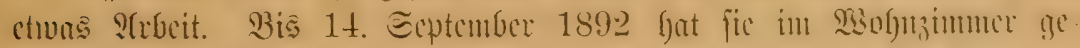

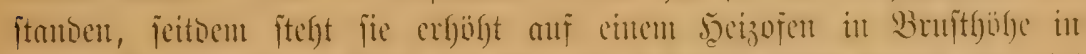

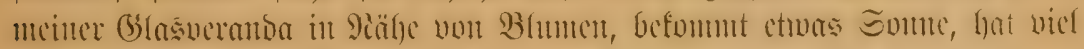

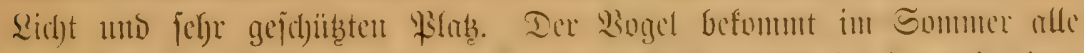

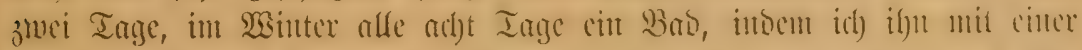

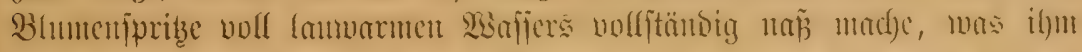

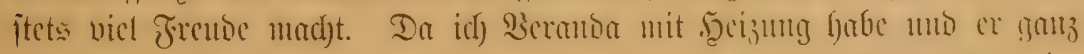

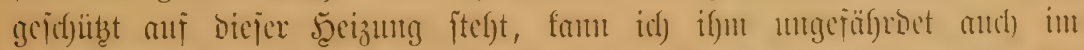

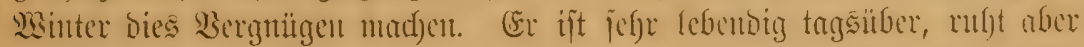

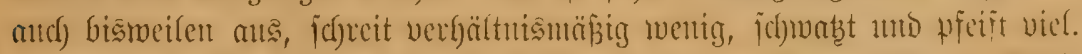

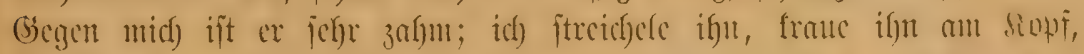

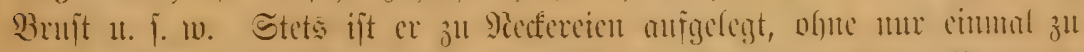

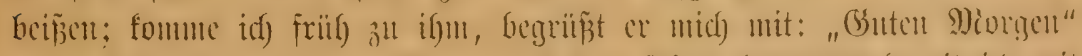
unter Irippeln anf fenter Stange, fommt fofort fermuter, bant id) mit

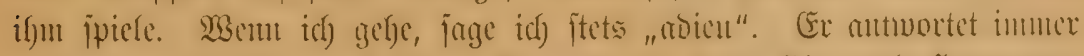

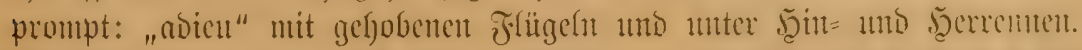

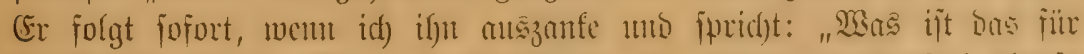

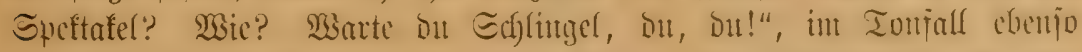

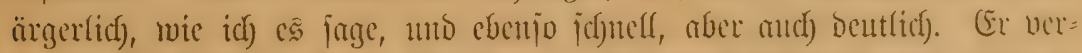

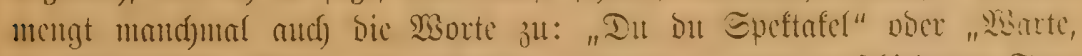

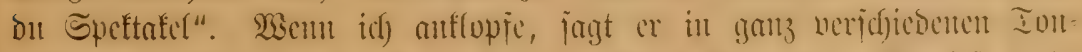

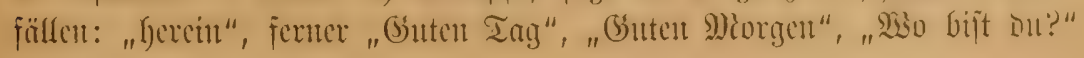




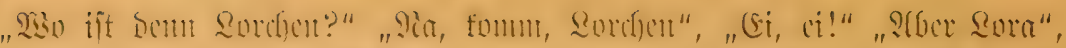

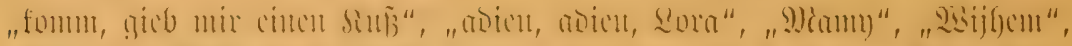

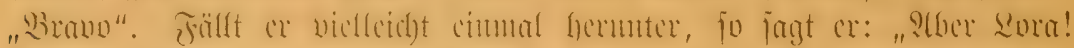

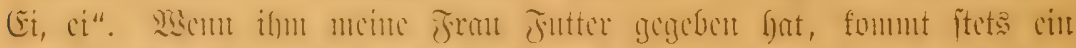

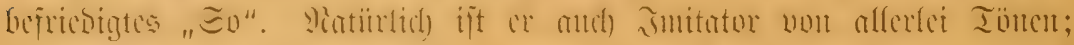

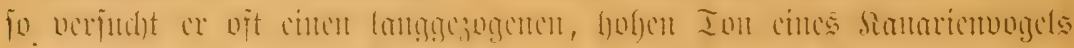

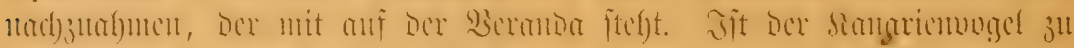

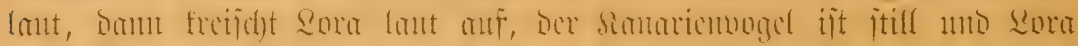

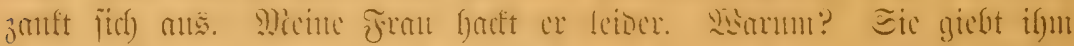

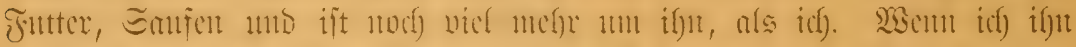

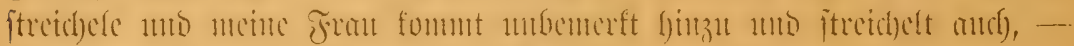

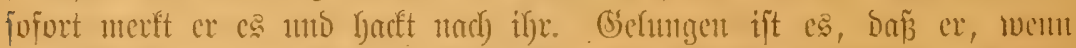

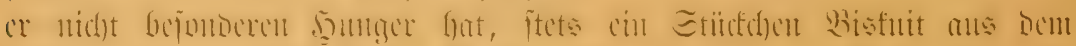

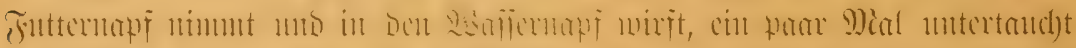

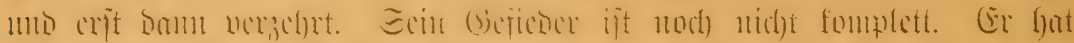

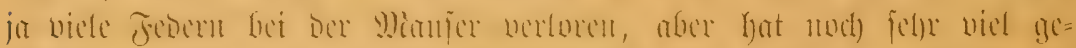

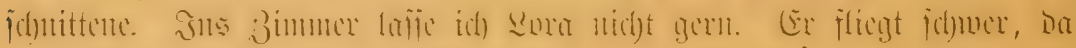

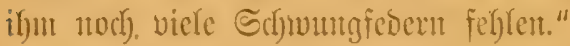

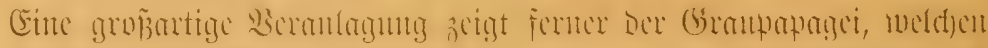

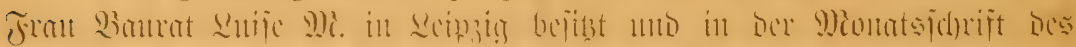

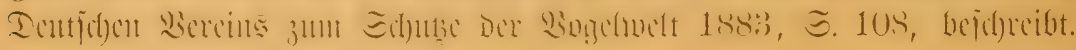

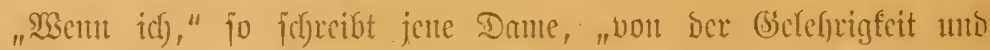

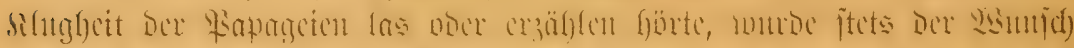

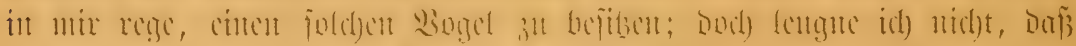

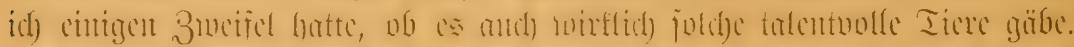

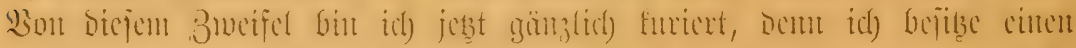

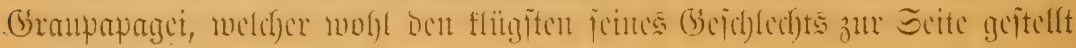
iverben fontut.

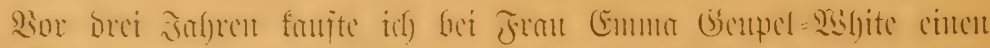

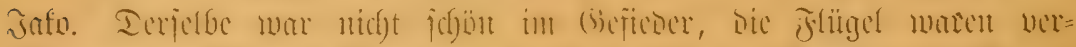

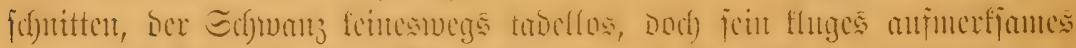

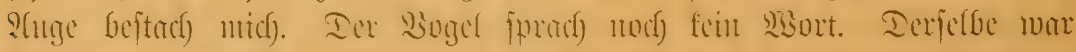

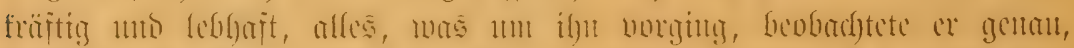

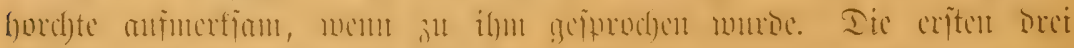

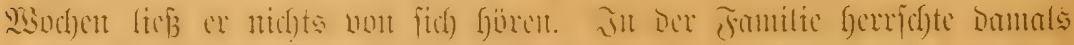

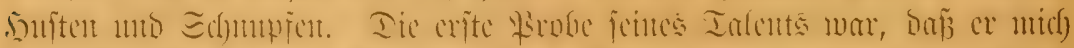

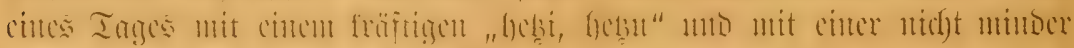

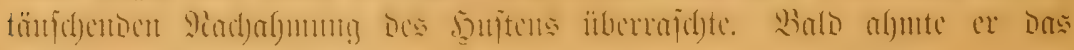




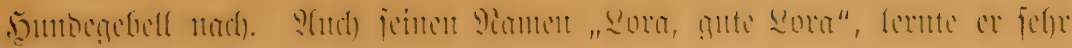

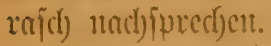

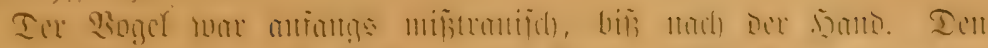

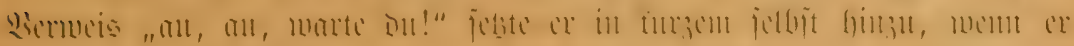
ficl) verga

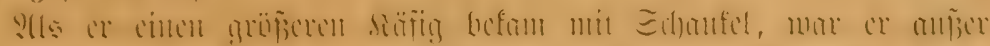

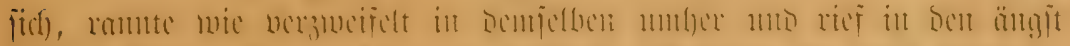

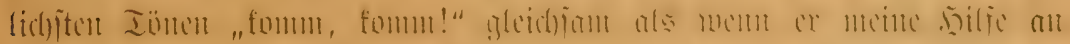

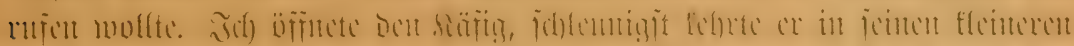

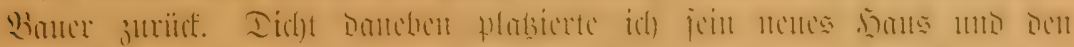

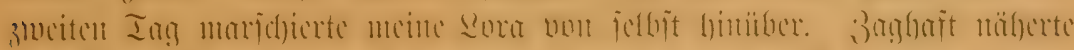

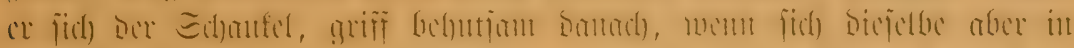

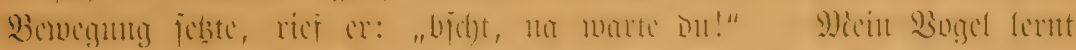

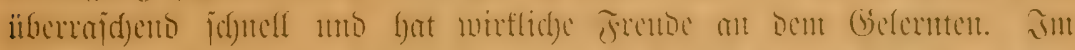

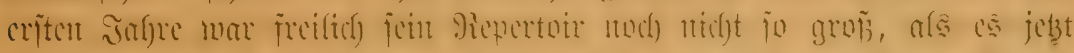

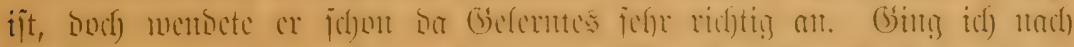

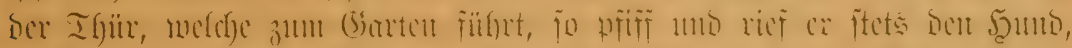

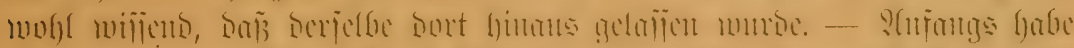

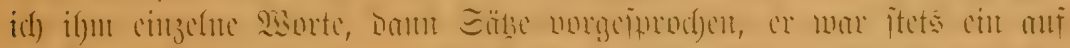

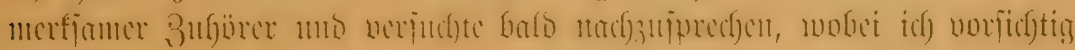
ciulualf.

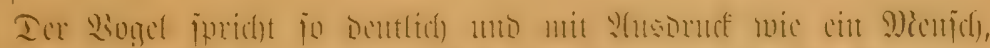

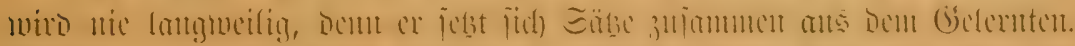

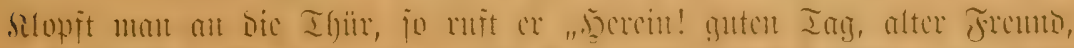

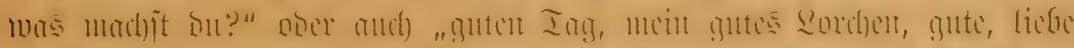

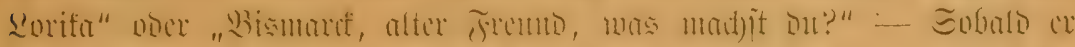

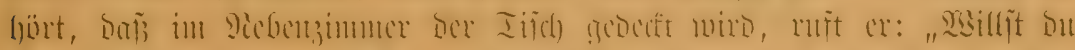

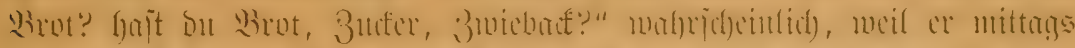

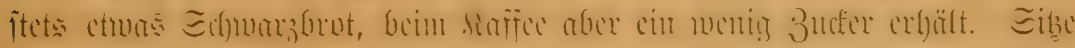

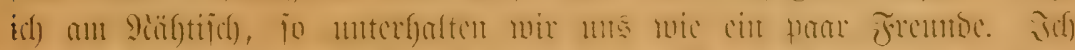

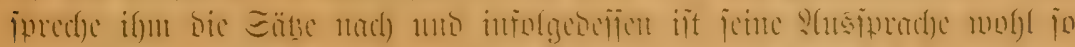

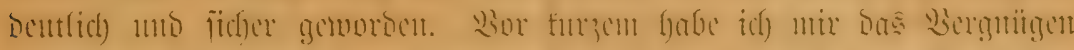

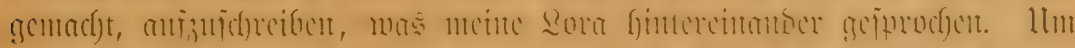

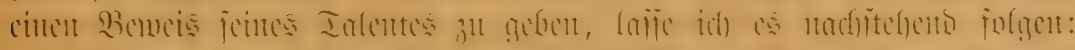

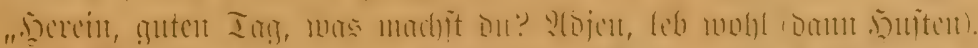

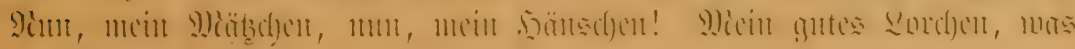
mad)jt bem? Göre!

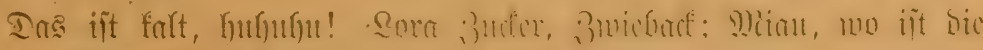

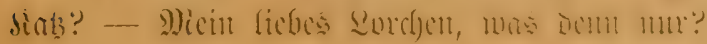


. Derein, guten Ing, arter Freuns, was madjit bem, mun, loas mad)ft

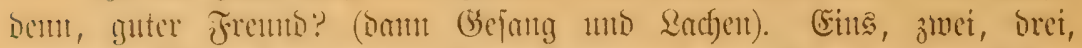

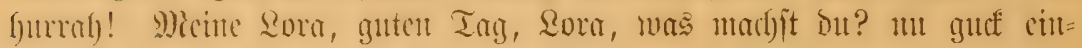

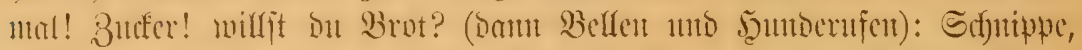

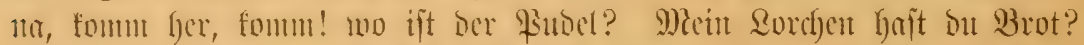

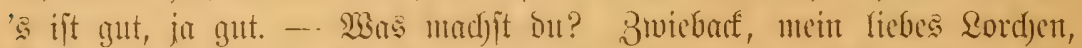

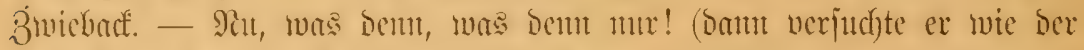

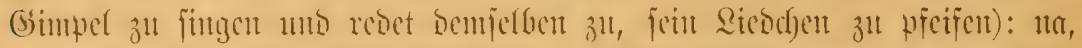

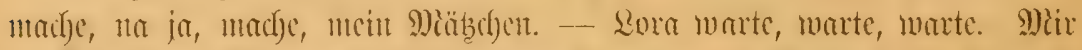

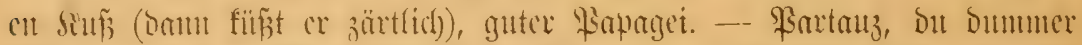

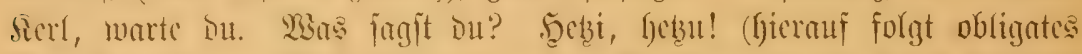

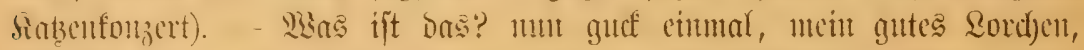

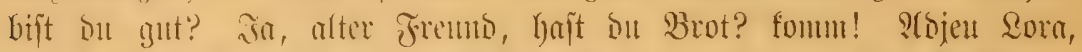

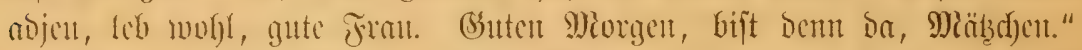

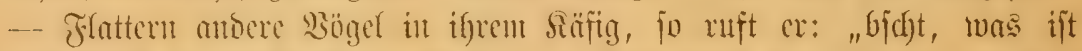

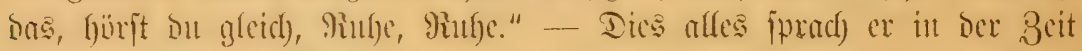
von ciner loalben Stunde.

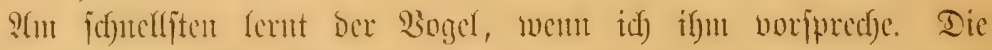
ticile Stimme meines Miannes fällt ifm fojwerer wiedorzugeben, Dod)

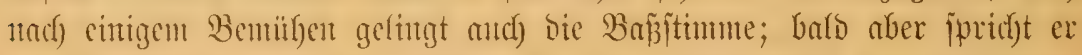
bas fo Erlernte in feincrer, Güherer Ionlage. Die meiften ber angefilifyrten

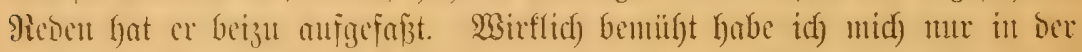

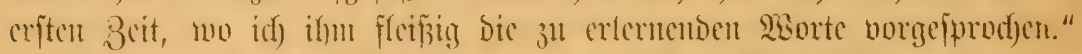

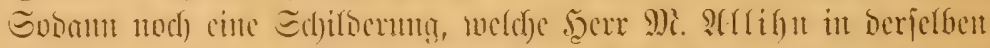

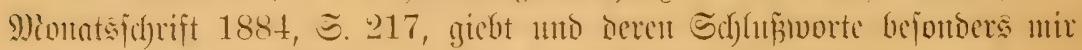

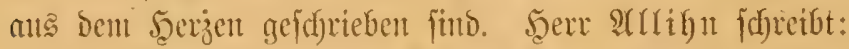

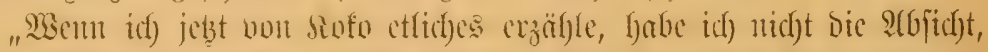

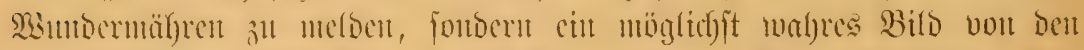

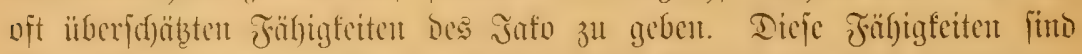

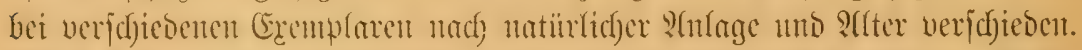

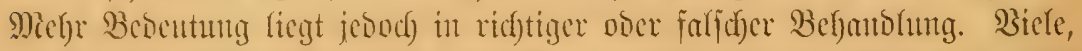

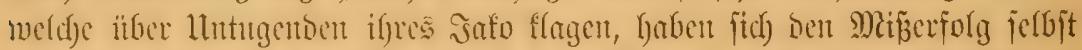

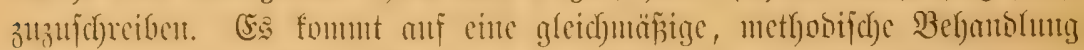

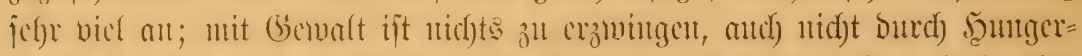

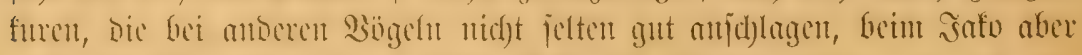

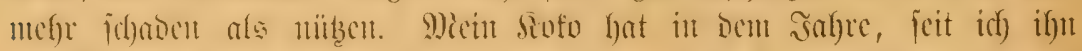

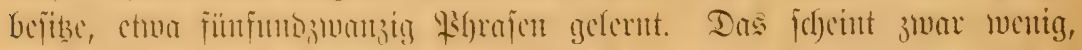

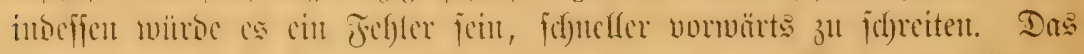

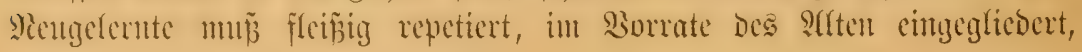




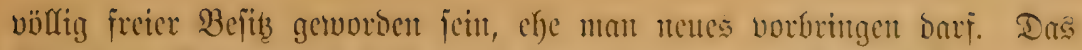

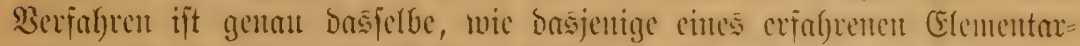

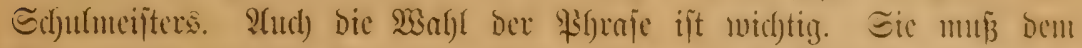

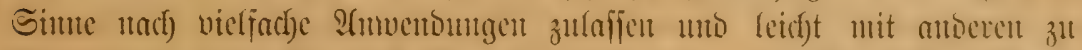

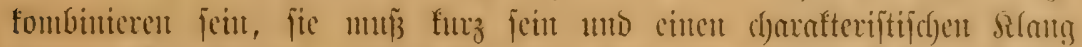
baben. Stuf Buresent meines Frembes babe id) meinem Siofo aud) cinc

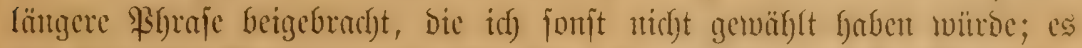

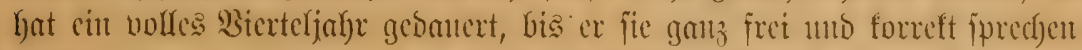

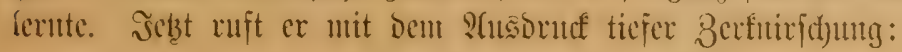

O jerum, jerum, jerum,

O quae mutatio rerum!

(Fes ift cin altes Studentenlico und heifipt zul bentij):

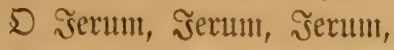

Die Sadje wentot fid fefr unt

aber weî́ ber gute Sofo auch, mas cr fagt? (5: ffingt ganz geutau fo. Siommt früh norgens bas Dienjtmäbdjen ins Bimmer, fo fpricht er

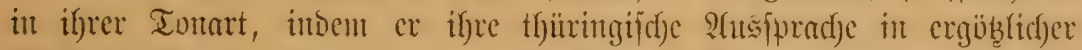

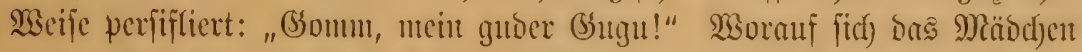
ärgert, beum fie glaubt wirf(id), Der Sinpagei veripotte fie, worauf fic mit

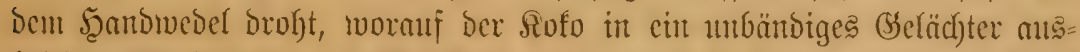

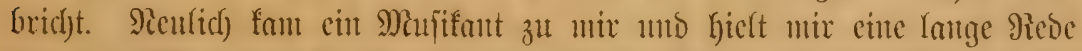

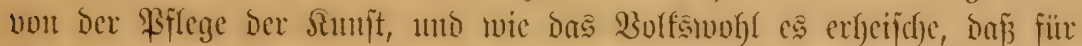

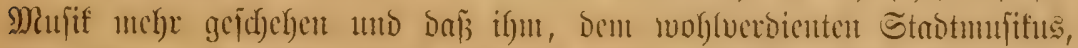

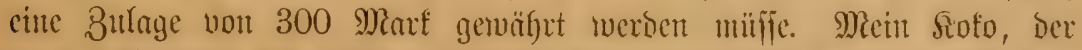
ganz ftifl hinter ber Thür anf jeiner Stange gejefjen hatte, ergreift mu

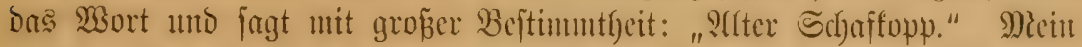

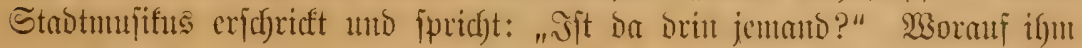

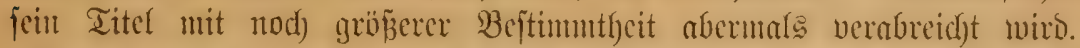

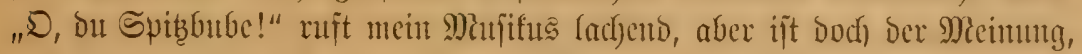
Dá̧ foldy ein Tier Berftano Gaben-müffe.

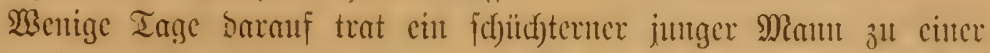

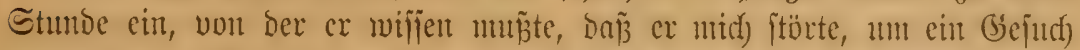

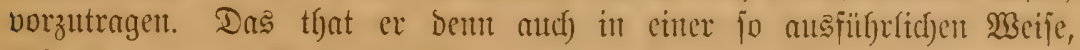

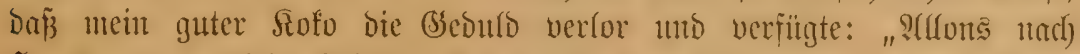

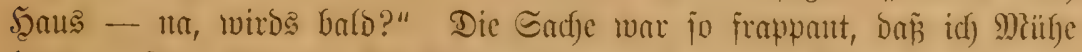
hatte, eruft zu bleiben. Gśücflicferweije max ber junge Dlant jo befangen,

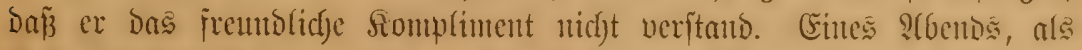
Siofo bie Unterfaltung, wie er bas licbt, an fidj gerijien und bic an=

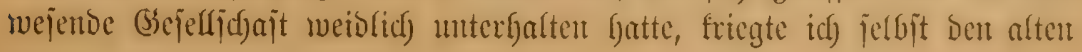




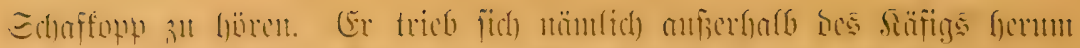

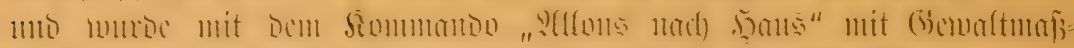

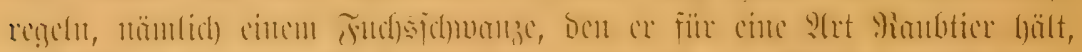

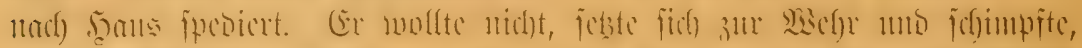

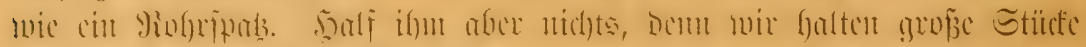

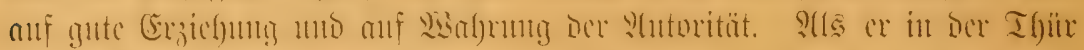

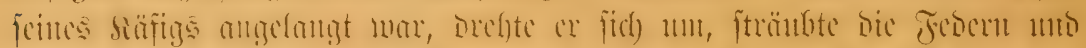

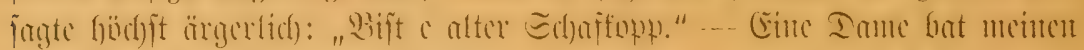

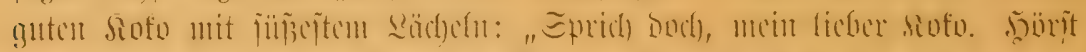

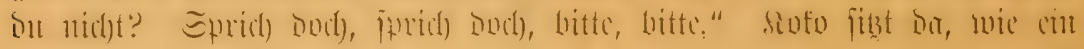

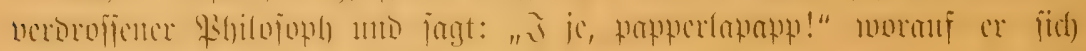
weiter maș

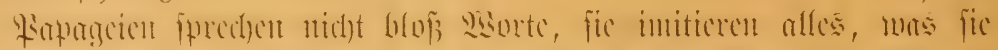

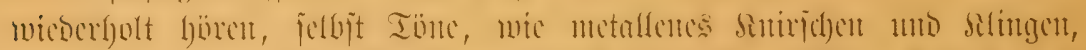

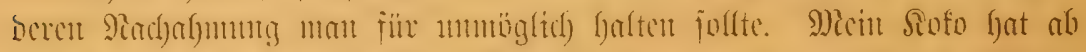

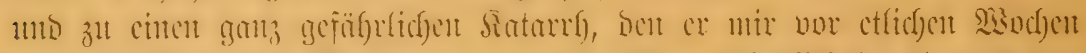

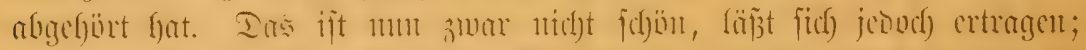

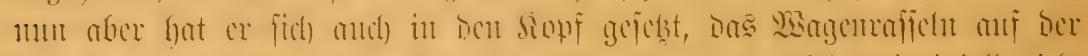

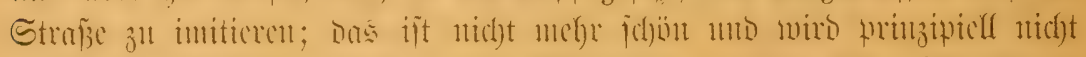

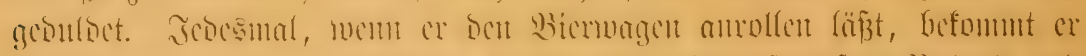

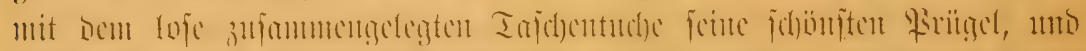

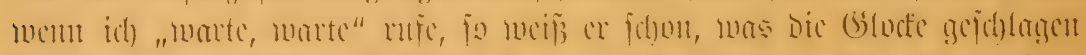

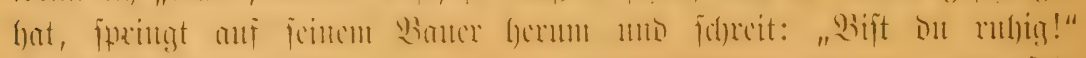

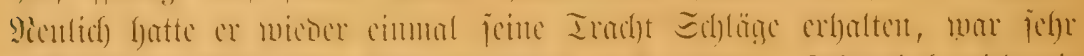

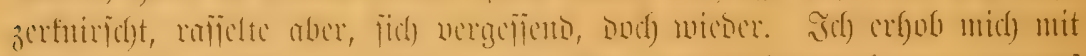

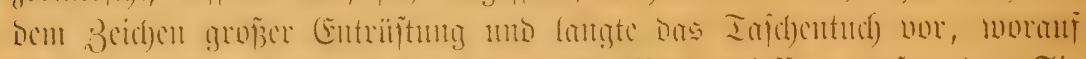

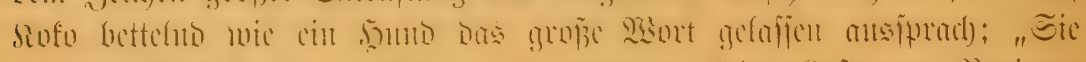

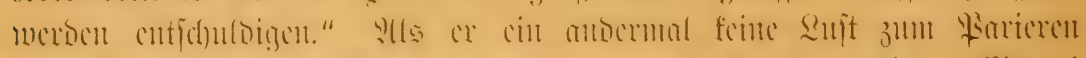

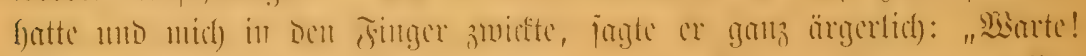

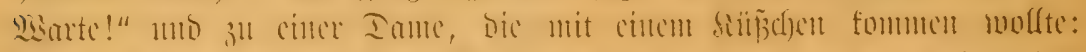

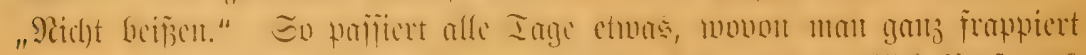

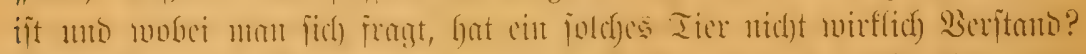

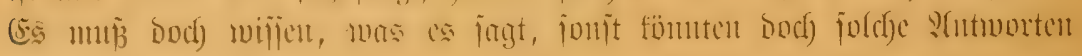
nicht zul jtonoe fomment.

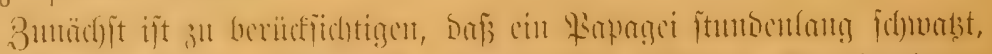

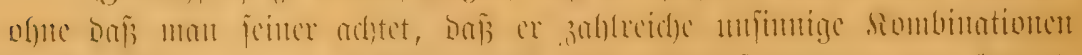

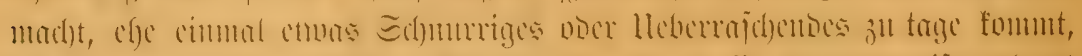

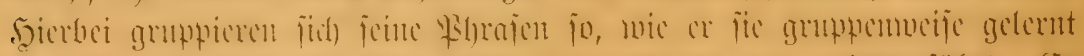

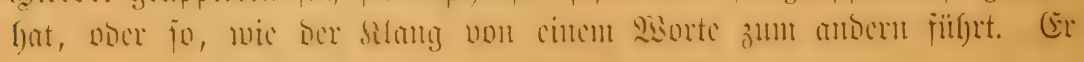




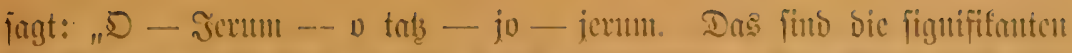

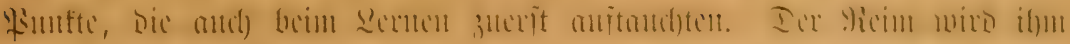

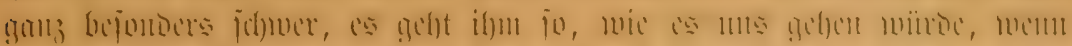

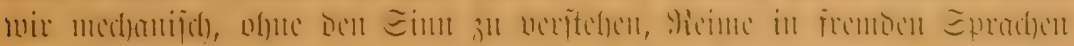

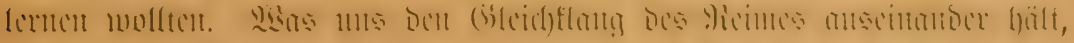

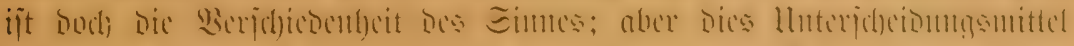

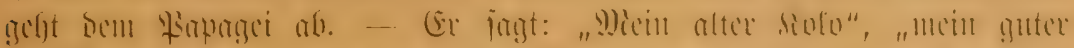

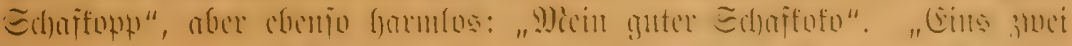

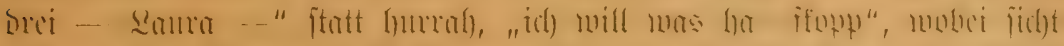

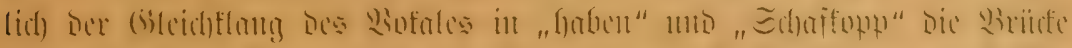

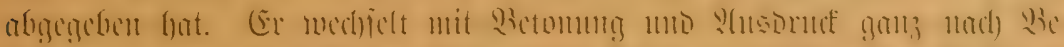

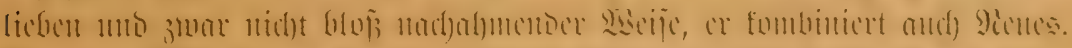

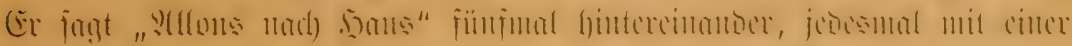

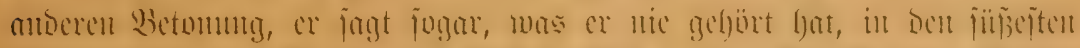

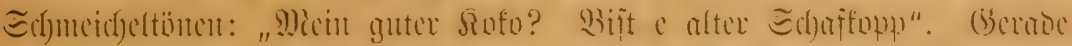

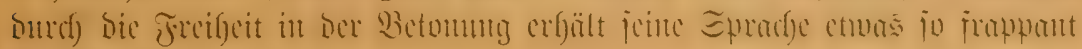

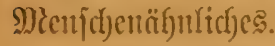

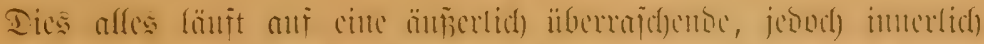

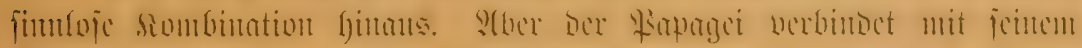

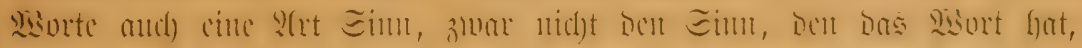

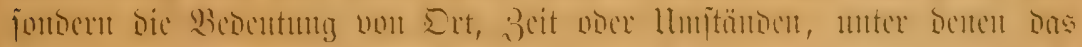

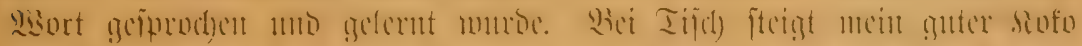

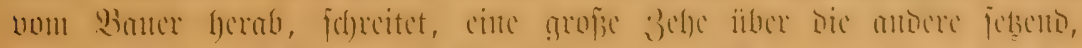

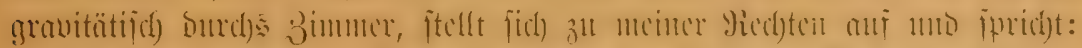

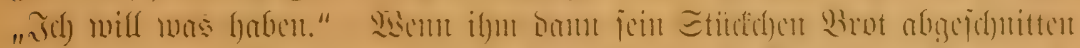

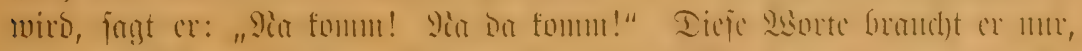

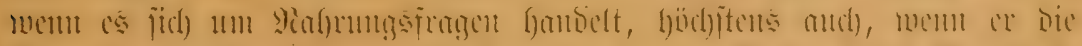

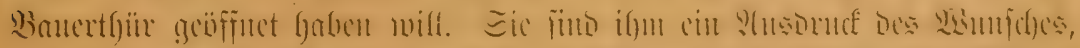

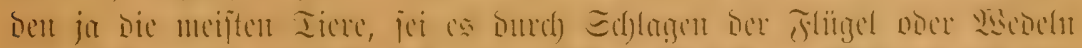

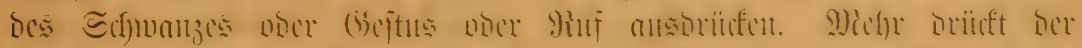

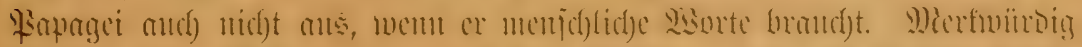

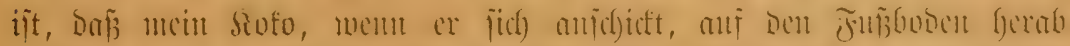

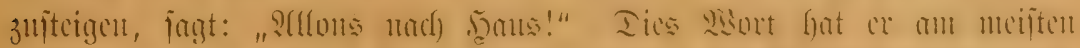

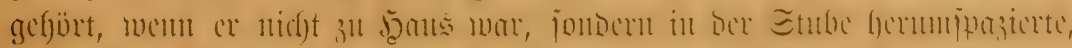

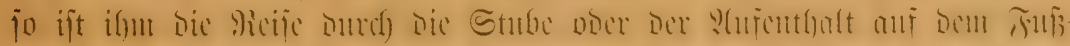

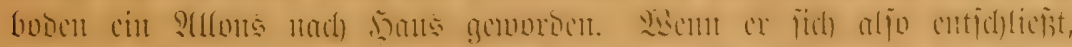

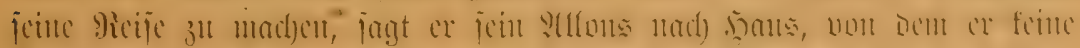

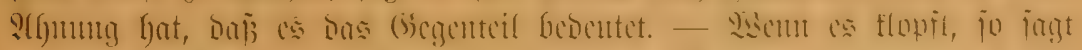

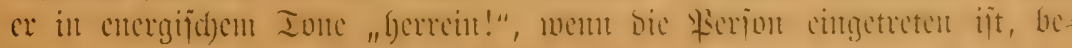




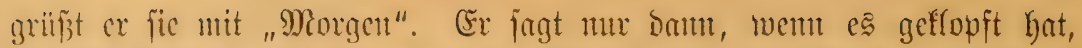

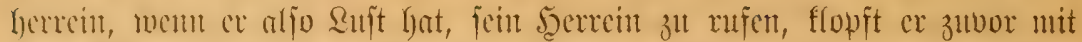

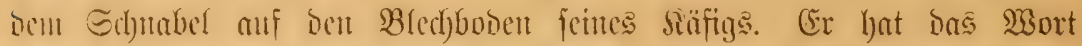

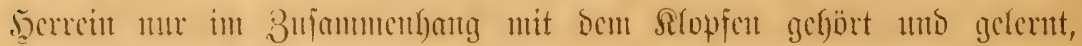

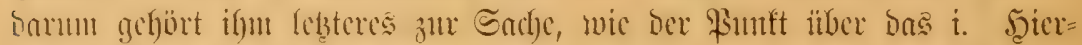

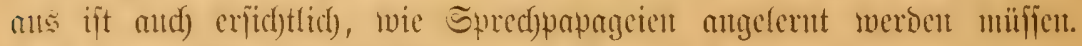

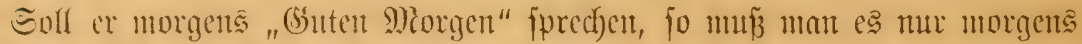
leftert, foll ar "bitte, bitte" ober "Danfef(t)bu" fagen, went man ifyu

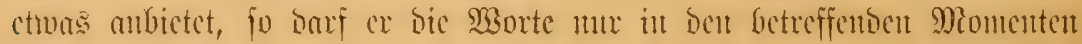
ljörcrt.

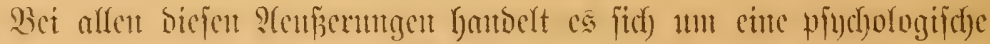

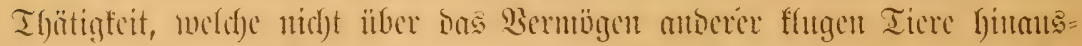

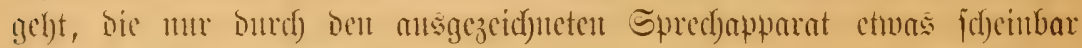
Hebernatirlidjes erbalten.

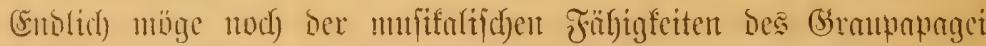

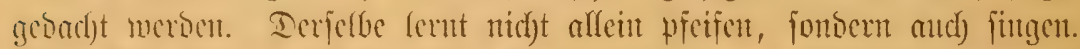

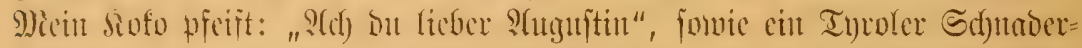

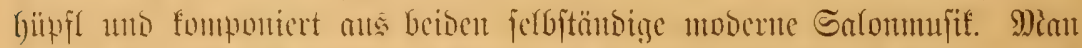

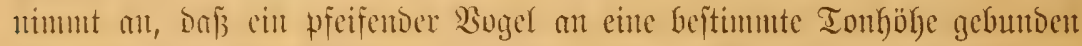
jei, was bcim Dompfaffen und Stan aud 3utrifft; mein guter Sofo ift

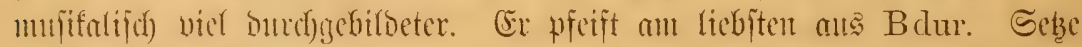

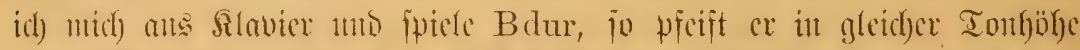

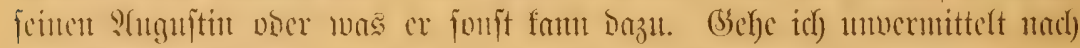

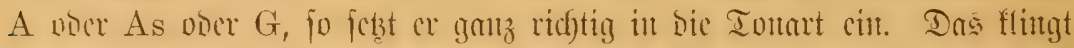

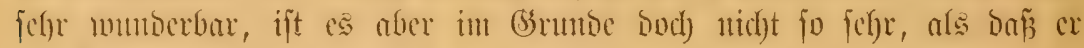

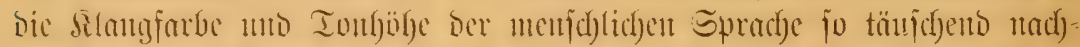
zunfuten vermag.

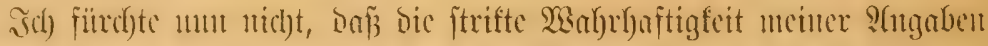

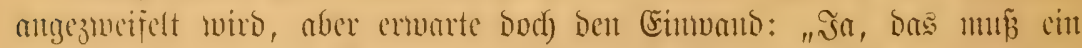

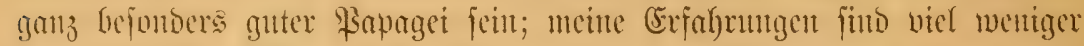

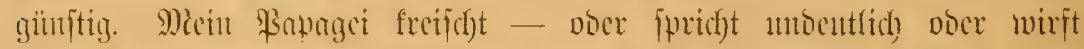

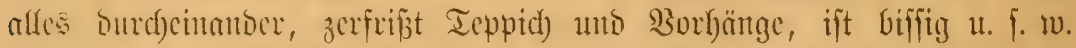

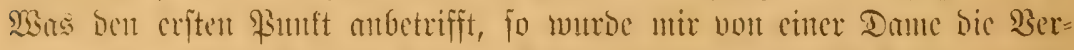

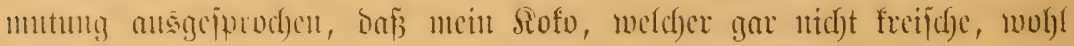

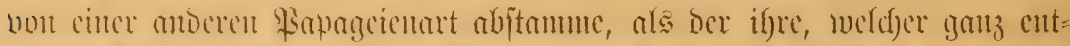

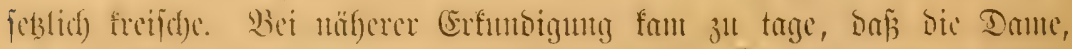
Inแ

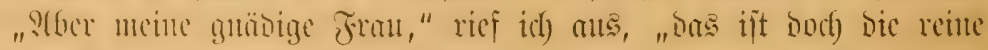

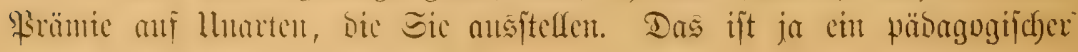




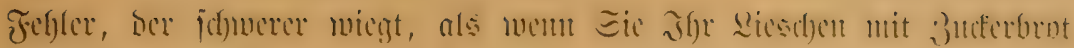
beruljigen, went es umartig ift."

"Warum fob)(iumer?"

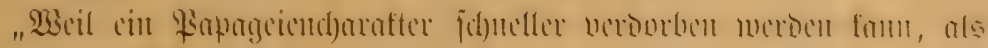
cin Sintoescharafter."

"2tber waอ thutu?"

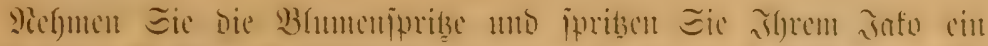

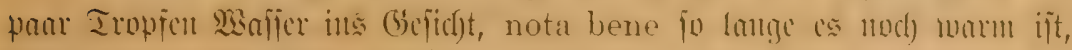
Dant witro er es fdjou Infïent."

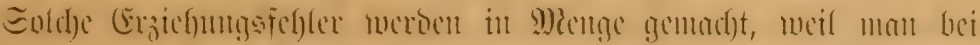

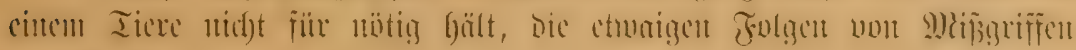
วัl bebentent.

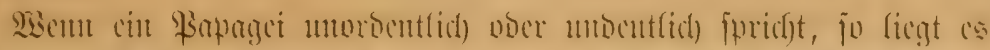

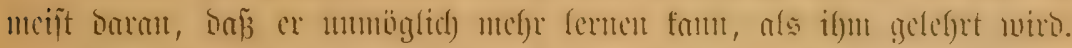

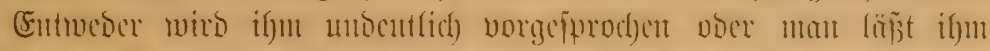

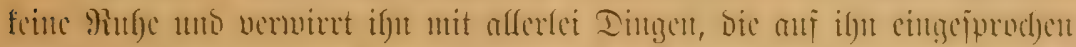

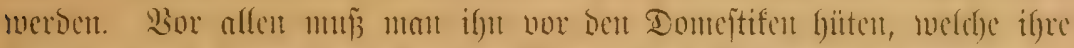

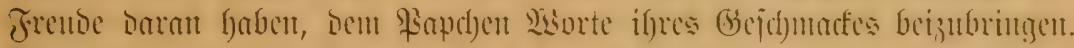

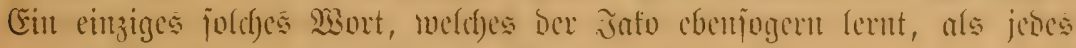
antoere, foum ifyt jalomutürifig machent.

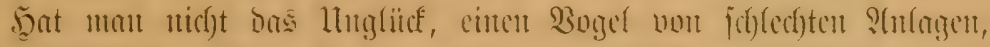

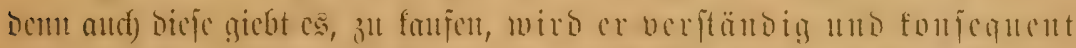

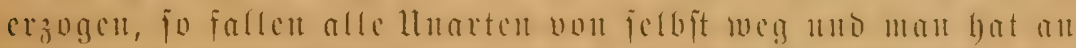

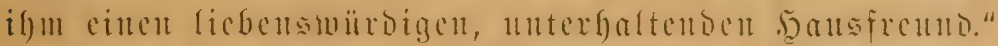

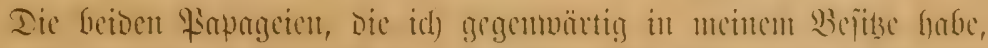

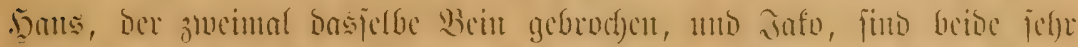

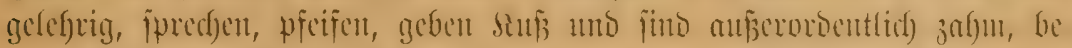

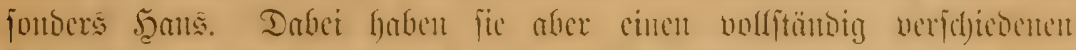

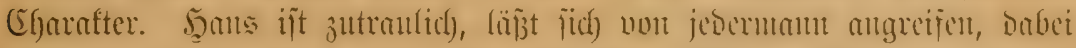

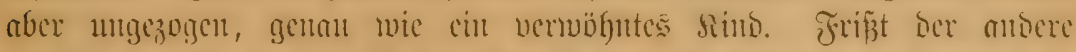

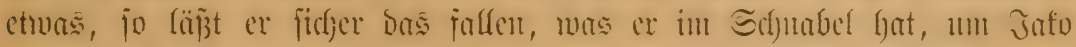

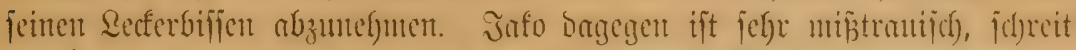

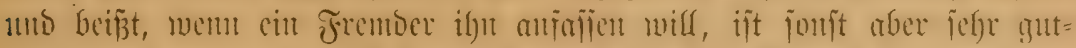

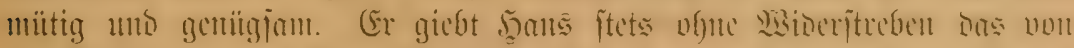

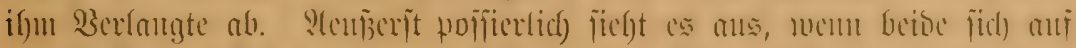

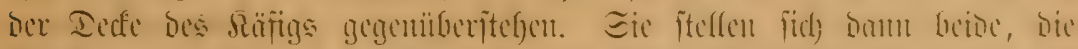

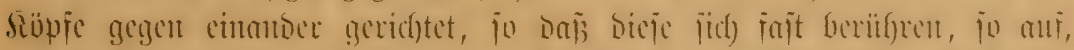

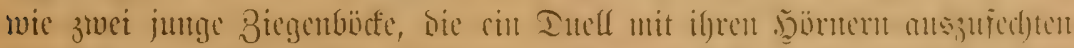

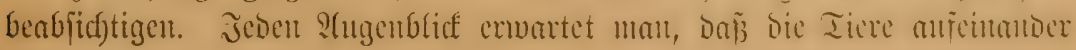




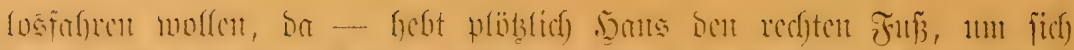

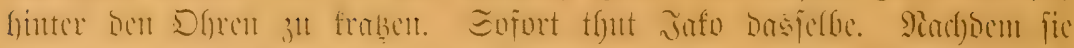

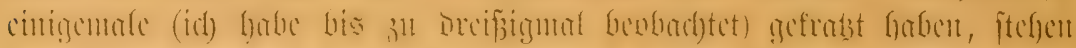

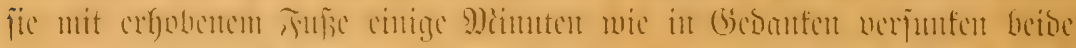

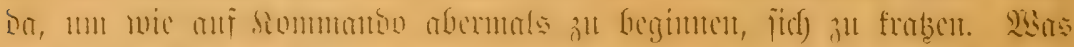

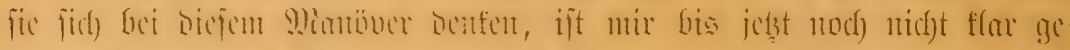

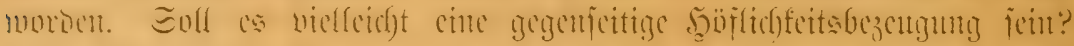

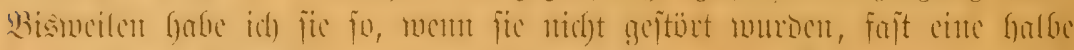

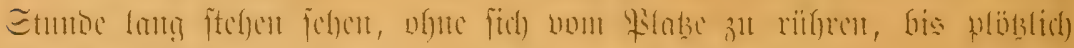

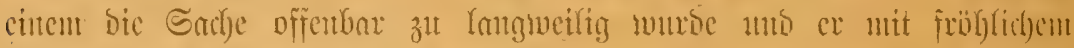

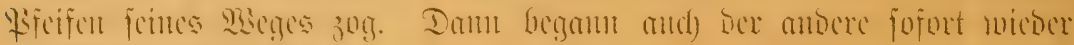

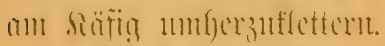

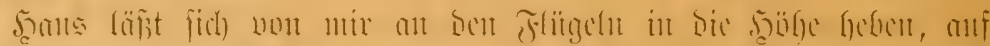

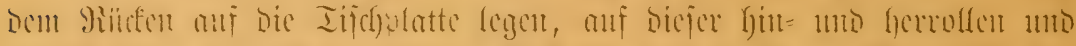

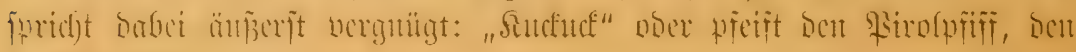
ar jefre lickt.

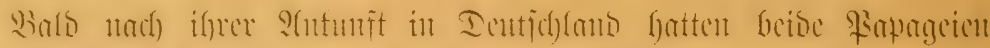

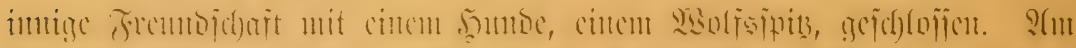

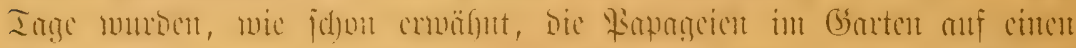

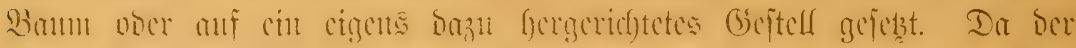

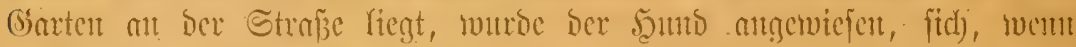

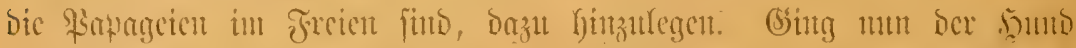

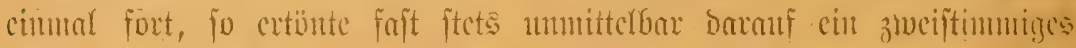

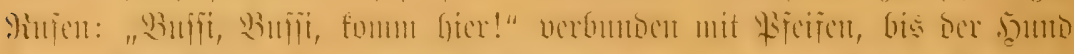

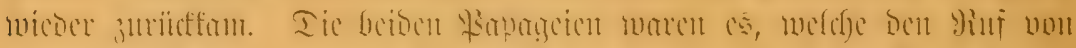

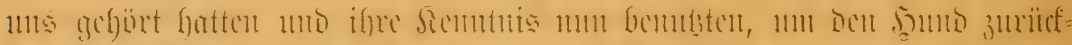

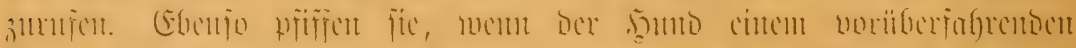

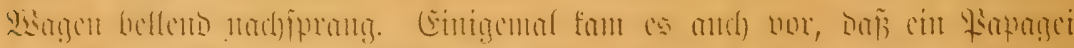

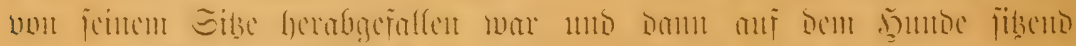

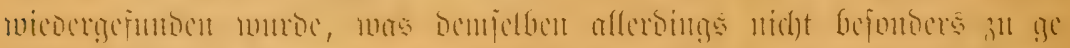

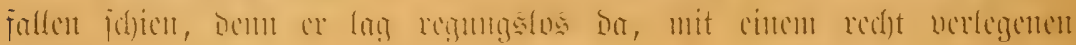
-(Sicficft.

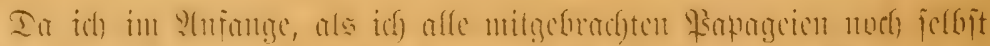

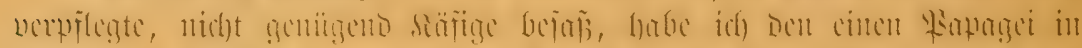

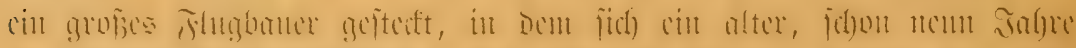

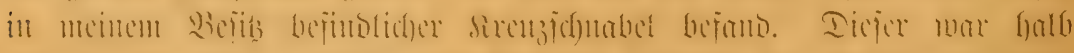

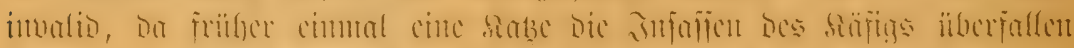

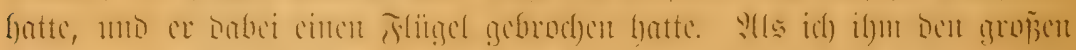

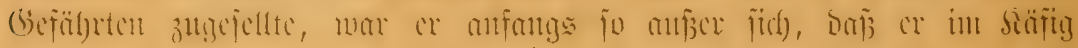




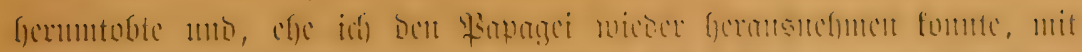

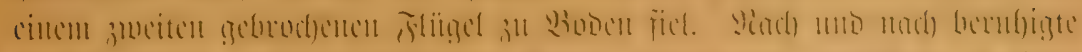

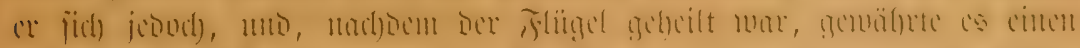

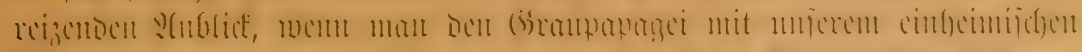

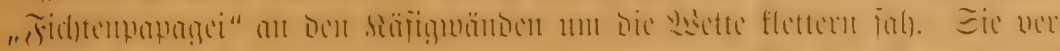

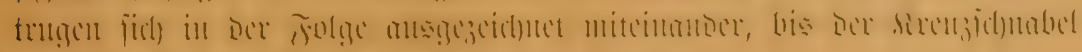

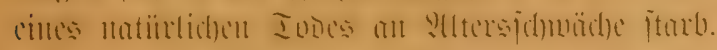

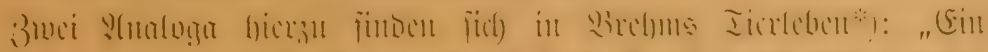

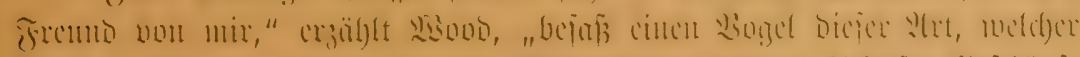

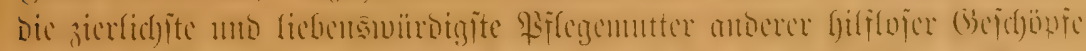

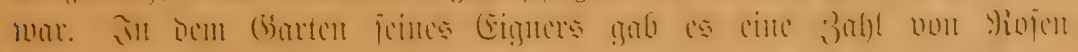

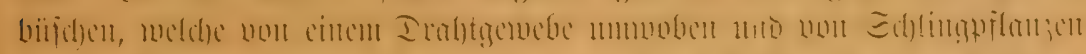

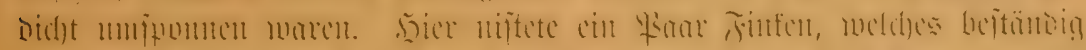

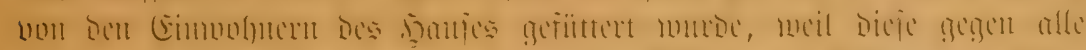

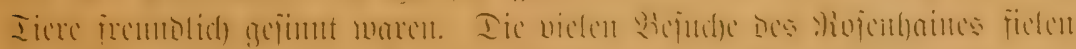

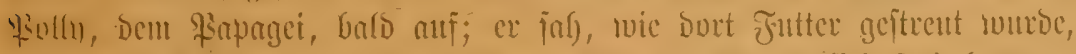

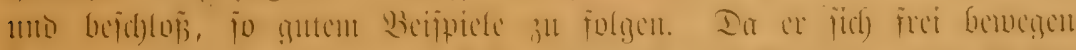

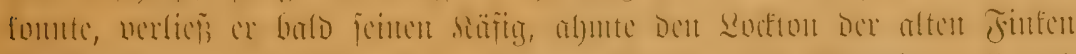

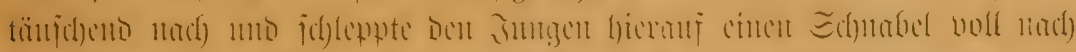

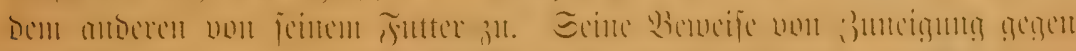

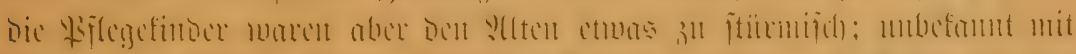

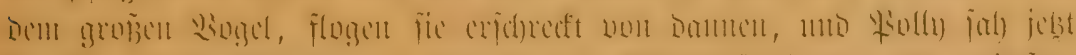

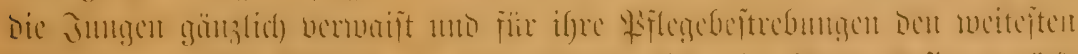

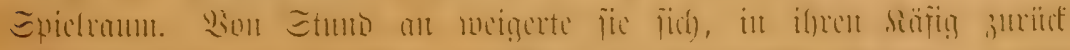

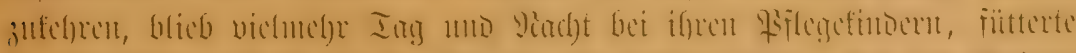

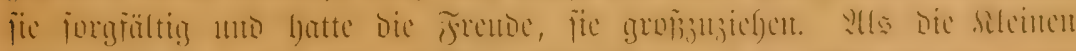

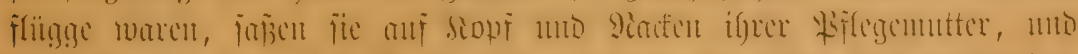

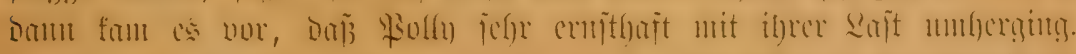

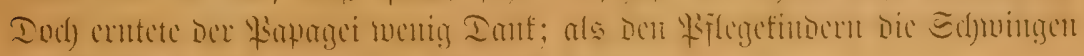

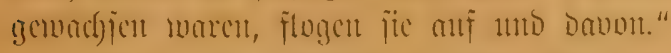

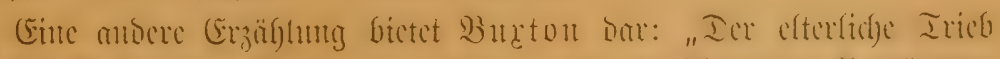

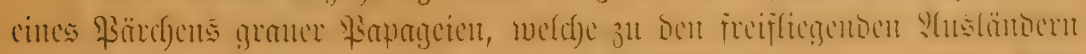

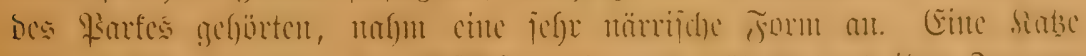

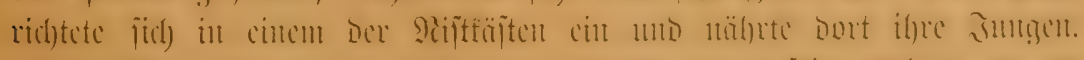

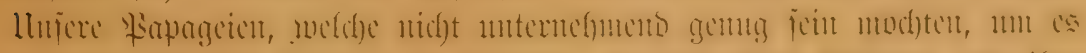

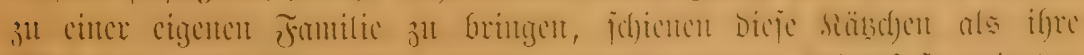

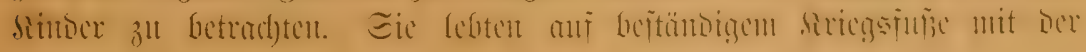
*) 1. c. $\Xi .6 \overline{\text {. }}$. 


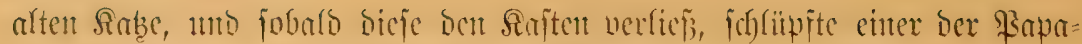

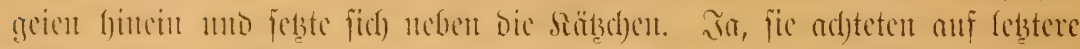

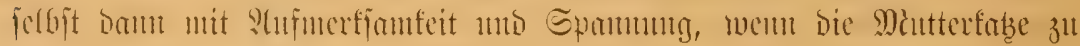
乌amie เบณx."

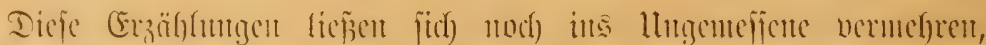

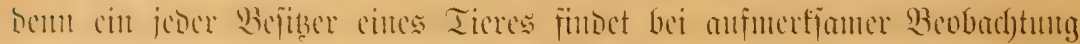

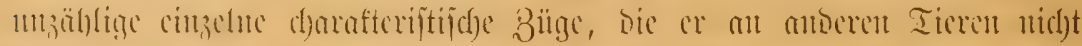
findet atto bie ilym gerabe fein Exemplar lieb nto mert madjent.

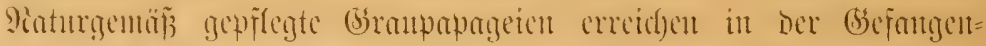

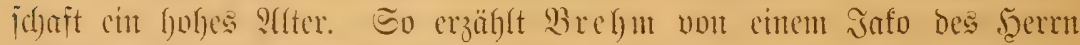

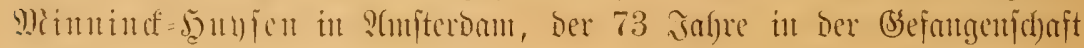
gelebt loat.

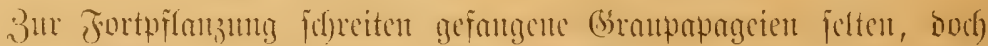

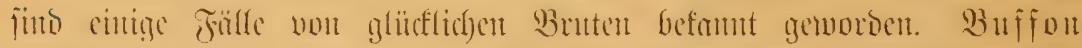

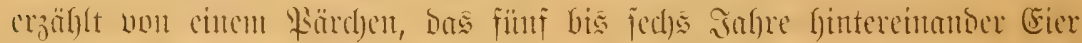

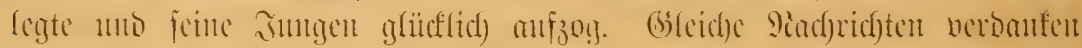

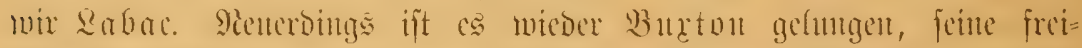

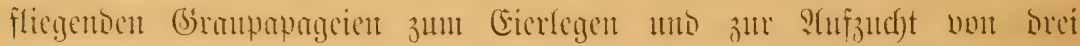

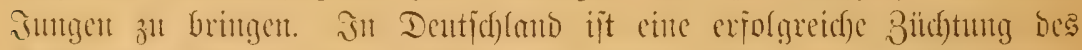

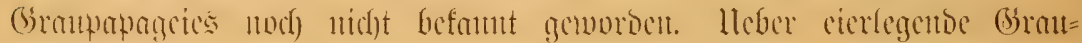

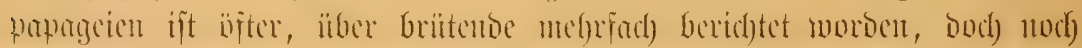

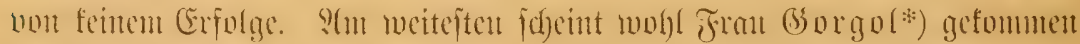

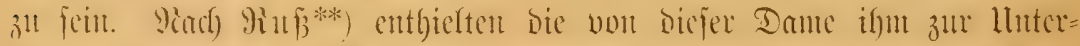

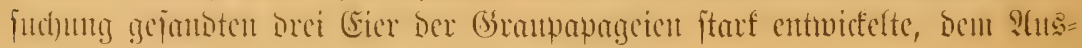

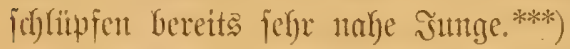

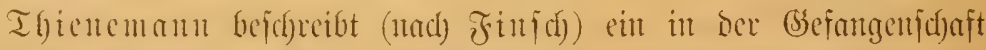

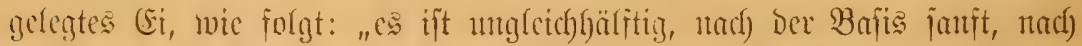

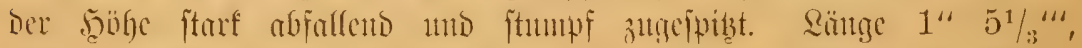

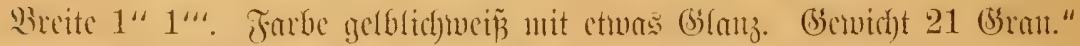

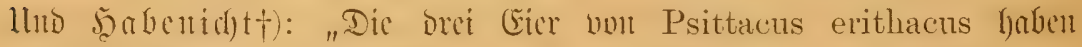
fulgende Mcafe: 1. $41 \times 28,5 \mathrm{~mm}, 2$. $42 \times 28,5 \mathrm{~mm}, 3.41 \times 29 \mathrm{~mm}$.

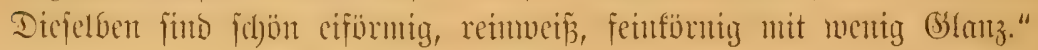

*) BSefiederte Mryt 1894, ऽ. 13.

**) Befiederte Welt i894, S. 14.

***) Wie id bicle 2(ngabe alleroings mit Der auf Seite 46 zu findenden Er=

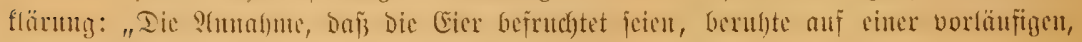

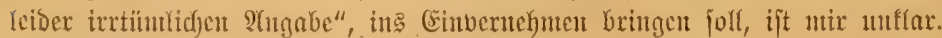

†) Befiederte $23 \mathrm{c}$ t 1894, S. 177. 


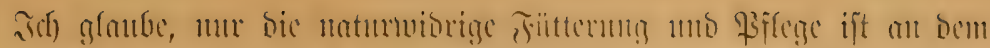

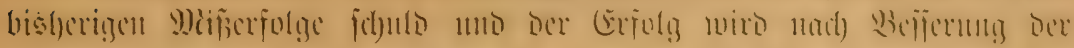

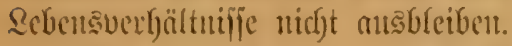

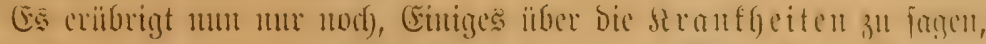

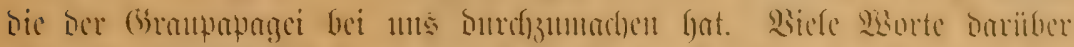

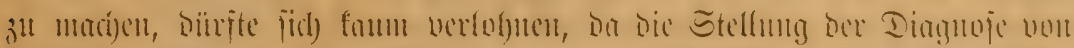

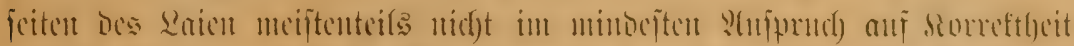

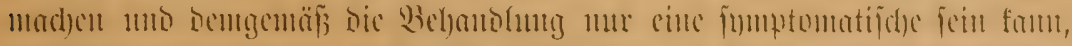

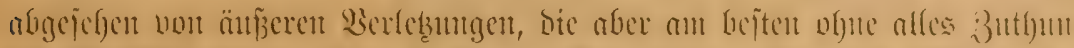

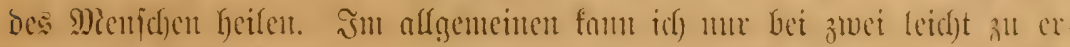

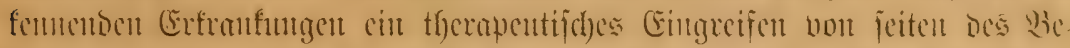

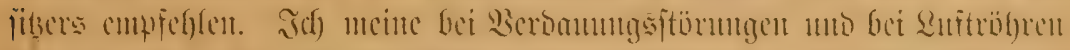

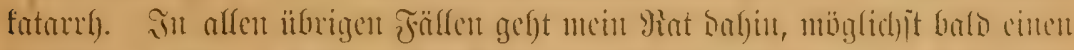

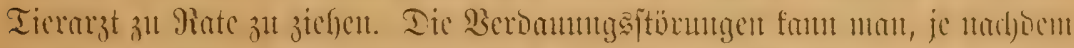

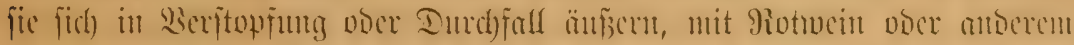

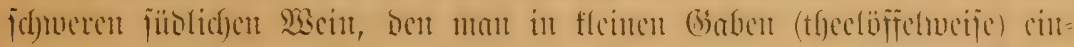

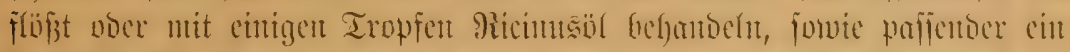

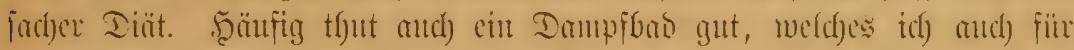

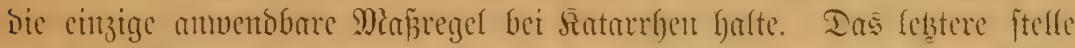

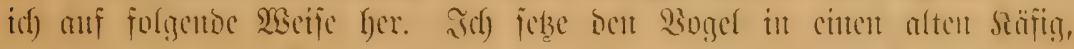

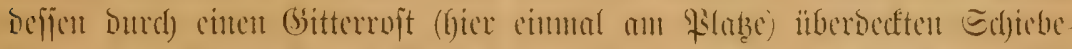

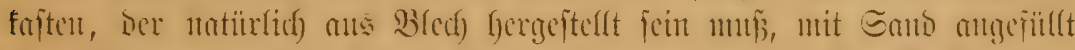

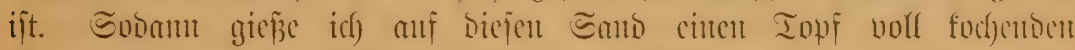

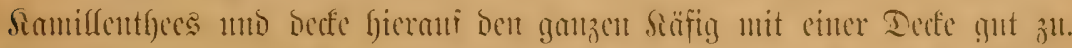

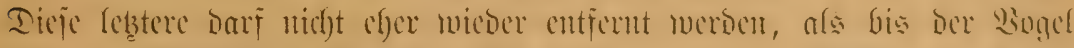

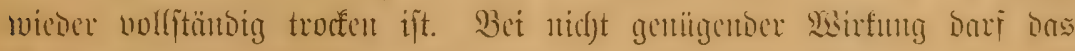
Bad norfunale wiederfyolt werben.

Sn allen iubrigen Fällen - idh) wieberlfole es - rate ich bon

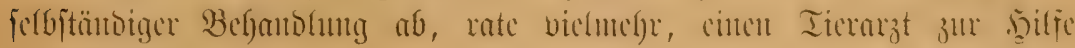
berbeizumufen.

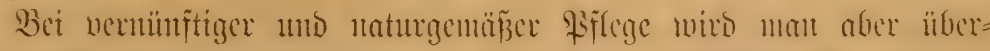

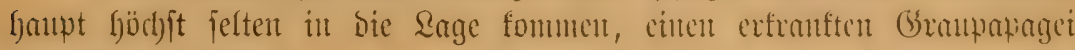
furieren zut mitffent.

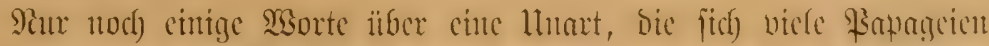

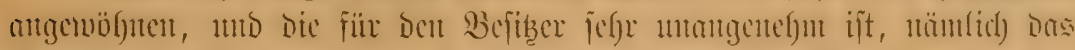

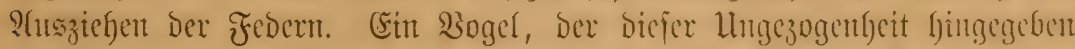

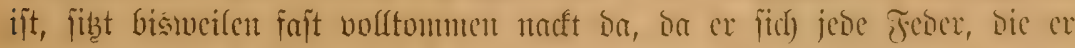

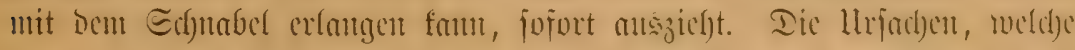

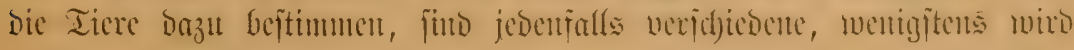




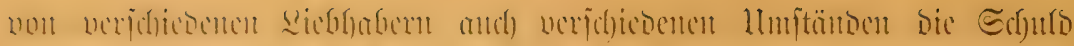

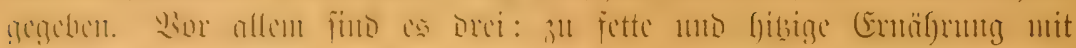
(1)

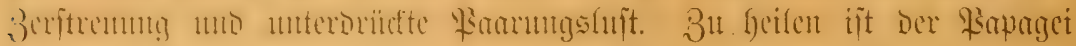

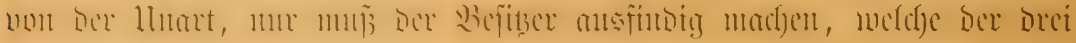

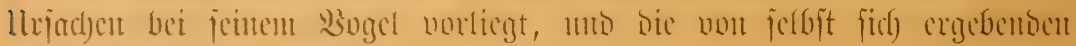
(begemuafregelt ergecifent.

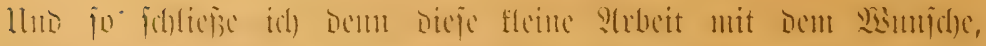

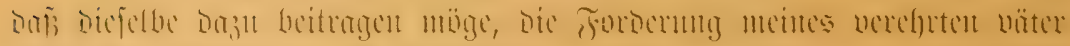

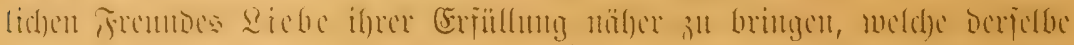

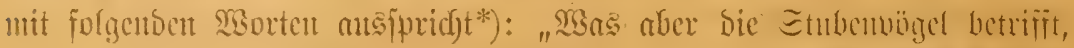

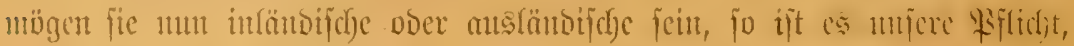

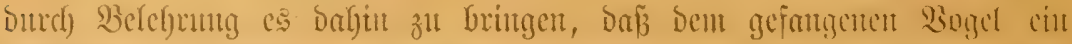

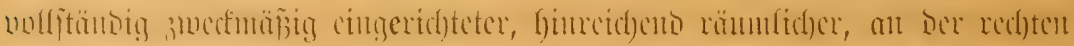

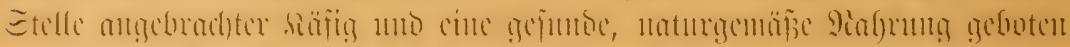

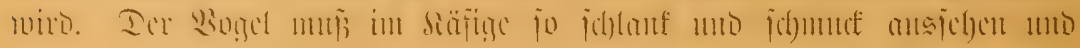

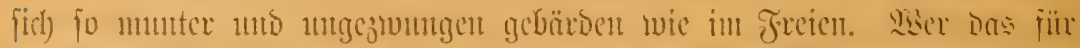

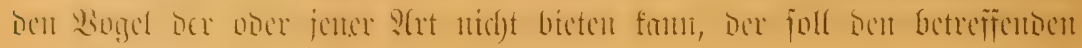
Bugel nicht balten." 


\section{Gitteruturundjuris.}

Dr. Otto Finfd, Die Papageien. Scioen 1868.

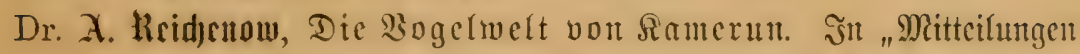

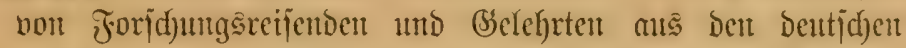
Sd)ubgebieten, herausgegeben von Dr. Freifhern von Danctét= mann". Berfin 1890. III. Bato.

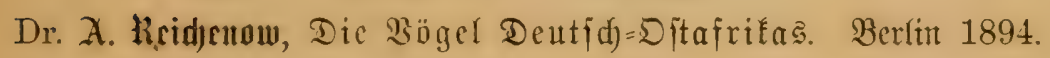

Befiederte. Welt 1894.

Brehms Tierleben, 2. Anflage. Reipzig 1878. Bano IV.

Druthorogifde Monatşdrift des Deutiden Bereing zum Sd)ube Der Bogelwelt 1883, 1884, 1892, 1893, 1894, 1895.

Kaloß, Der Grampapagei. Reipzig.

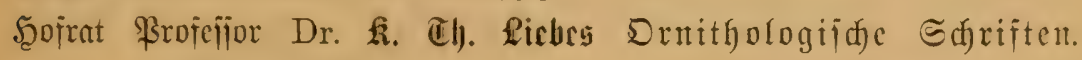

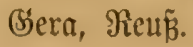





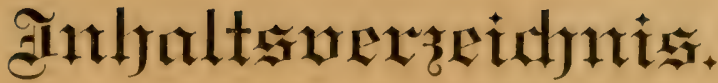

Bormort

Snthaltsuerzeidutis

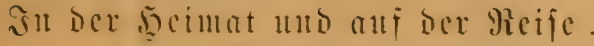

5eimat

Stelfung int Syjten

Beidoreibutng

1. Gröbe

2. Bsefieder

(9)

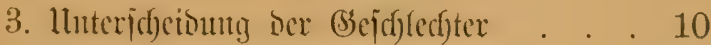

4. Arterŝnterjutebe . . . . . . . 10

5. Farbenuarietäten . . . . . . . . 12

Freileben

1. Rebentineije. . . . . . . . 14

2. Brutgeiduäft . . . . . . . . 15

3. Fflug . . . . . . . . . 16

Fantg . . . . . . . . . . . . . 18

Berhältuis zแm Timmeh. . . . . . . . . . 20

ந̧andel . . . . . . . . . . . 23

Jn ber Frembe

Utradjen ber Sterblidfeteit . . . . . . . . . 27

Piflege . . . . 35

1. Fütterung . . . . . . . . . . 35

2. Pflege . . . . . . . . 42

3. Räfig . . . . . . . . . 42

4. Bäl)muntg uno A(brif)tung . . . . . 49

Begabutg . . . . . . . . . . . . . . 49

Einzelte Sidjlberungen . . . . . . . . . . 50

2llter . . . . . . . . . . . 62

Brïten . . . . . . . . . . . . 62

Srantfeiten . . . . . . . . . . 63

Sitteraturnachucię . 



SMITHSONIAN INSTITUTION LIBRARIES 